\title{
Self-Assembly, Drug Encapsulation, and Cellular Uptake of Block and Gradient Copolymers of 2-Methyl-2-oxazine and 2-n-Propyl/butyl-2-oxazoline
}

David Babuka, ${ }^{1,2}$ Kristyna Kolouchova, ${ }^{1,3}$ Lenka Loukotova, ${ }^{1}$ Ondrej Sedlacek, ${ }^{3,4}$ Ondrej Groborz, ${ }^{1,5,6}$ Aneta Skarkova, ${ }^{7,8}$ Alexander Zhigunov, ${ }^{1}$ Ewa Pavlova, ${ }^{1}$ Richard Hoogenboom, ${ }^{*}, 4$ Martin Hruby, ${ }^{*, 1}$ Petr Stepanek ${ }^{1}$

${ }^{1}$ Institute of Macromolecular Chemistry, Czech Academy of Sciences, Heyrovskeho sq. 2, Prague 6, 162 06, Czech Republic

${ }^{2}$ Department of Biophysics, Institute of Physics, Faculty of Mathematics and Physics, Charles University, Ke Karlovu 3, Prague 2, 121 16, Czech Republic

${ }^{3}$ Department of Physical and Macromolecular Chemistry, Faculty of Science, Charles University, Hlavova 8, Prague 2, 128 00, Czech Republic

${ }^{4}$ Department of Organic and Macromolecular Chemistry, Ghent University, Krijgslaan 281-S4, 9000 Ghent, Belgium

${ }^{5}$ Institute of Organic Chemistry and Biochemistry, Czech Academy of Sciences, Flemingovo sq., Prague 6, 16206

${ }^{6}$ Institute of Biophysics and Informatics, Charles University, First Faculty of Medicine, Salmovská 1, 12000 Prague 2, Czech Republic

${ }^{7}$ Department of Cell Biology, Charles University, Vinicna 7, 12843 Prague, Czech Republic.

${ }^{8}$ Biotechnology and Biomedicine Centre of the Academy of Sciences and Charles University (BIOCEV), Prumyslova 595, 25242 Vestec u Prahy, Czech Republic.

*Corresponding authors, E-mail: mhruby@centrum.cz, richard.hoogenboom@ugent.be

Keywords: 2-oxazoline, 2-oxazine, gradient copolymer, block copolymer, drug delivery, drug loading, rifampicin, cell internalization, cell uptake, comparison 


\section{Table of content}

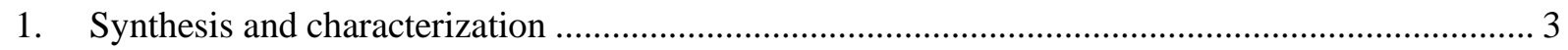

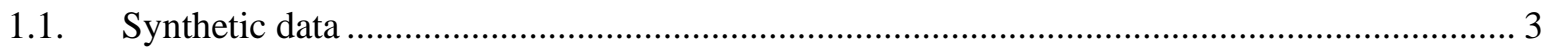

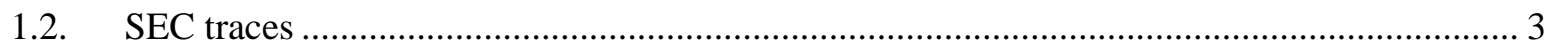

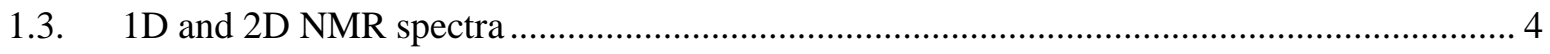

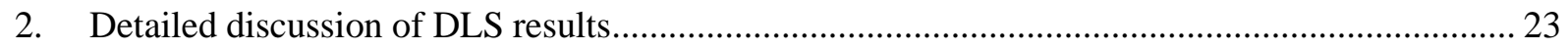

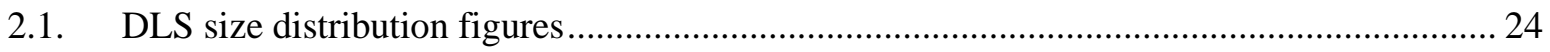

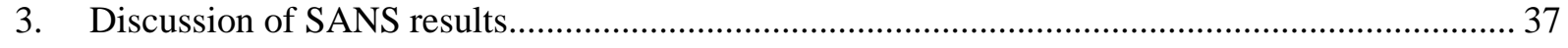

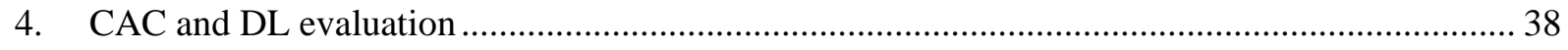

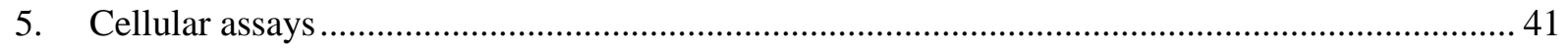

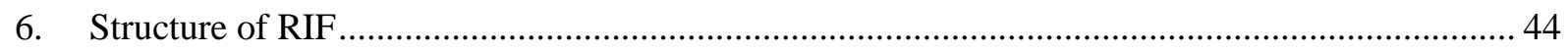

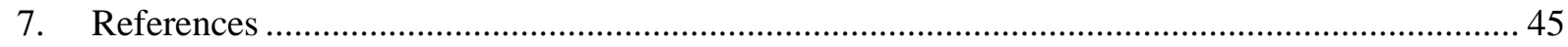




\section{Synthesis and characterization}

\subsection{Synthetic data}

Table S1. Details of polymer synthesis - series with PrOx: monomer ratios and reaction times.

\begin{tabular}{ccccccc}
\hline Code & Architecture & $\begin{array}{c}\text { MeOzi } \\
(\mathrm{mL})\end{array}$ & $\begin{array}{c}\text { MeOzi } \\
(\mathrm{mmol})\end{array}$ & $\begin{array}{c}\text { PrOx } \\
(\mathrm{mL})\end{array}$ & $\begin{array}{c}\text { PrOx } \\
(\mathrm{mmol})\end{array}$ & $\begin{array}{c}\text { Reaction } \\
\text { time }(\mathrm{min})\end{array}$ \\
\hline BP1 & Block & 0.620 & 6.38 & 1.416 & 12.6 & $20+15$ \\
BP2 & Block & 0.931 & 9.59 & 1.062 & 9.37 & $25+10$ \\
BP3 & Block & 1.240 & 12.8 & 0.709 & 6.27 & $25+10$ \\
GP1 & Gradient & 0.620 & 6.38 & 1.416 & 12.6 & 35 \\
GP2 & Gradient & 0.931 & 9.59 & 1.062 & 9.37 & 35 \\
GP3 & Gradient & 1.240 & 12.8 & 0.709 & 6.27 & 35 \\
\hline
\end{tabular}

Table S2. Details of polymer synthesis - series with BuOx: monomer ratios and reaction times.

\begin{tabular}{ccccccc}
\hline Code & Architecture & $\begin{array}{c}\text { MeOzi } \\
(\mathrm{mL})\end{array}$ & $\begin{array}{c}\mathrm{MeOzi} \\
(\mathrm{mmol})\end{array}$ & $\begin{array}{c}\mathrm{BuOx} \\
(\mathrm{mL})\end{array}$ & $\begin{array}{c}\mathrm{BuOx} \\
(\mathrm{mmol})\end{array}$ & $\begin{array}{c}\text { Reaction } \\
\text { time }(\mathrm{min})\end{array}$ \\
\hline BB1 & Block & 0.620 & 6.38 & 1.566 & 12.3 & $20+15$ \\
BB2 & Block & 0.931 & 9.59 & 1.175 & 9.27 & $25+10$ \\
BB3 & Block & 1.240 & 12.8 & 0.783 & 6.13 & $25+10$ \\
GB1 & Gradient & 0.620 & 6.38 & 1.566 & 12.3 & 35 \\
GB2 & Gradient & 0.931 & 9.59 & 1.175 & 9.27 & 35 \\
GB3 & Gradient & 1.240 & 12.8 & 0.783 & 6.13 & 35 \\
\hline
\end{tabular}

\subsection{SEC traces}
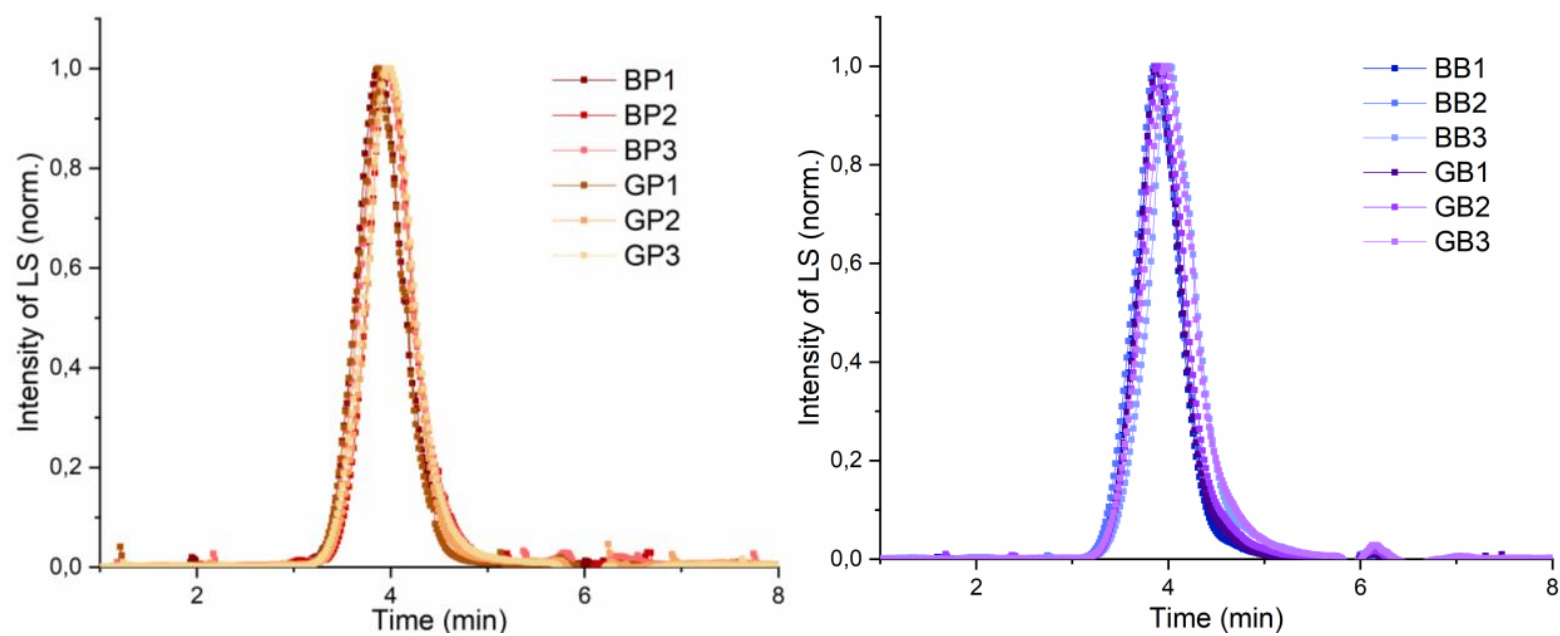

Figure S1. Size exclusion chromatography (SEC) traces for prepared polymers BP1, BP2, BP3; GP1, GP2, GP3; BB1, BB2, BB3; GB1, GB2, GB3 using Agilent 1260-series HPLC system equipped with a 1260 ISO-pump, a 1260 automatic liquid sampler, a thermostated column compartment at $50{ }^{\circ} \mathrm{C}$ equipped with two PLgel $5 \mu \mathrm{m}$ mixed-D columns and a precolumn in series, a 1260 diode array detector 1260 RI detector and multi-angle light scattering detector (Wyatt miniDawn Treos II). The used eluent was DMA containing $50 \mathrm{mM}$ of $\mathrm{LiCl}$ at a flow rate of $0.5 \mathrm{~mL} \mathrm{~min}^{-1}$. 


\subsection{D and 2D NMR spectra}

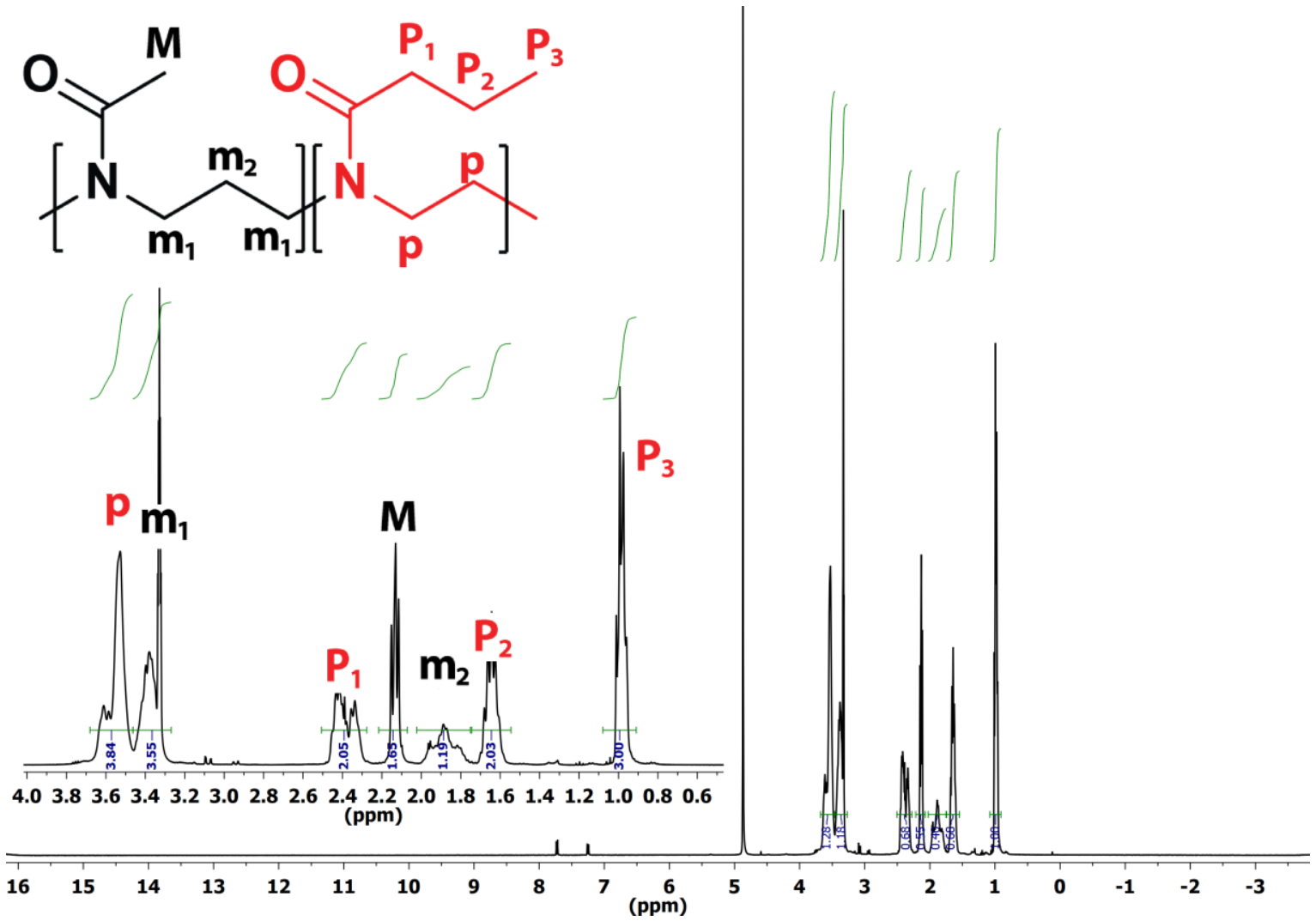

Figure S2. ${ }^{1} \mathrm{H}$ NMR spectrum of polymer BP1 in MeOH-D4 $\left(c_{\mathrm{pol}}=14.3 \mathrm{mg} / \mathrm{mL}\right) ; \mathrm{NS}=32 ; \mathrm{D}_{1}=20.0 \mathrm{~s}$; recorded with a Bruker $400 \mathrm{MHz}$ spectrometer.

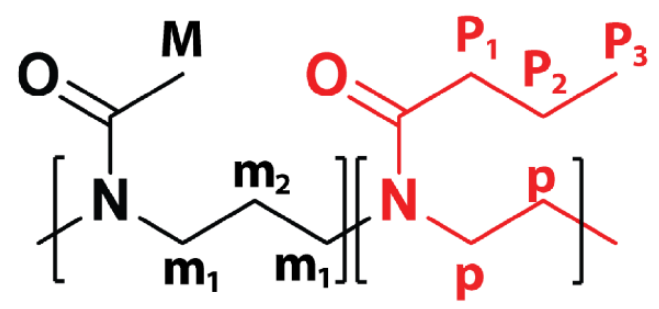

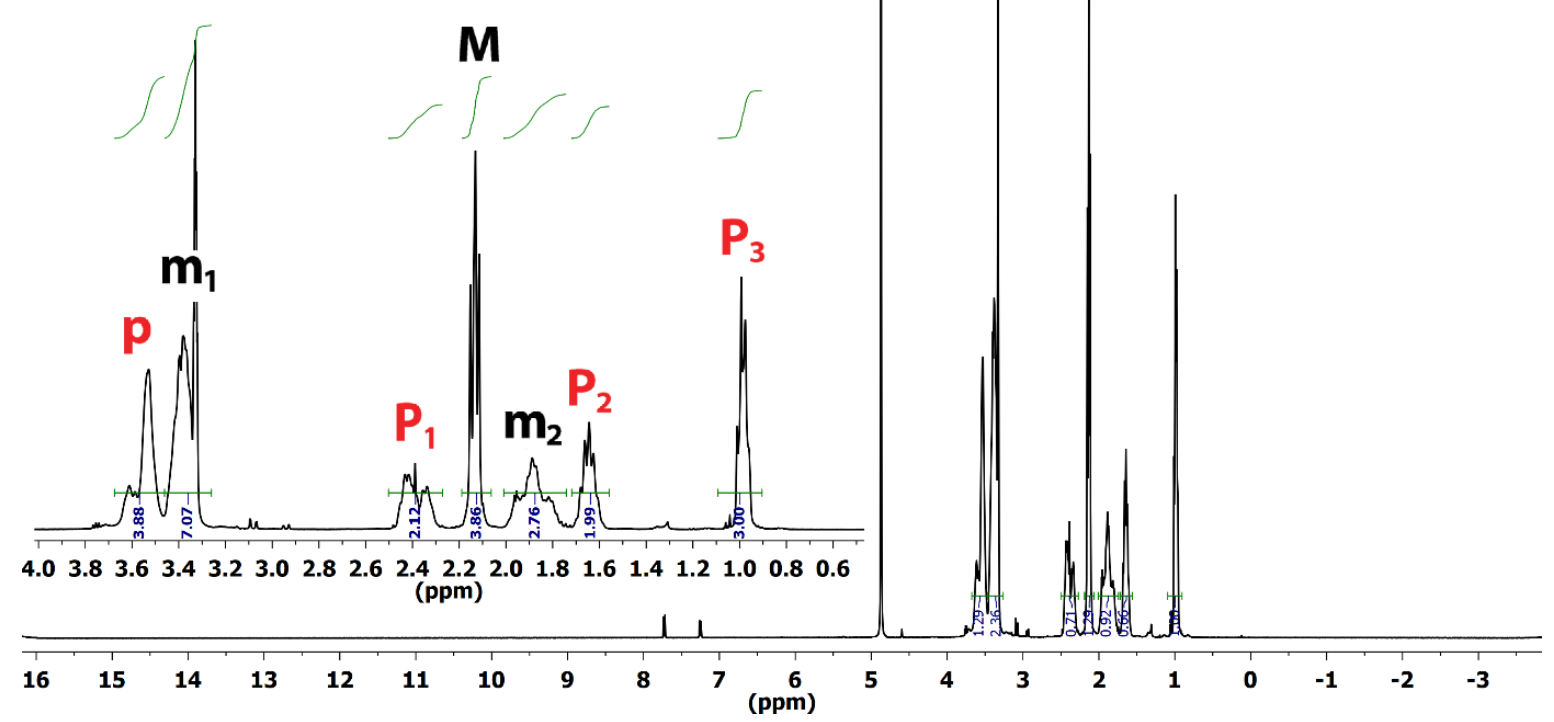

Figure S3. ${ }^{1} \mathrm{H}$ NMR spectrum of polymer BP2 in MeOH-D4 $\left(c_{\mathrm{pol}}=14.3 \mathrm{mg} / \mathrm{mL}\right) ; \mathrm{NS}=32 ; \mathrm{D}_{1}=20.0 \mathrm{~s}$; recorded with a Bruker $400 \mathrm{MHz}$ spectrometer. 

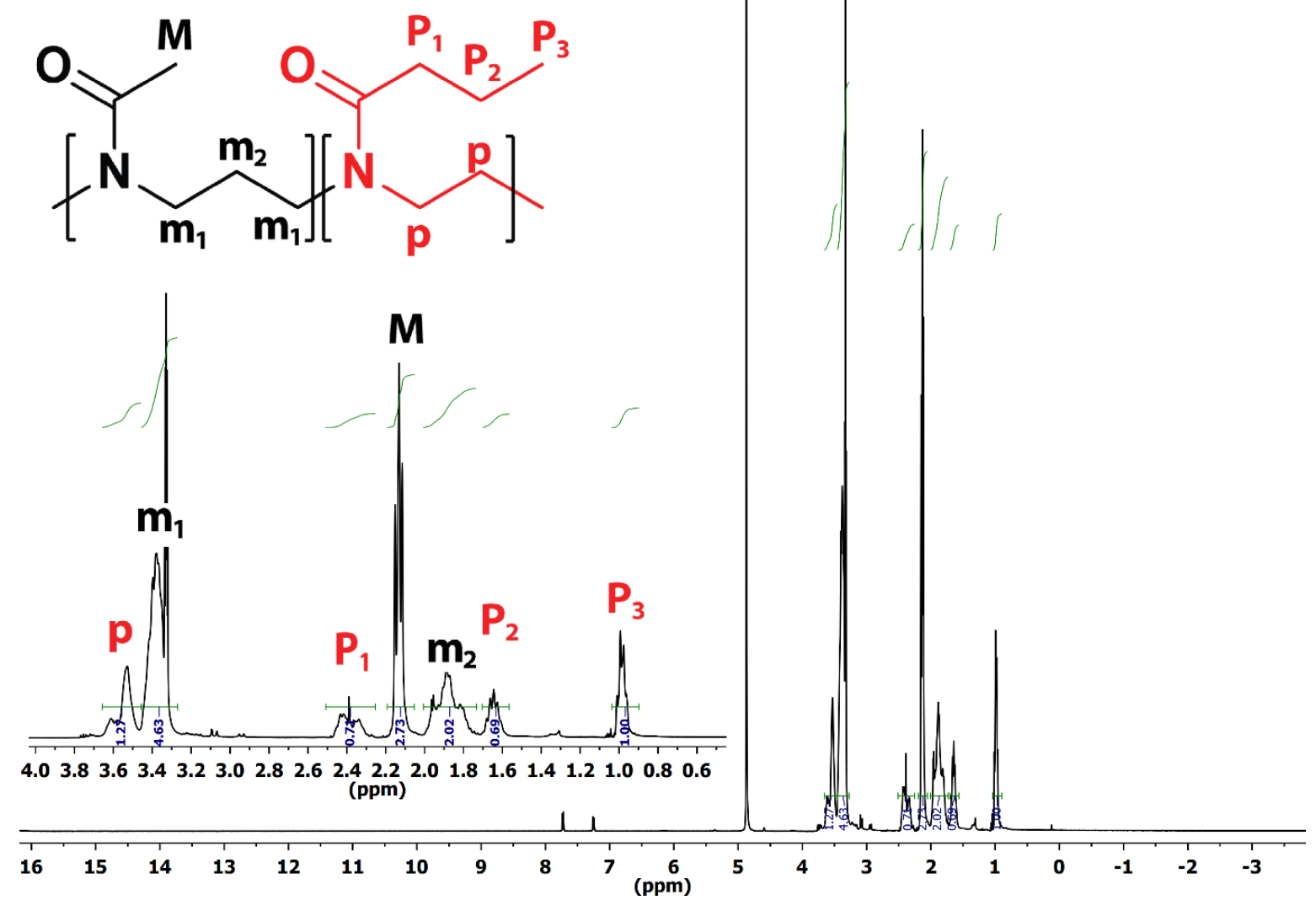

Figure S4. ${ }^{1} \mathrm{H}$ NMR spectrum of polymer BP3 in MeOH-D4 $\left(c_{\mathrm{pol}}=14.3 \mathrm{mg} / \mathrm{mL}\right) ; \mathrm{NS}=32 ; \mathrm{D}_{1}=20.0 \mathrm{~s}$; recorded with a Bruker $400 \mathrm{MHz}$ spectrometer.

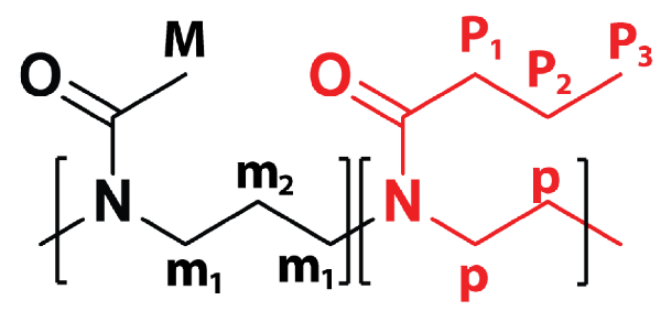

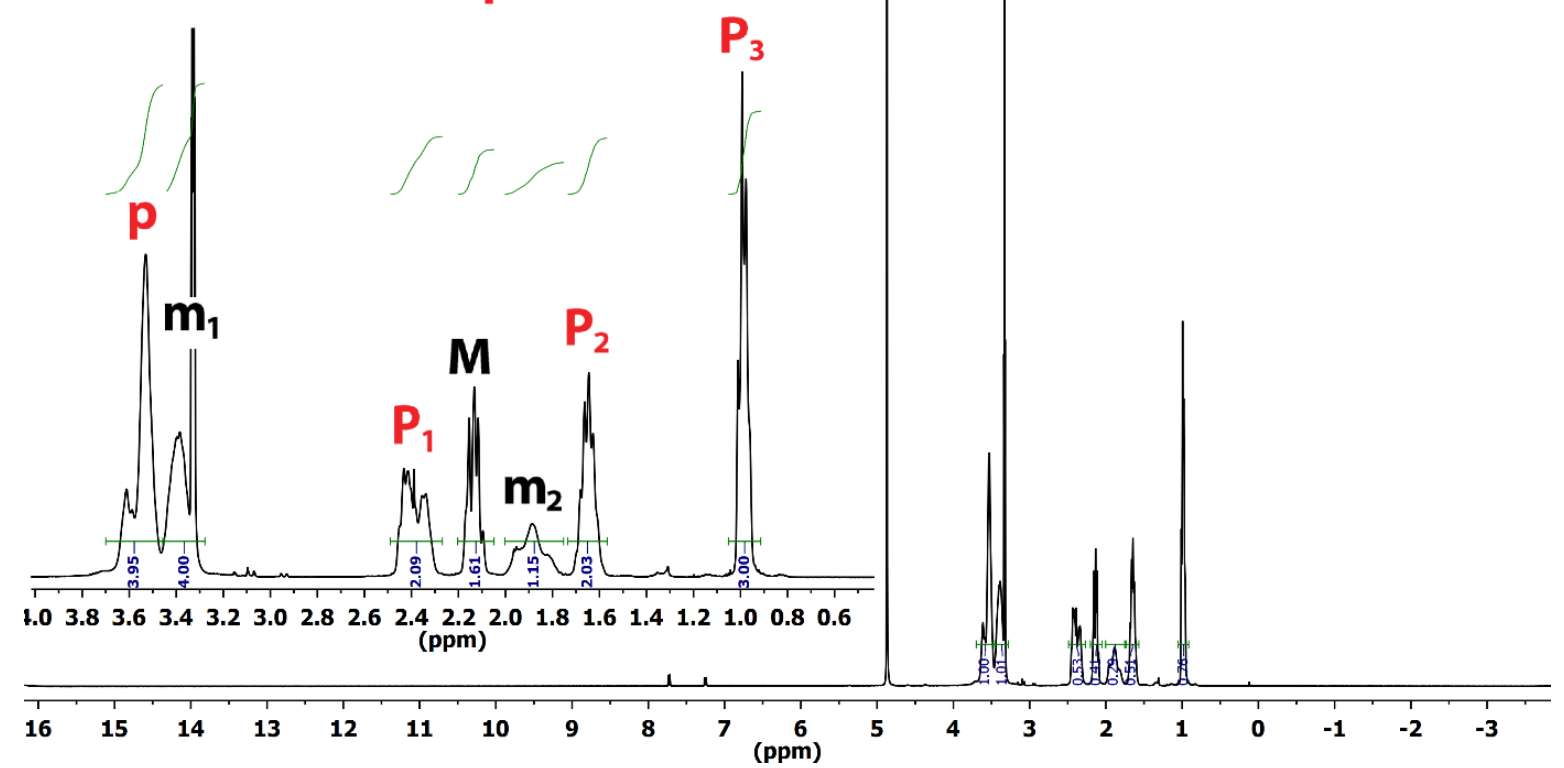

Figure S5. ${ }^{1} \mathrm{H}$ NMR spectrum of polymer GP1 in MeOH-D4 $\left(c_{\mathrm{pol}}=14.3 \mathrm{mg} / \mathrm{mL}\right) ; \mathrm{NS}=32 ; \mathrm{D}_{1}=20.0 \mathrm{~s}$; recorded with a Bruker $400 \mathrm{MHz}$ spectrometer. 


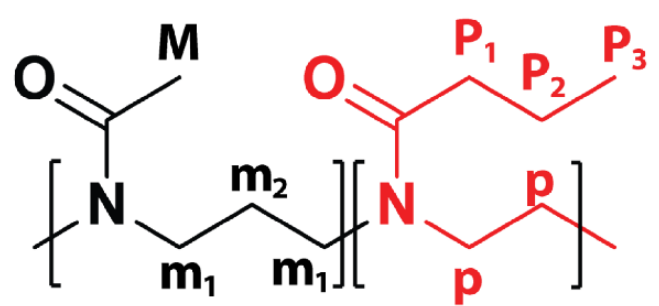
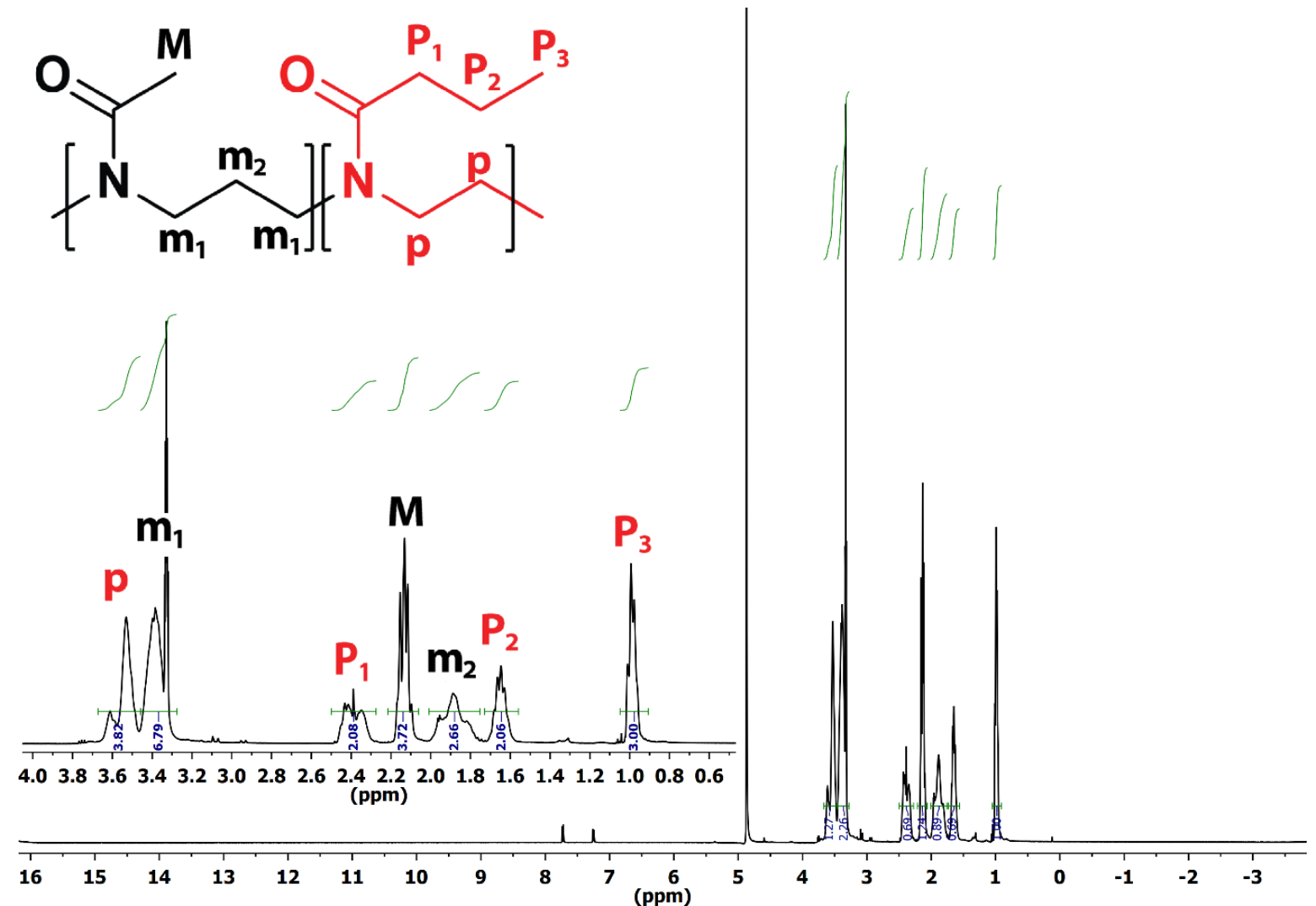

Figure S6. ${ }^{1} \mathrm{H}$ NMR spectrum of polymer GP2 in MeOH-D4 $\left(c_{\mathrm{pol}}=14.3 \mathrm{mg} / \mathrm{mL}\right) ; \mathrm{NS}=32 \mathrm{D}_{1}=20.0 \mathrm{~s}$; recorded with a Bruker $400 \mathrm{MHz}$ spectrometer.

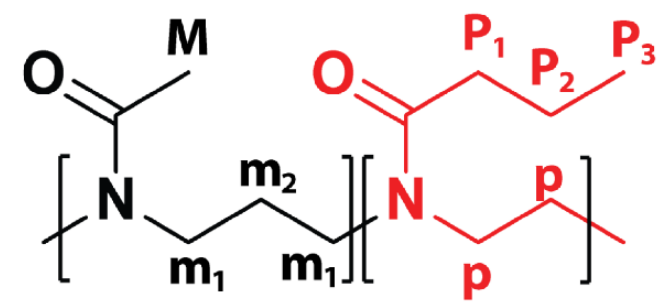
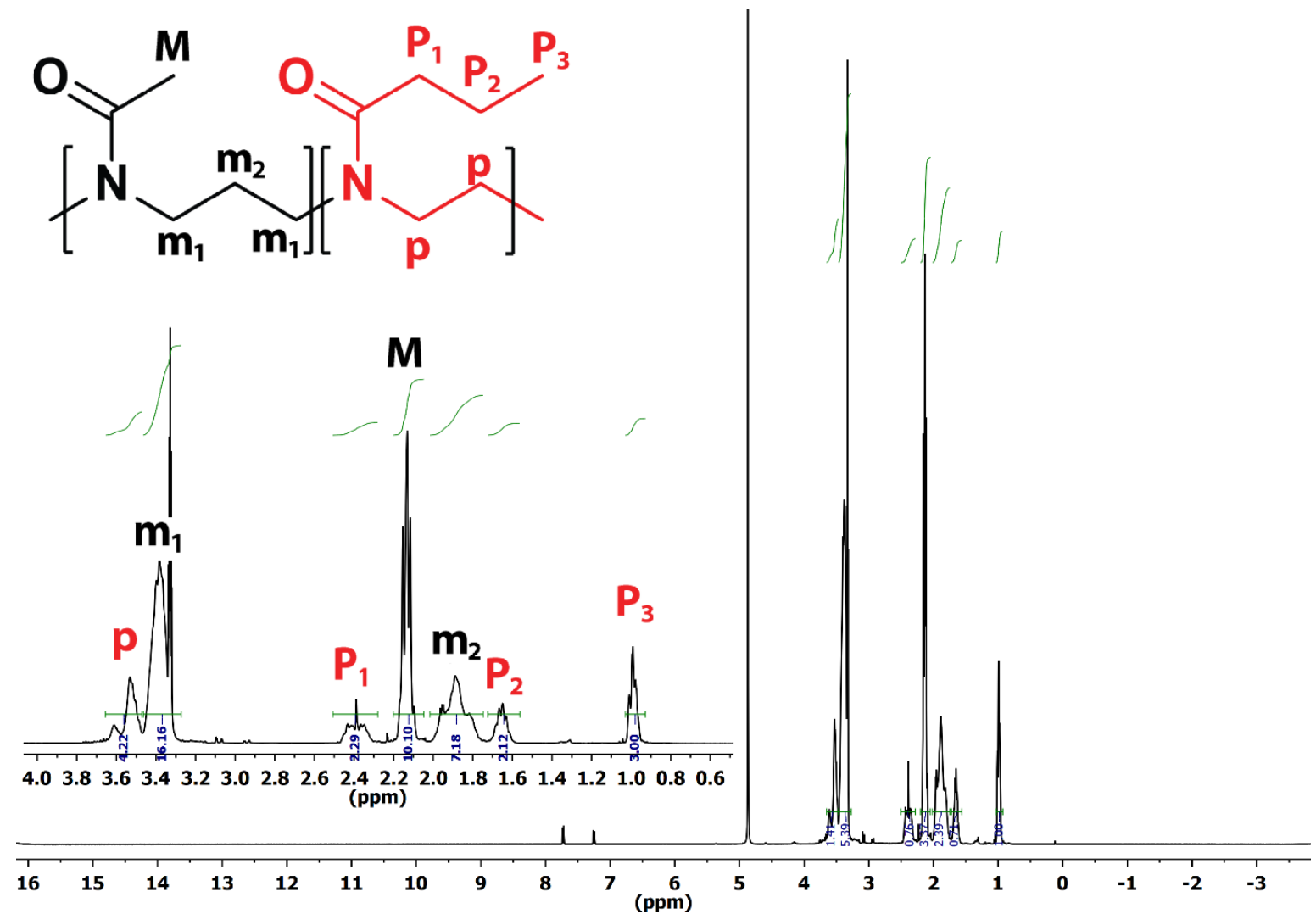

Figure S7. ${ }^{1} \mathrm{H}$ NMR spectrum of polymer GP3 in MeOH-D4 $\left(c_{\mathrm{pol}}=14.3 \mathrm{mg} / \mathrm{mL}\right) ; \mathrm{NS}=32 ; \mathrm{D}_{1}=20.0 \mathrm{~s}$; recorded with a Bruker $400 \mathrm{MHz}$ spectrometer. 
<smiles>[R8]CCCC(=O)N(CCCCC(=O)N(C)C(C)C)CCC(C)(C)C</smiles>

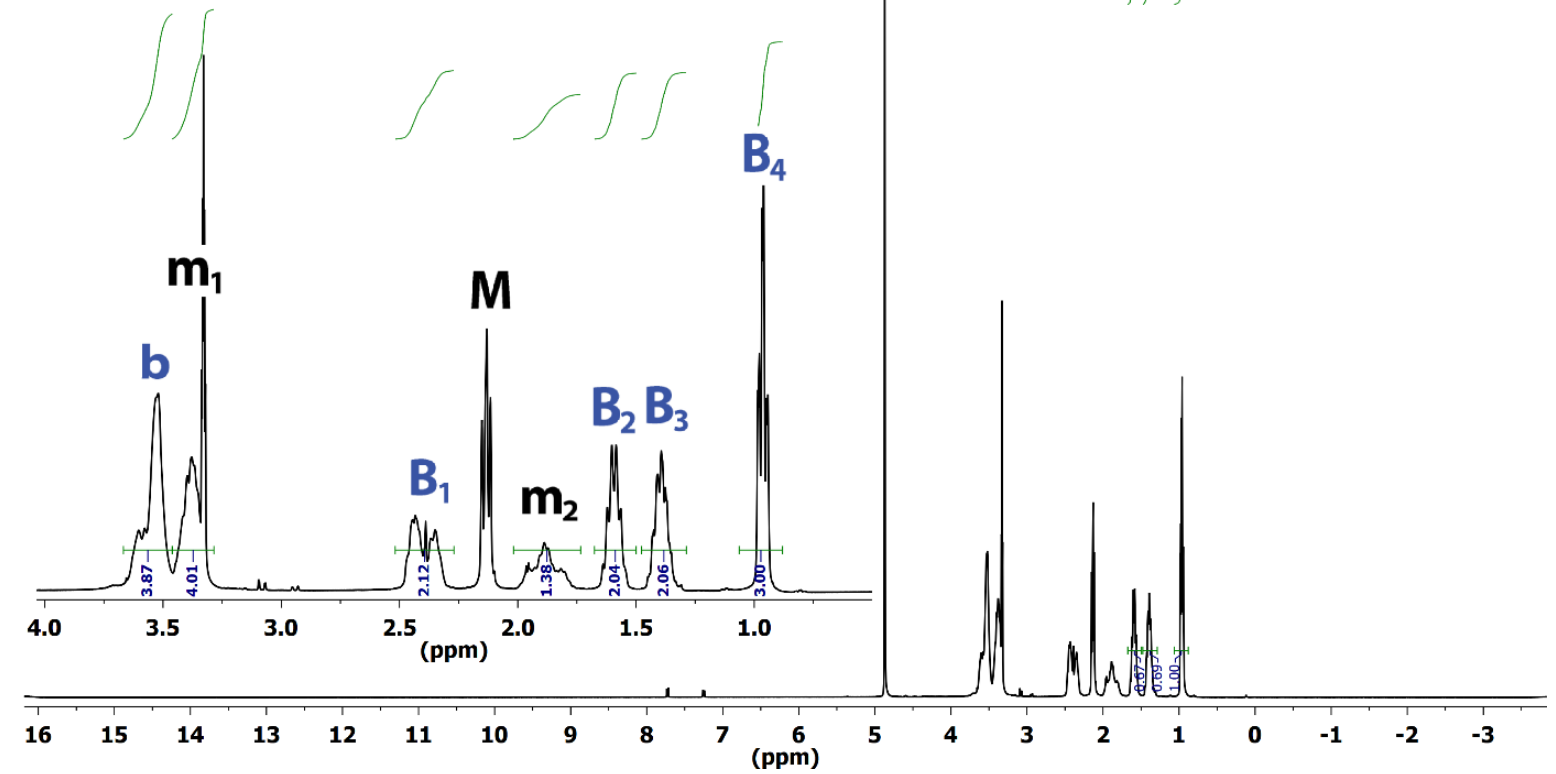

Figure S8. ${ }^{1} \mathrm{H}$ NMR spectrum of polymer BB1 in MeOH-D4 $\left(c_{\mathrm{pol}}=14.3 \mathrm{mg} / \mathrm{mL}\right) ; \mathrm{NS}=32 ; \mathrm{D}_{1}=20.0 \mathrm{~s}$; recorded with a Bruker $400 \mathrm{MHz}$ spectrometer.<smiles>[R8]CCCC(=O)N(CCCCCC(=O)N(C)C(C)C)CCC(C)(C)C</smiles>

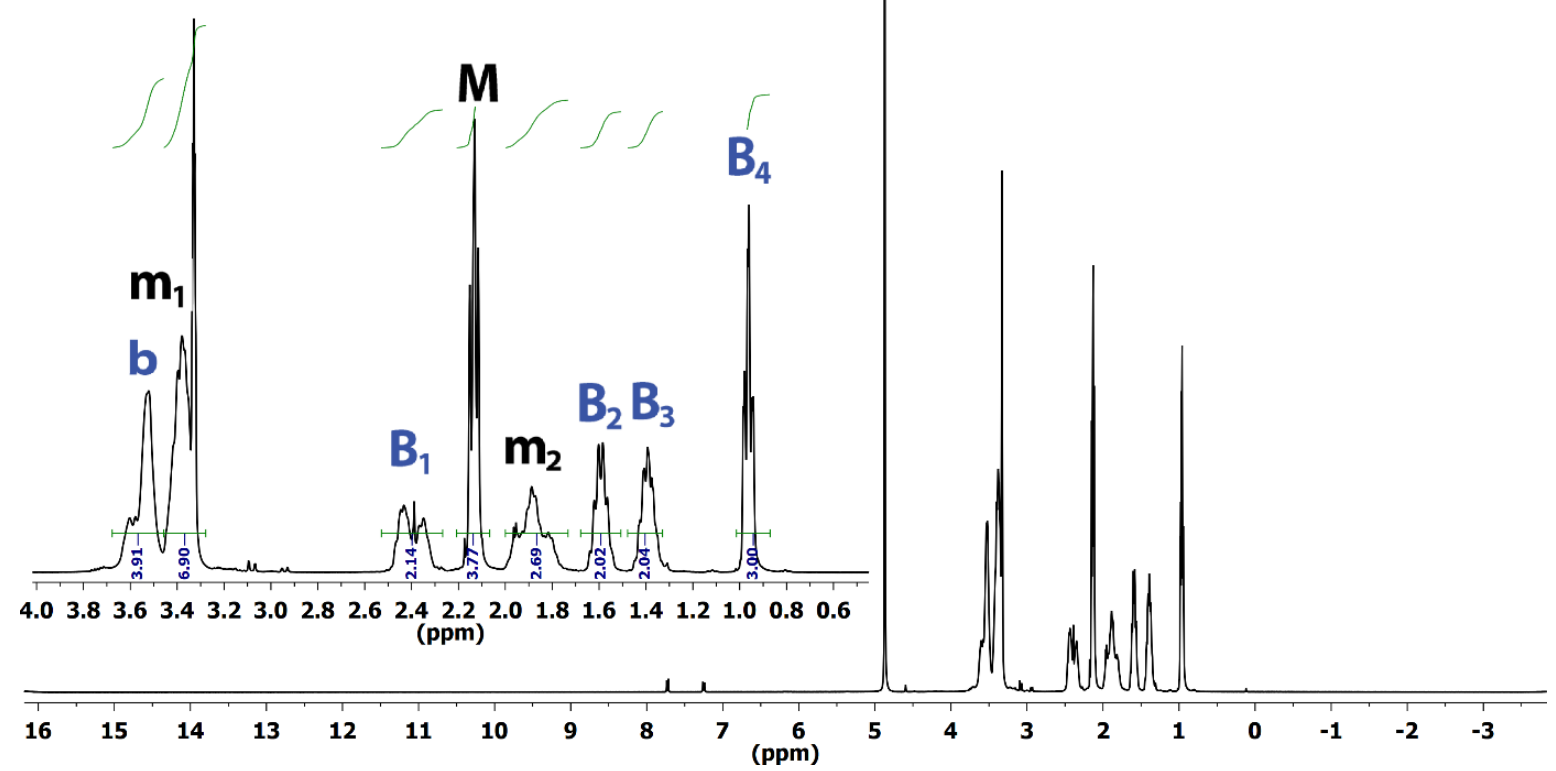

Figure S9. ${ }^{1} \mathrm{H}$ NMR spectrum of polymer BB2 in MeOH-D4 $\left(c_{\mathrm{pol}}=14.3 \mathrm{mg} / \mathrm{mL}\right) ; \mathrm{NS}=32 ; \mathrm{D}_{1}=20.0 \mathrm{~s}$; recorded with a Bruker $400 \mathrm{MHz}$ spectrometer. 


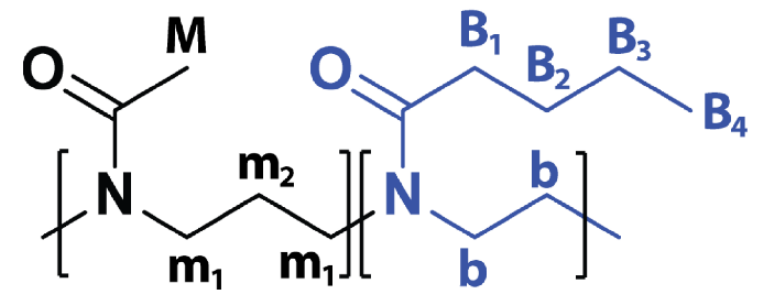
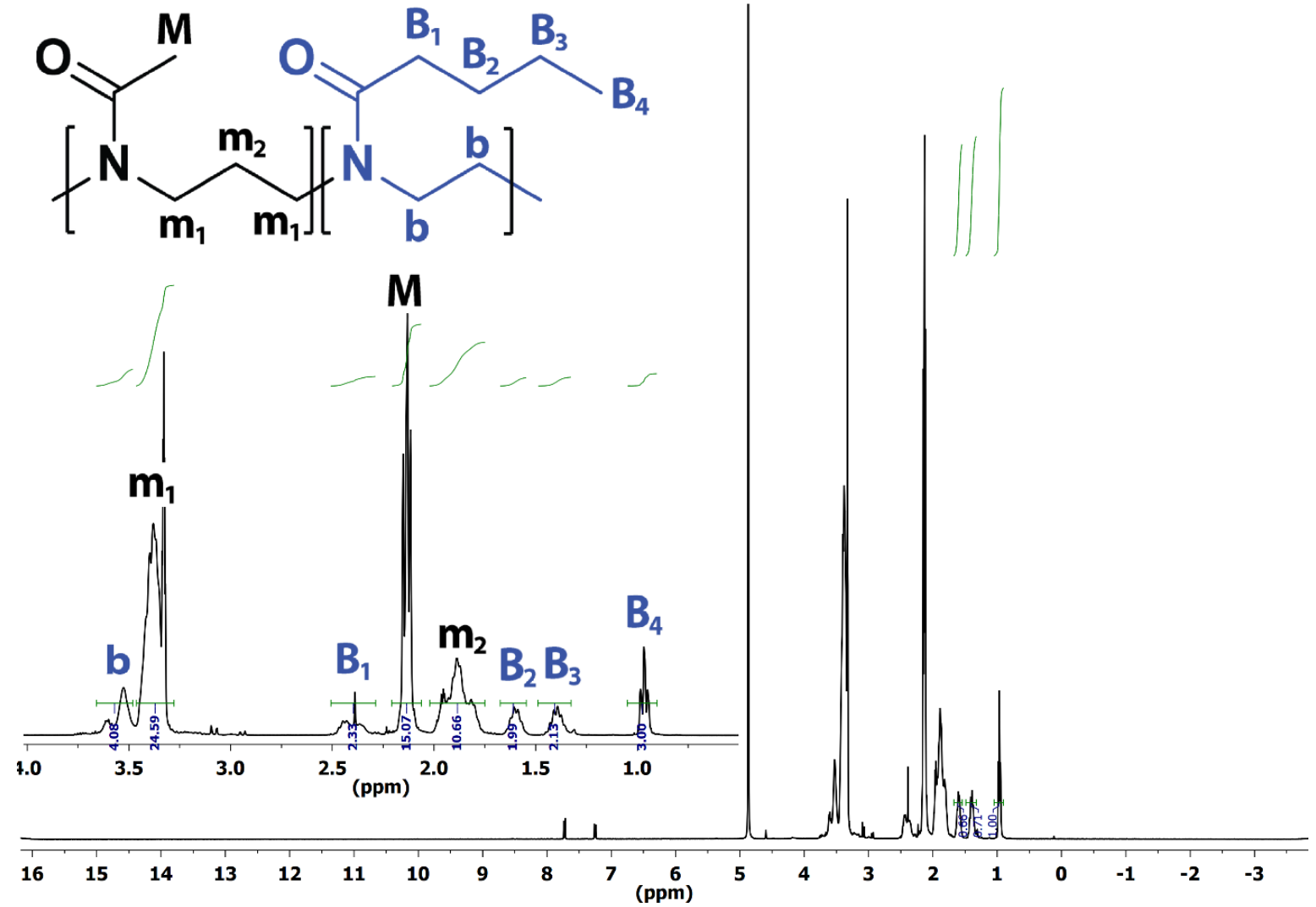

Figure S10. ${ }^{1} \mathrm{H}$ NMR spectrum of polymer BB3 in MeOH-D4 $\left(c_{\mathrm{pol}}=14.3 \mathrm{mg} / \mathrm{mL}\right)$; NS $=32 ; \mathrm{D}_{1}=$ $20.0 \mathrm{~s}$; recorded with a Bruker $400 \mathrm{MHz}$ spectrometer.

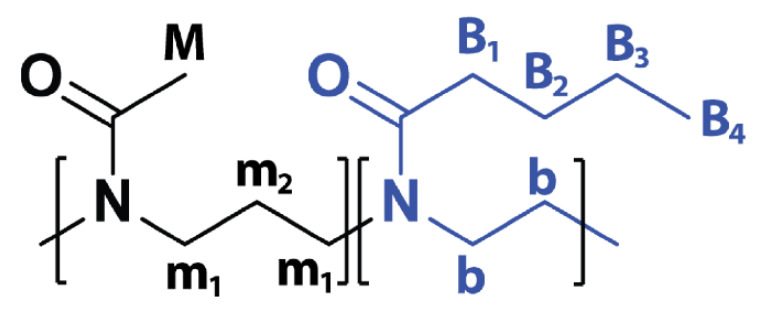

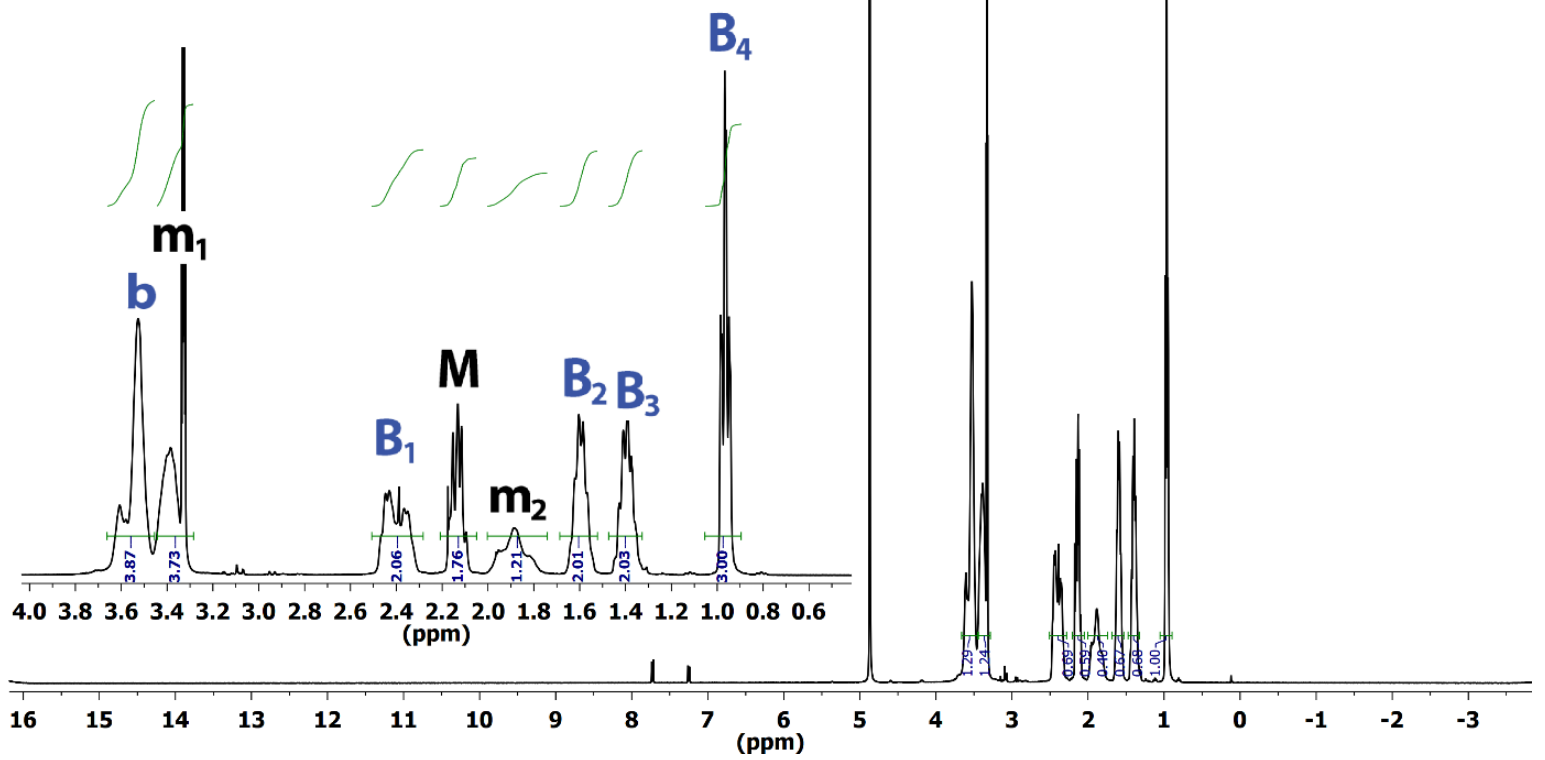

Figure S11. ${ }^{1} \mathrm{H}$ NMR spectrum of polymer GB1 in MeOH-D4 $\left(c_{\mathrm{pol}}=14.3 \mathrm{mg} / \mathrm{mL}\right) ; \mathrm{NS}=32 ; \mathrm{D}_{1}=$ $20.0 \mathrm{~s}$; recorded with a Bruker $400 \mathrm{MHz}$ spectrometer. 


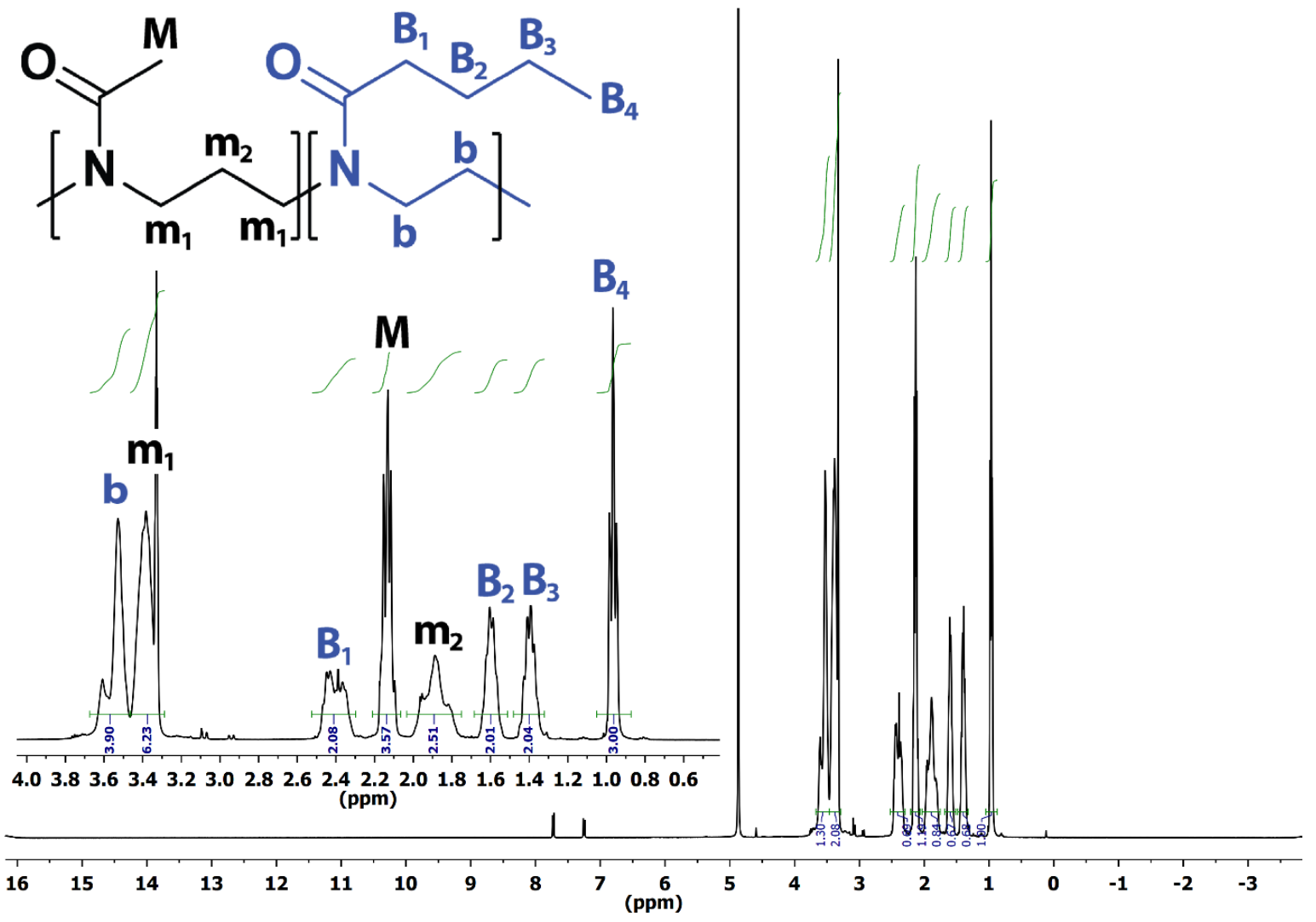

Figure S12. ${ }^{1} \mathrm{H}$ NMR spectrum of polymer GB2 in MeOH-D4 $\left(c_{\mathrm{pol}}=14.3 \mathrm{mg} / \mathrm{mL}\right) ; \mathrm{NS}=32 ; \mathrm{D}_{1}=$ $20.0 \mathrm{~s}$; recorded with a Bruker $400 \mathrm{MHz}$ spectrometer.

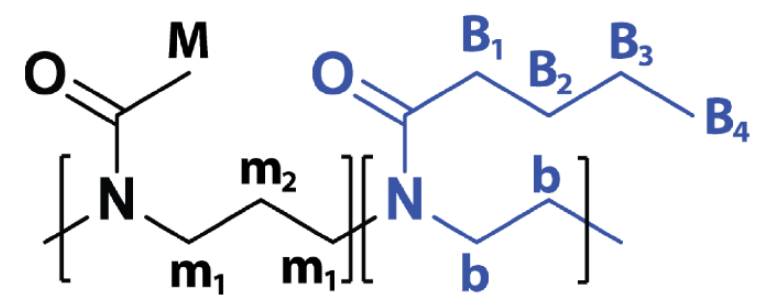
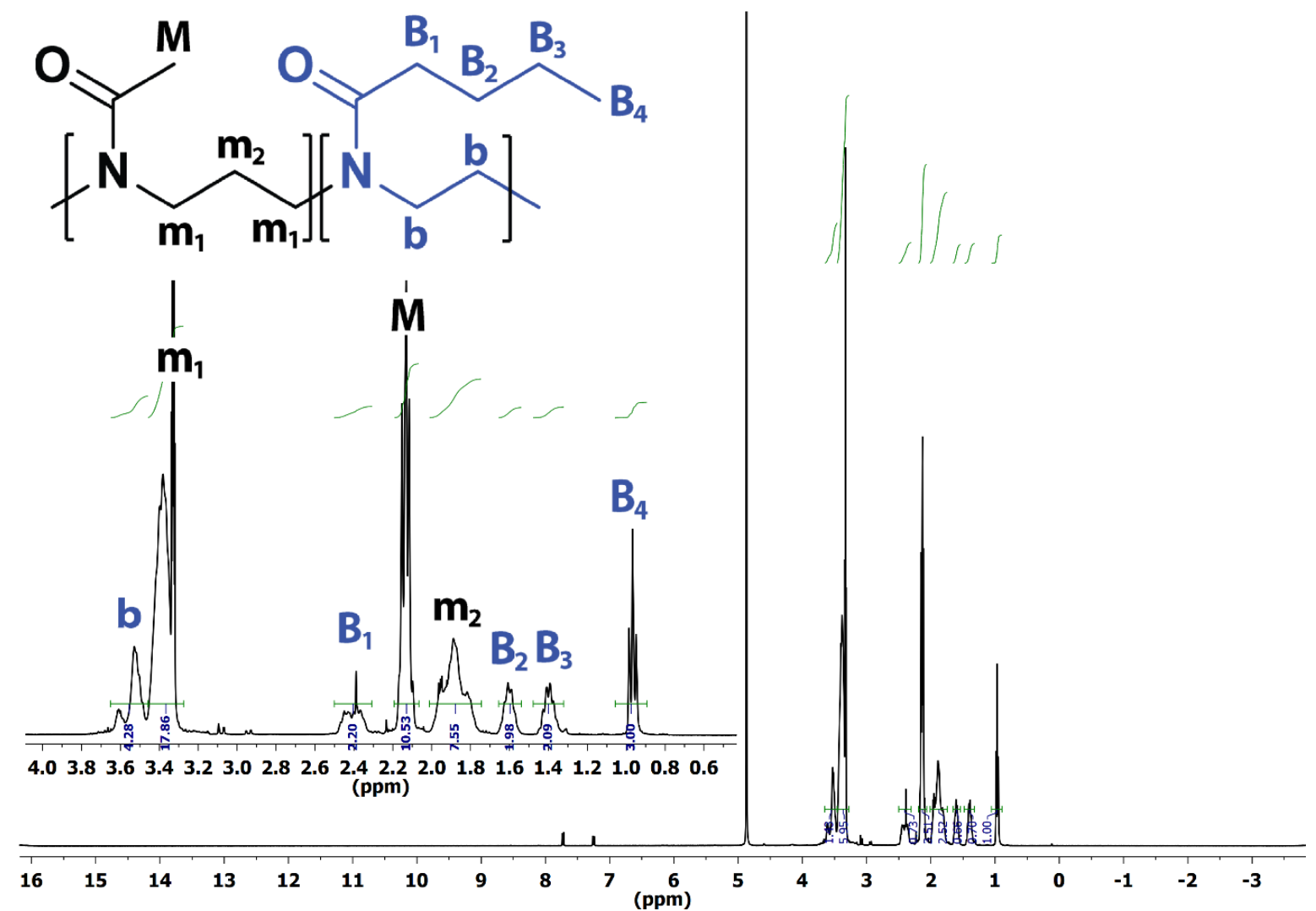

Figure S13. ${ }^{1} \mathrm{H}$ NMR spectrum of polymer GB3 in MeOH-D4 $\left(c_{\mathrm{pol}}=14.3 \mathrm{mg} / \mathrm{mL}\right) ; \mathrm{NS}=32 ; \mathrm{D}_{1}=$ $20.0 \mathrm{~s}$; recorded with a Bruker $400 \mathrm{MHz}$ spectrometer. 


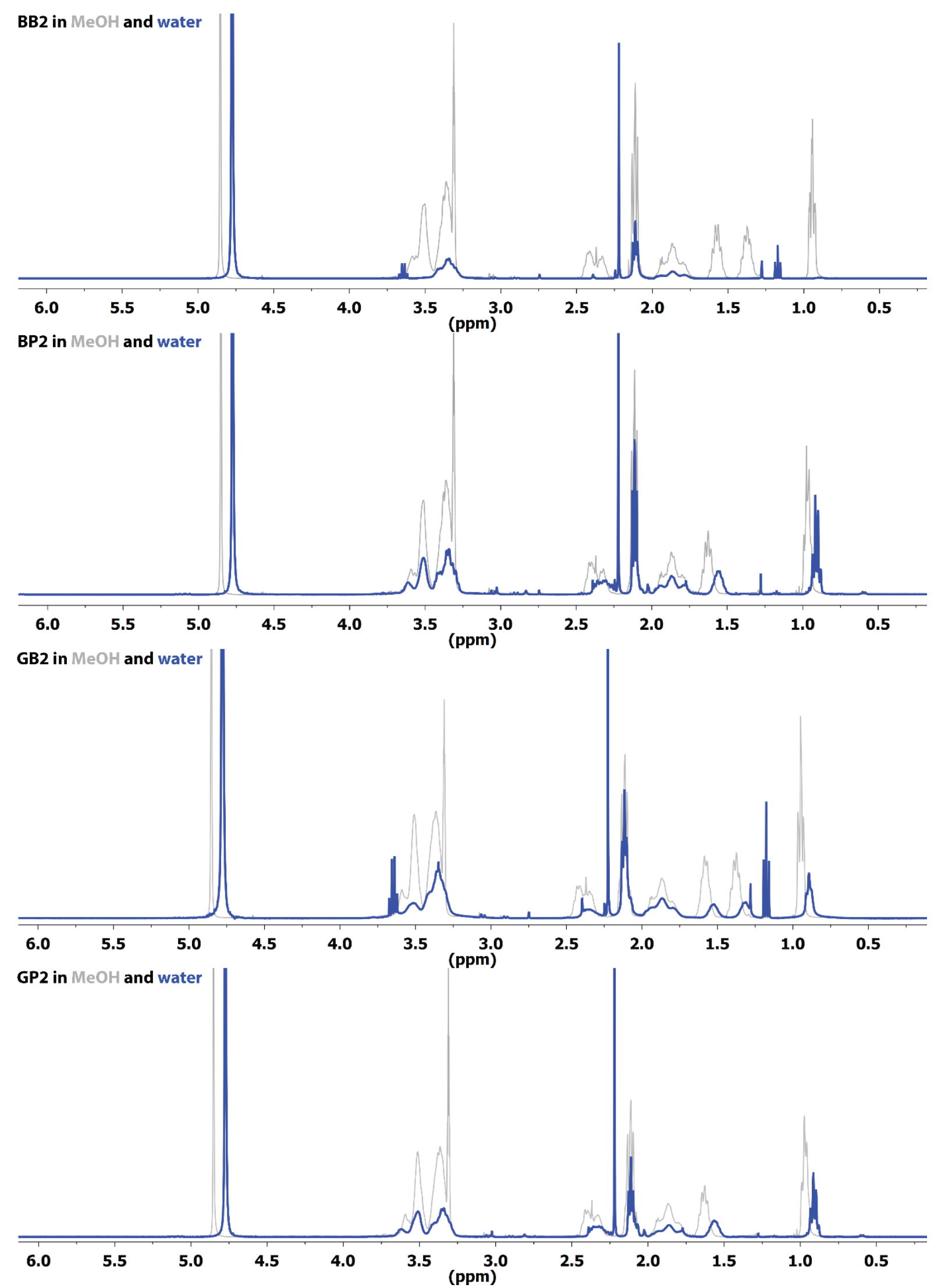

Figure S14. A comparison of ${ }^{1} \mathrm{H}$ NMR spectra of rifampicin-loaded polymer nanoparticles BB2, BP2, GB2 and GP2 in $\mathrm{D}_{2} \mathrm{O}$ (blue) and the corresponding spectrum of pure polymer in methanol-4d (gray). The spectra were aligned so that the corresponding peaks have the same/similar chemical shifts. Solvent trace peaks not shown in their original amplitude for clarity. 


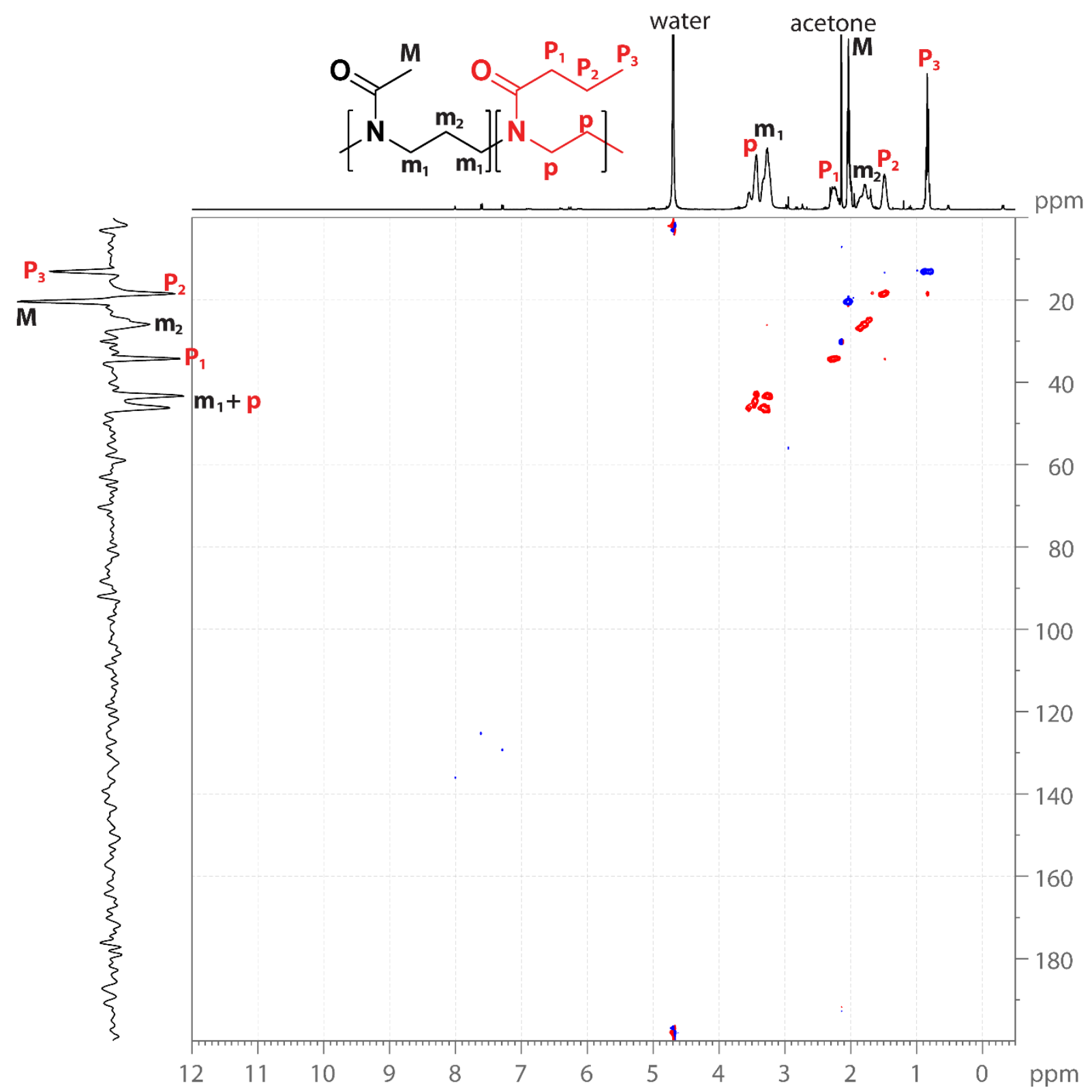

Figure S15. Multiplicity edited ${ }^{1} \mathrm{H}^{13}{ }^{13} \mathrm{C}$ HSQC spectrum of GP2 in $\mathrm{D}_{2} \mathrm{O}\left(\mathrm{NS}=8\right.$ scans, $\mathrm{D}_{1}=1.50 \mathrm{~s}$, TD $=2048$ by 256). External projections for ${ }^{1} \mathrm{H}$ were used. Blue contours indicate a positive signal $\left(\mathrm{CH}_{3}\right.$ or $\mathrm{CH}$ moieties), red contours indicate a negative signal $\left(\mathrm{CH}_{2}\right.$ moiety). 


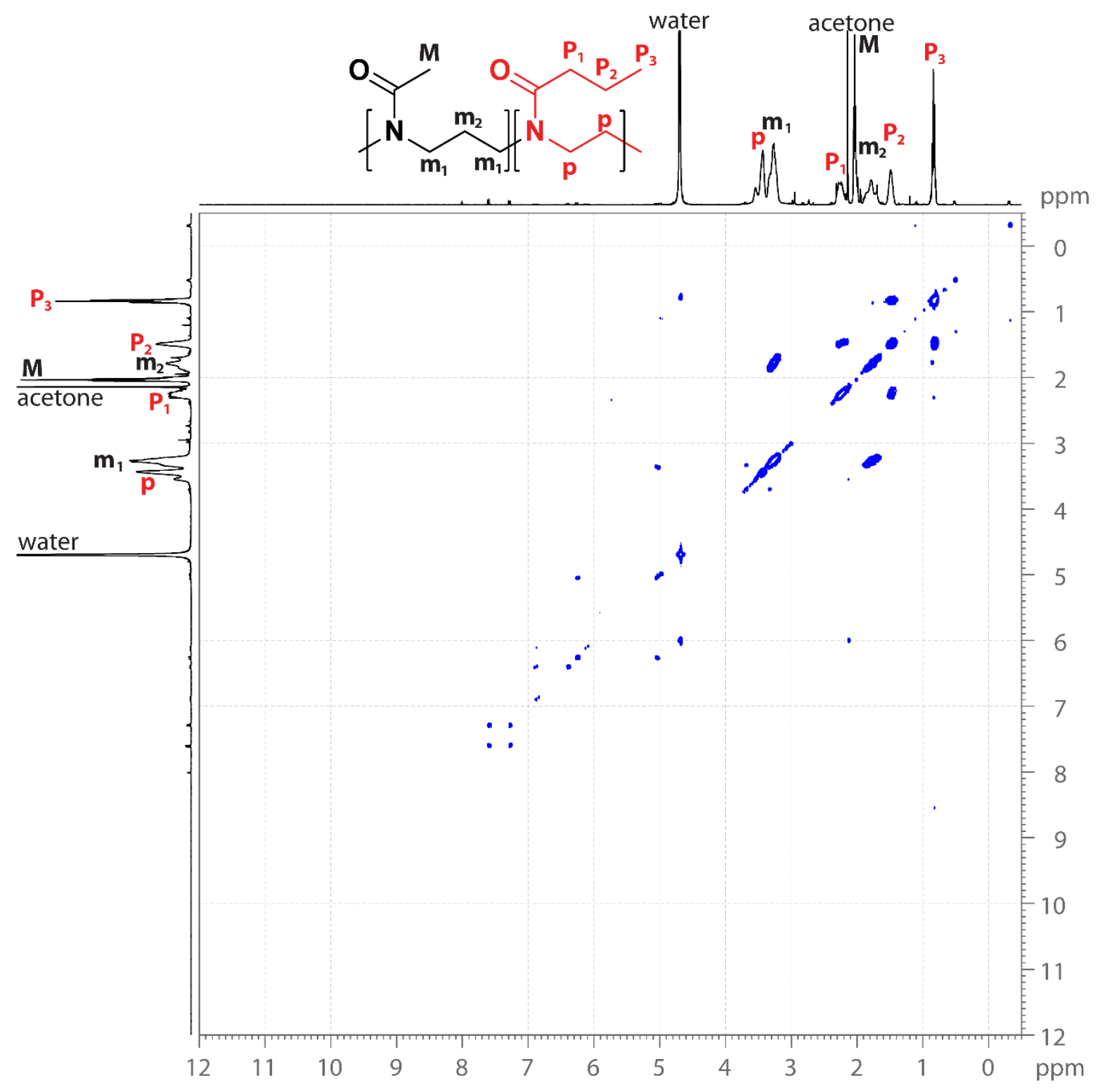

Figure S16. ${ }^{1} \mathrm{H}-{ }^{1} \mathrm{H}$ COSY spectrum of GP2 in $\mathrm{D}_{2} \mathrm{O}$. (NS $=8$ scans, $\mathrm{D}_{1}=2.00 \mathrm{~s}, \mathrm{TD}=2048$ by 256 ). 


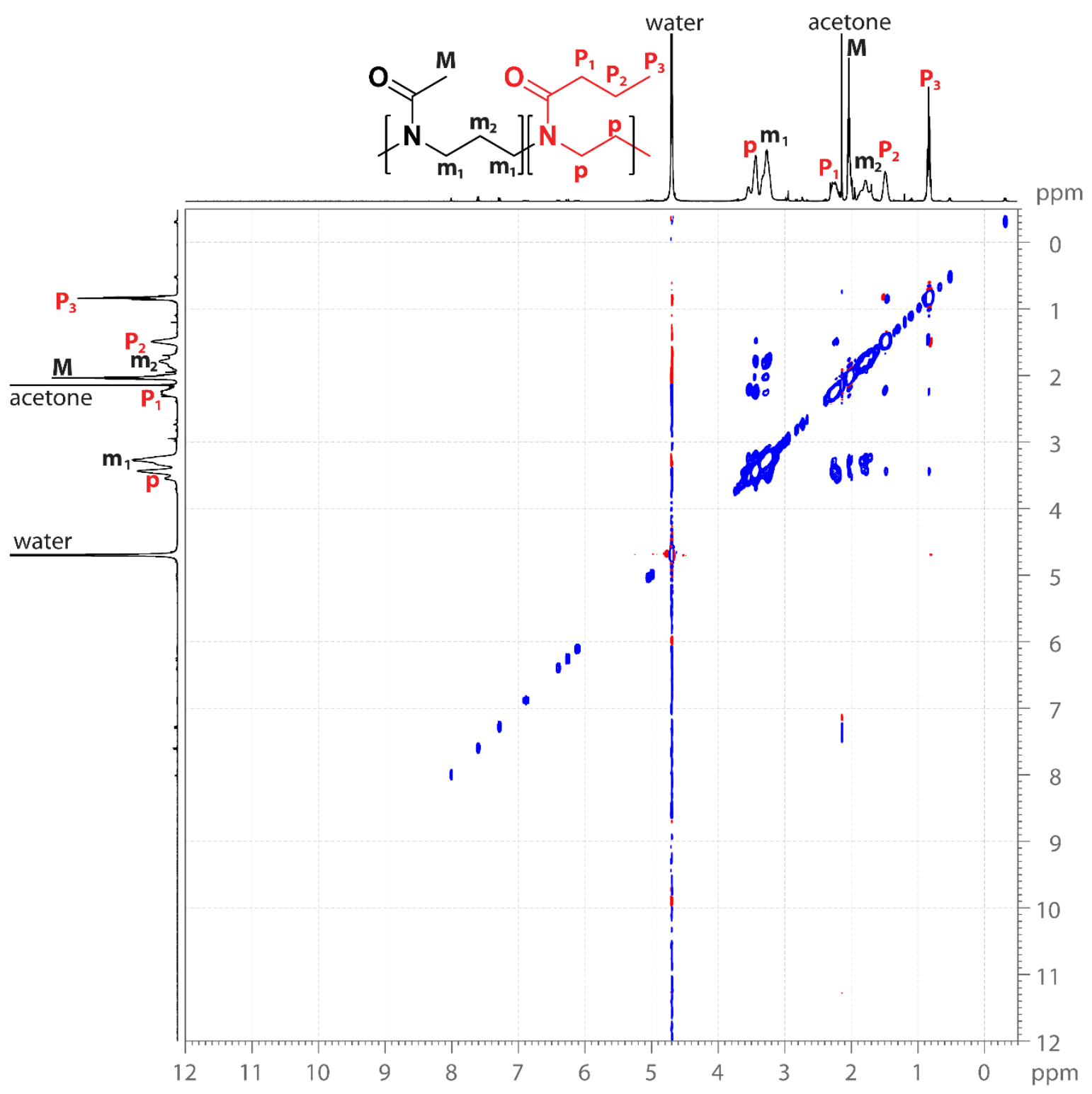

Figure S17. ${ }^{1} \mathrm{H}-{ }^{1} \mathrm{H}$ NOESY spectrum of GP2 in $\mathrm{D}_{2} \mathrm{O}$. (NS = 8 scans, mixing time $300 \mathrm{~ms}, \mathrm{D}_{1}$ delay $2.00 \mathrm{~s}$, size of fid 2048 by 256) 


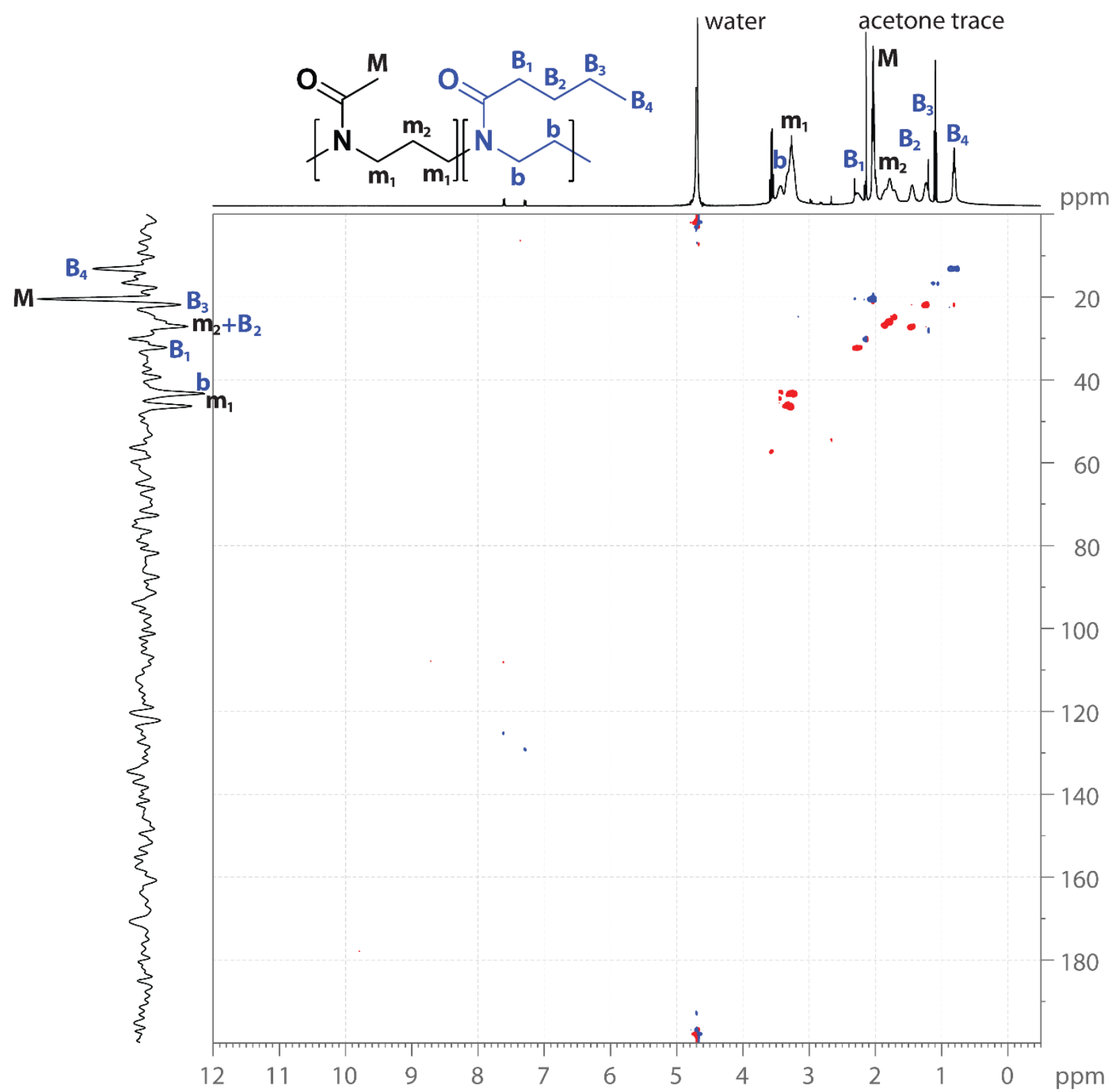

Figure S18. Multiplicity edited ${ }^{1} \mathrm{H}^{-1}{ }^{13} \mathrm{C}$ HSQC spectrum of GB2 in $\mathrm{D}_{2} \mathrm{O}\left(\mathrm{NS}=8\right.$ scans, $\mathrm{D}_{1}=1.50 \mathrm{~s}$, TD $=2048$ by 256). External projections for ${ }^{1} \mathrm{H}$ were used. Blue contours indicate a positive signal $(\mathrm{CH} 3$ or $\mathrm{CH}$ moieties), red contours indicate a negative signal ( $\mathrm{CH} 2$ moiety). 


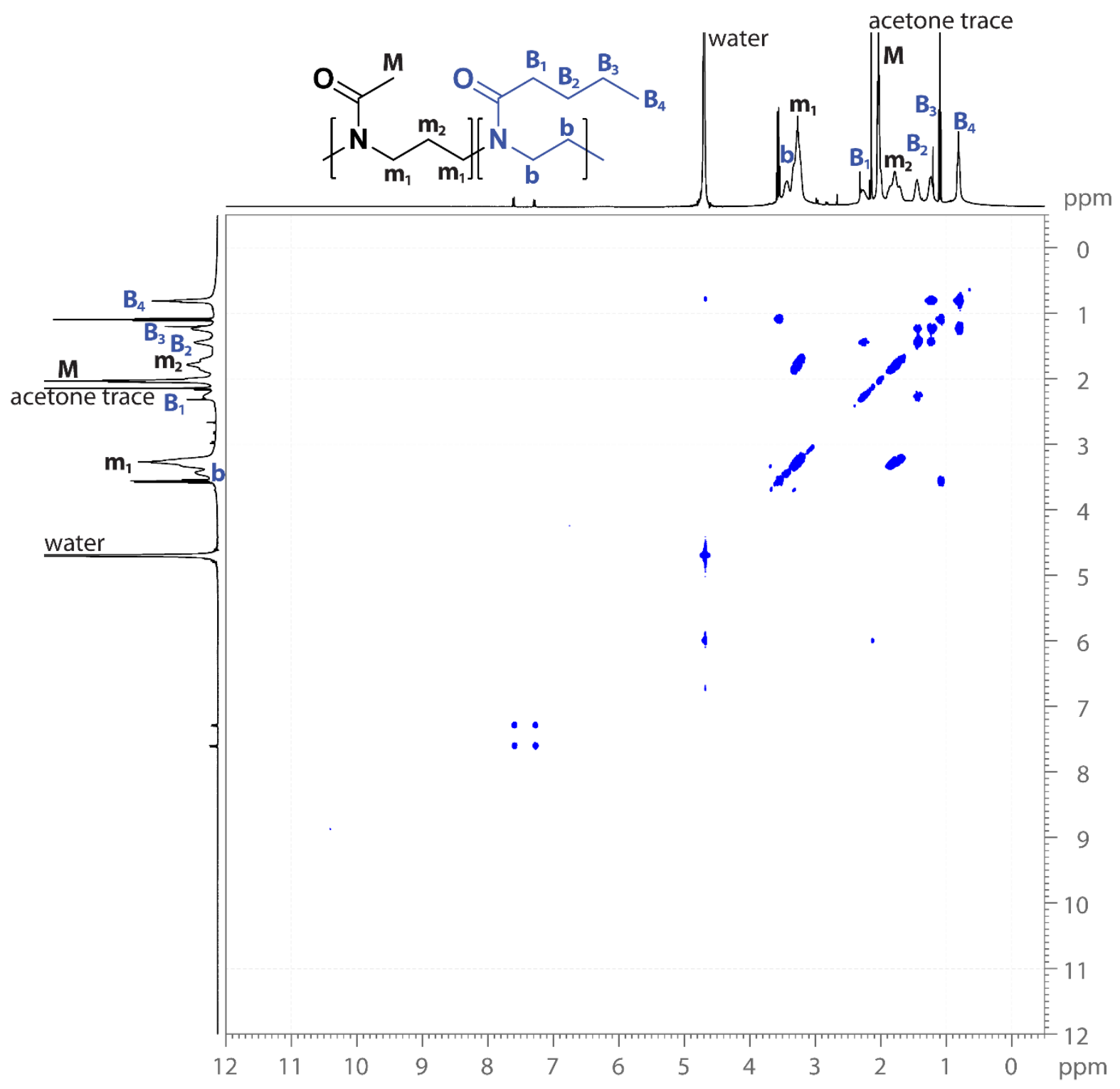

Figure S19. ${ }^{1} \mathrm{H}^{-1} \mathrm{H}$ COSY spectrum of GB2 in $\mathrm{D}_{2} \mathrm{O}$. (NS = 8 scans, $\mathrm{D}_{1}=2.00 \mathrm{~s}, \mathrm{TD}=2048$ by 256). 


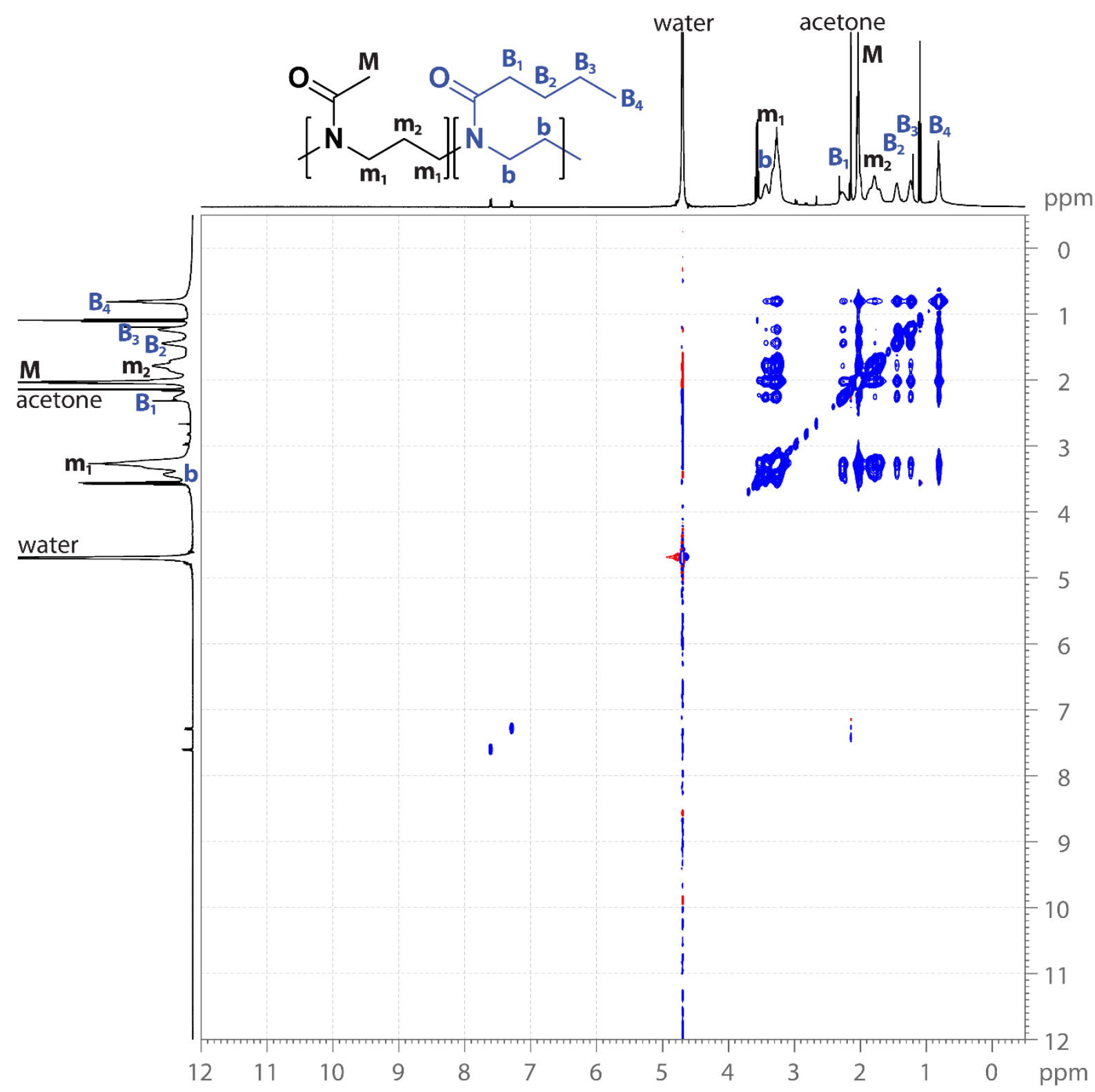

Figure S20. ${ }^{1} \mathrm{H}-{ }^{1} \mathrm{H}$ NOESY spectrum of GB2 in $\mathrm{D}_{2} \mathrm{O}$. (NS = 8 scans, mixing time $300 \mathrm{~ms}, \mathrm{D}_{1}$ delay $2.00 \mathrm{~s}$, acquisition time $0.20 \mathrm{~s}$, size of fid 2048 by 256) 


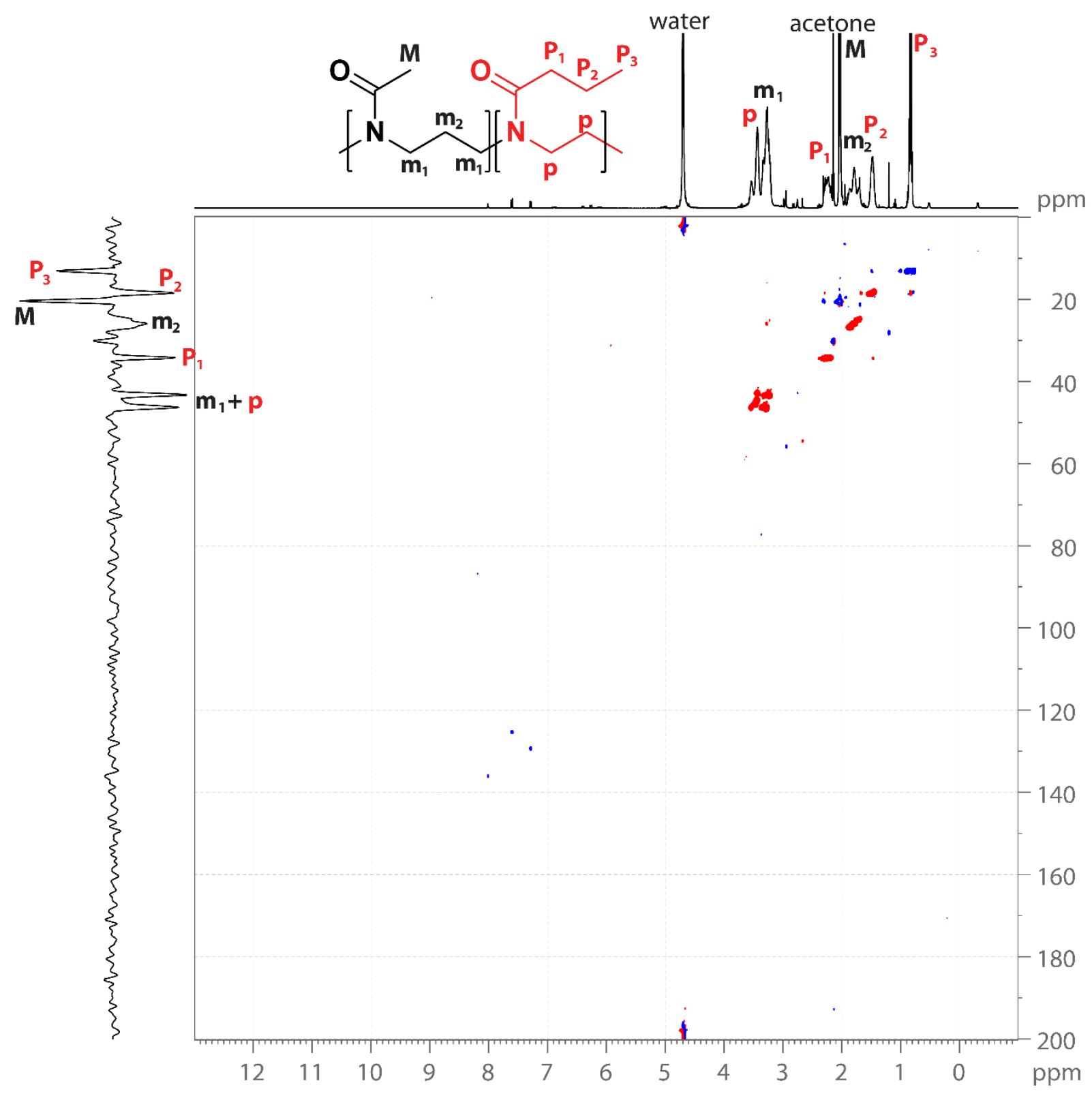

Figure S21. Multiplicity edited ${ }^{1} \mathrm{H}^{-1}{ }^{13} \mathrm{C}$ HSQC spectrum of $\mathrm{BP} 2$ in $\mathrm{D}_{2} \mathrm{O}\left(\mathrm{NS}=8\right.$ scans, $\mathrm{D}_{1}=1.50 \mathrm{~s}$, TD $=2048$ by 256). External projections for ${ }^{1} \mathrm{H}$ were used. Blue contours indicate a positive signal $(\mathrm{CH} 3$ or $\mathrm{CH}$ moieties), red contours indicate a negative signal ( $\mathrm{CH} 2$ moiety). 


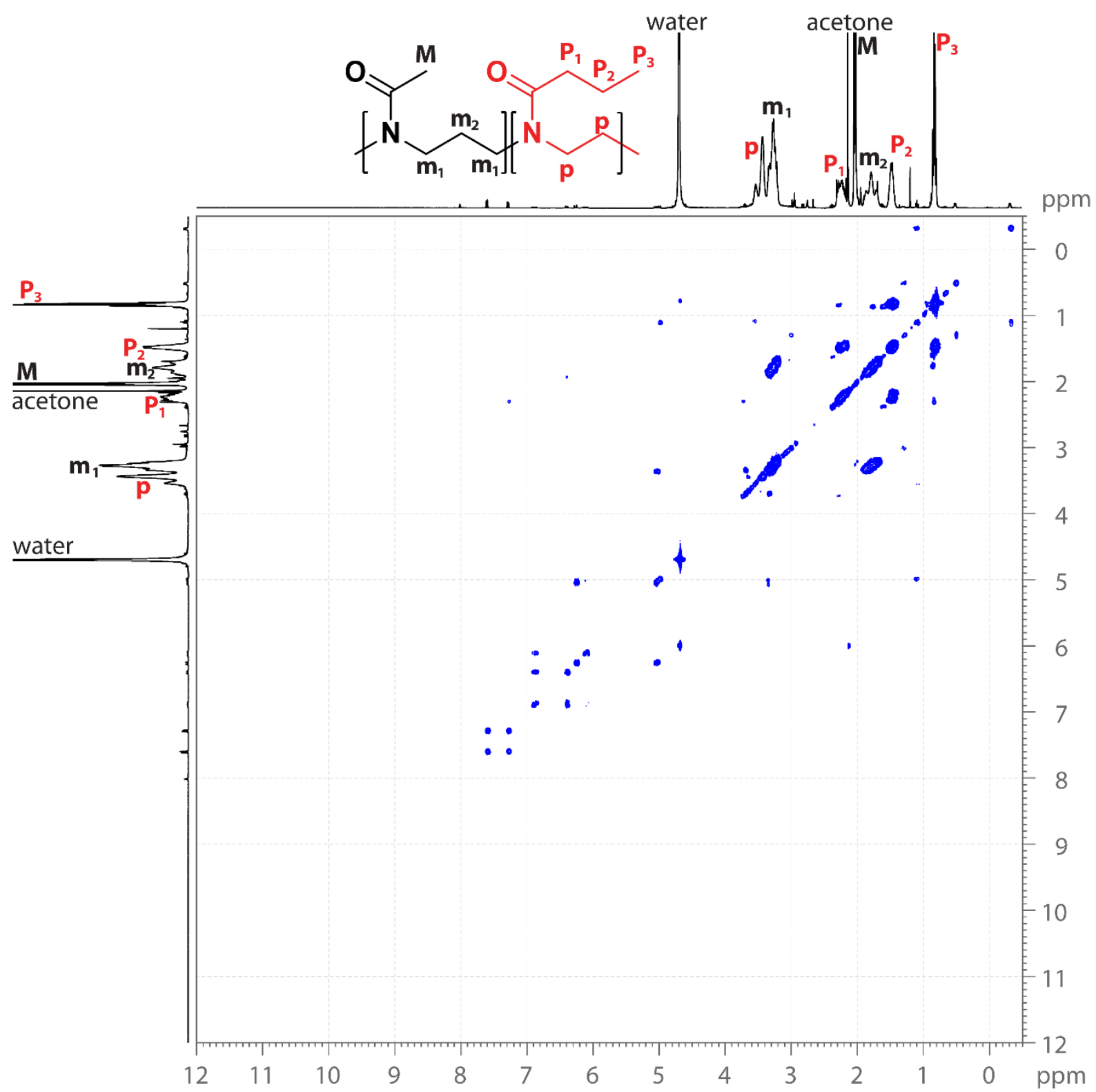

Figure S22. ${ }^{1} \mathrm{H}-{ }^{1} \mathrm{H}$ COSY spectrum of $\mathrm{BP} 2$ in $\mathrm{D}_{2} \mathrm{O}$. ( $\mathrm{NS}=8$ scans, $\mathrm{D}_{1}=2.00 \mathrm{~s}, \mathrm{TD}=2048$ by 256). 


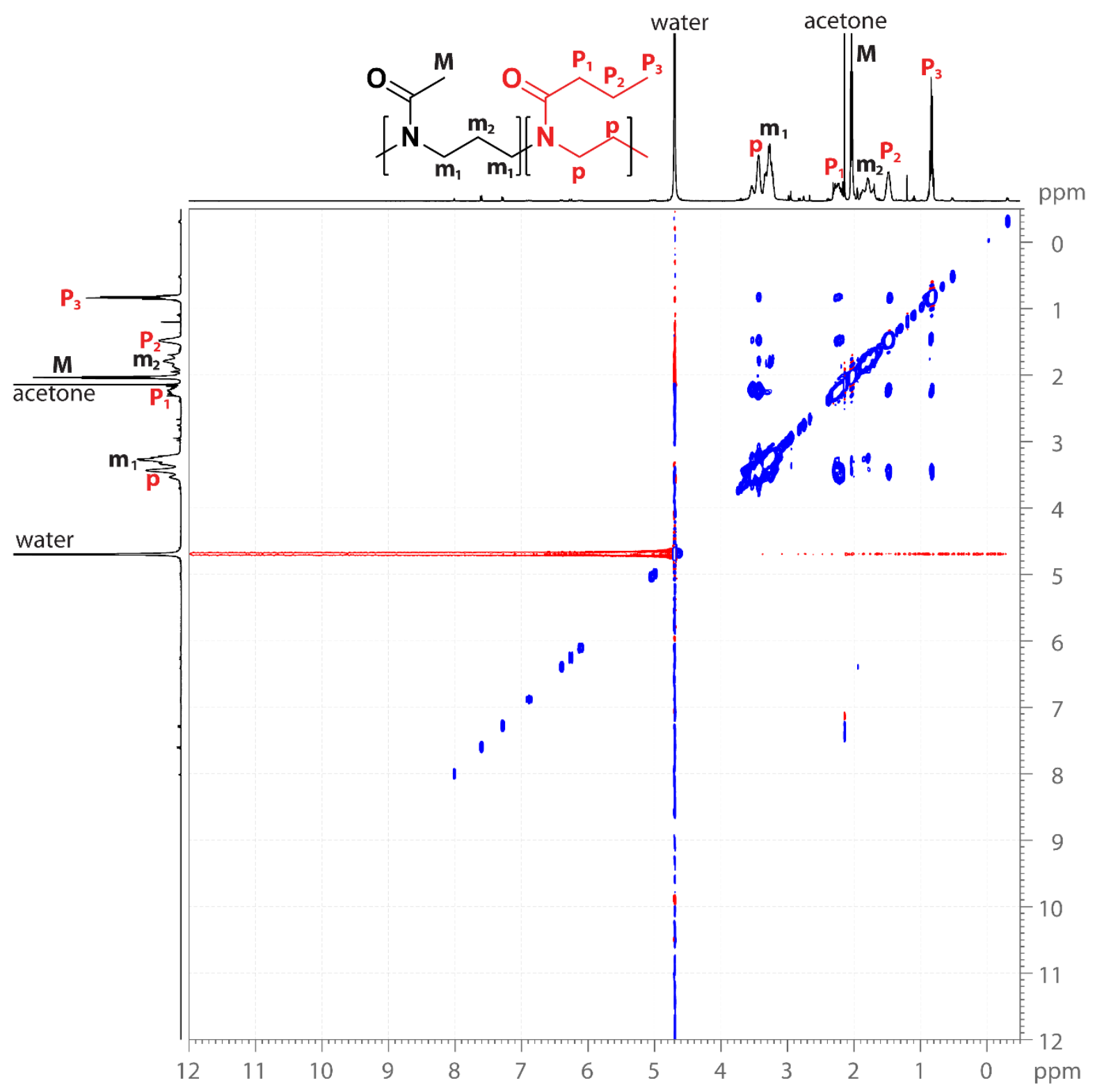

Figure S23. ${ }^{1} \mathrm{H}-{ }^{1} \mathrm{H}$ NOESY spectrum of $\mathrm{BP} 2$ in $\mathrm{D}_{2} \mathrm{O}$. (NS $=8$ scans, mixing time $300 \mathrm{~ms}, \mathrm{D}_{1}$ delay $2.00 \mathrm{~s}, \mathrm{TD}=2048$ by 256 ) 


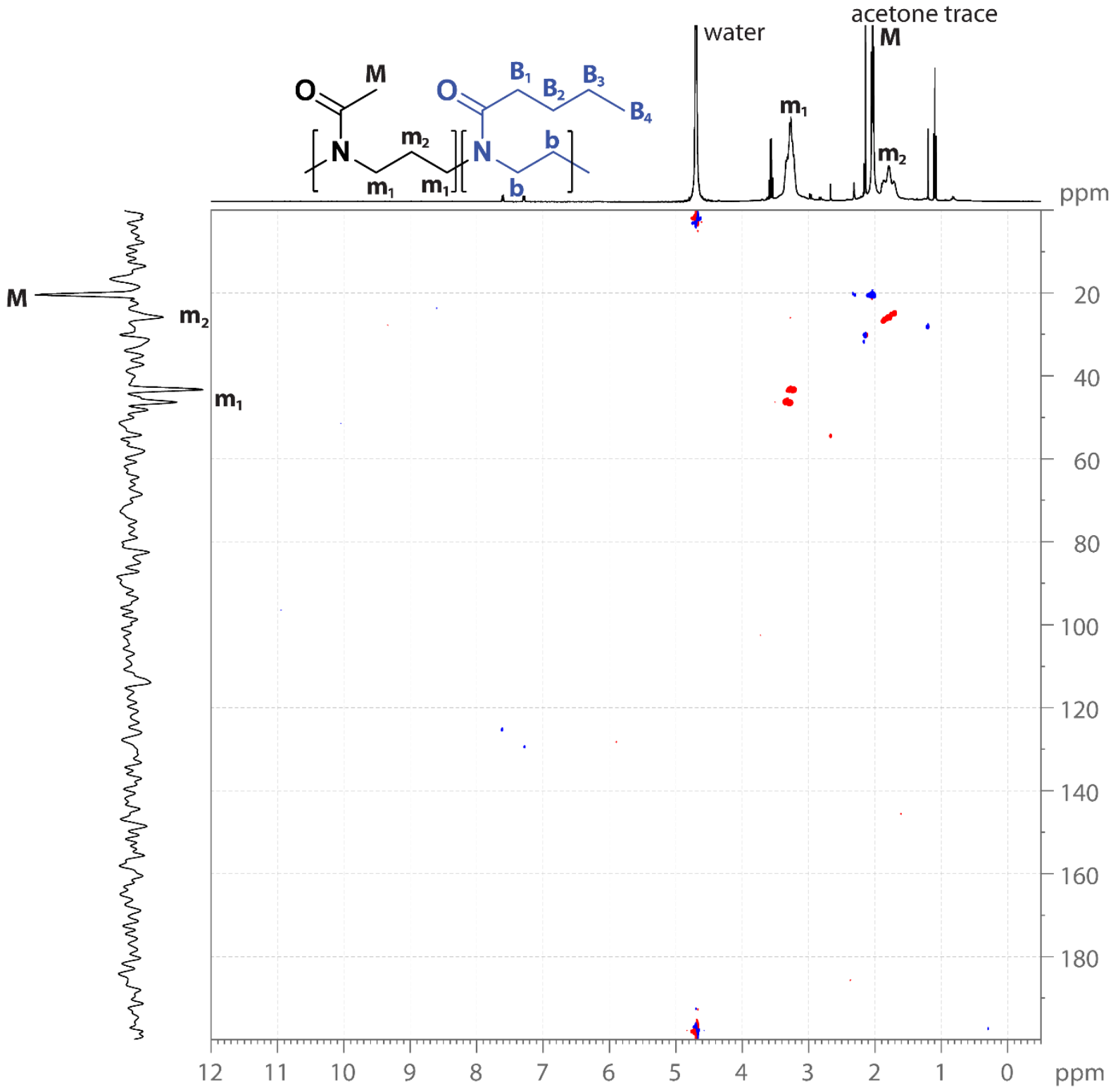

Figure S24. Multiplicity edited ${ }^{1} \mathrm{H}^{-13} \mathrm{C}$ HSQC spectrum of $\mathrm{BB} 2$ in $\mathrm{D}_{2} \mathrm{O}\left(\mathrm{NS}=8\right.$ scans, $\mathrm{D}_{1}=1.50 \mathrm{~s}, \mathrm{TD}=$ 2048 by 256). External projections for ${ }^{1} \mathrm{H}$ were used. Blue contours indicate a positive signal (CH3 or $\mathrm{CH}$ moieties), red contours indicate a negative signal ( $\mathrm{CH} 2$ moiety). 


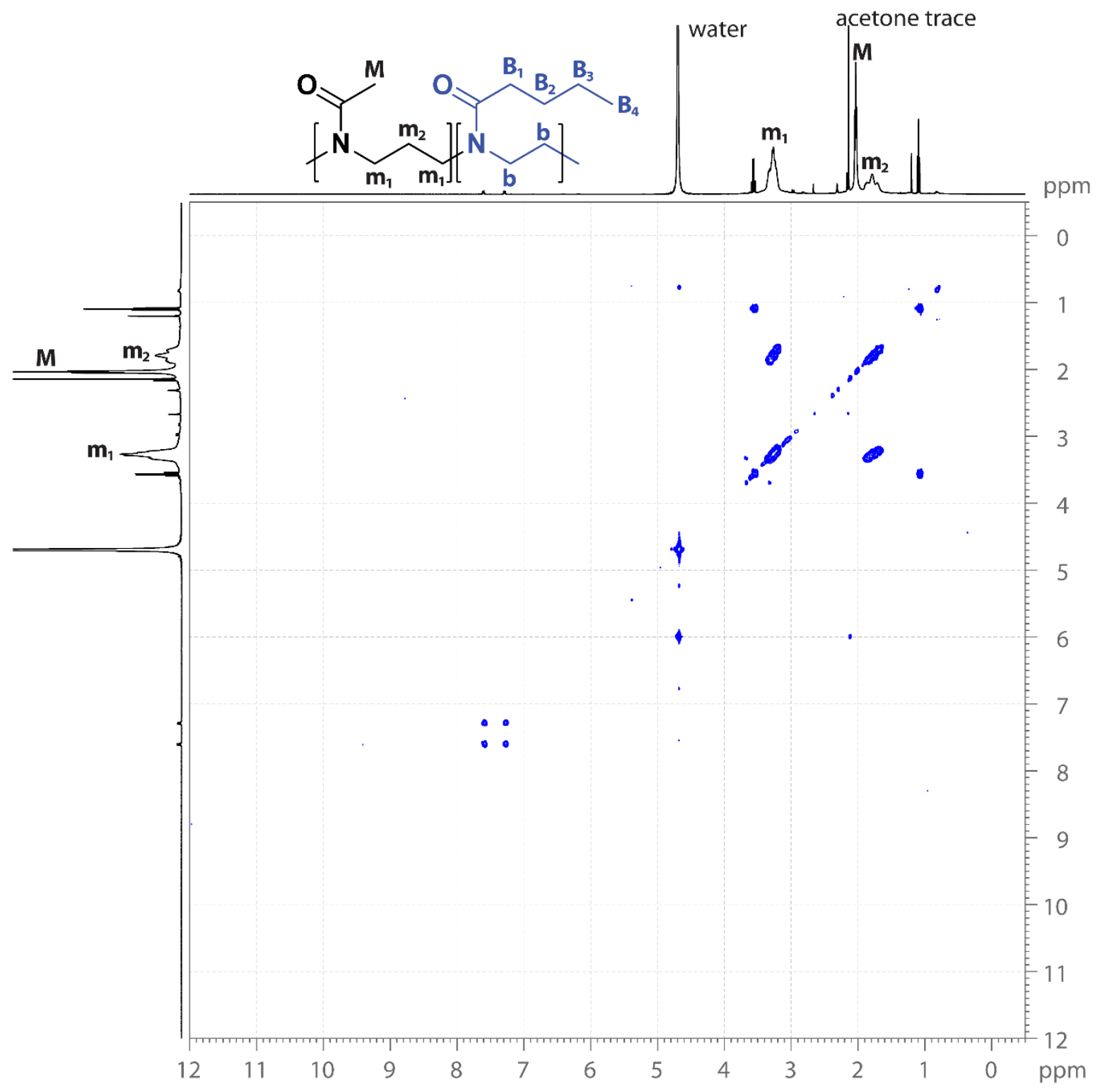

Figure S25. ${ }^{1} \mathrm{H}-{ }^{1} \mathrm{H}$ COSY spectrum of $\mathrm{BB} 2$ in $\mathrm{D}_{2} \mathrm{O}$. ( $\mathrm{NS}=8$ scans, $\mathrm{D}_{1}=2.00 \mathrm{~s}, \mathrm{TD}=2048$ by 256 ). 


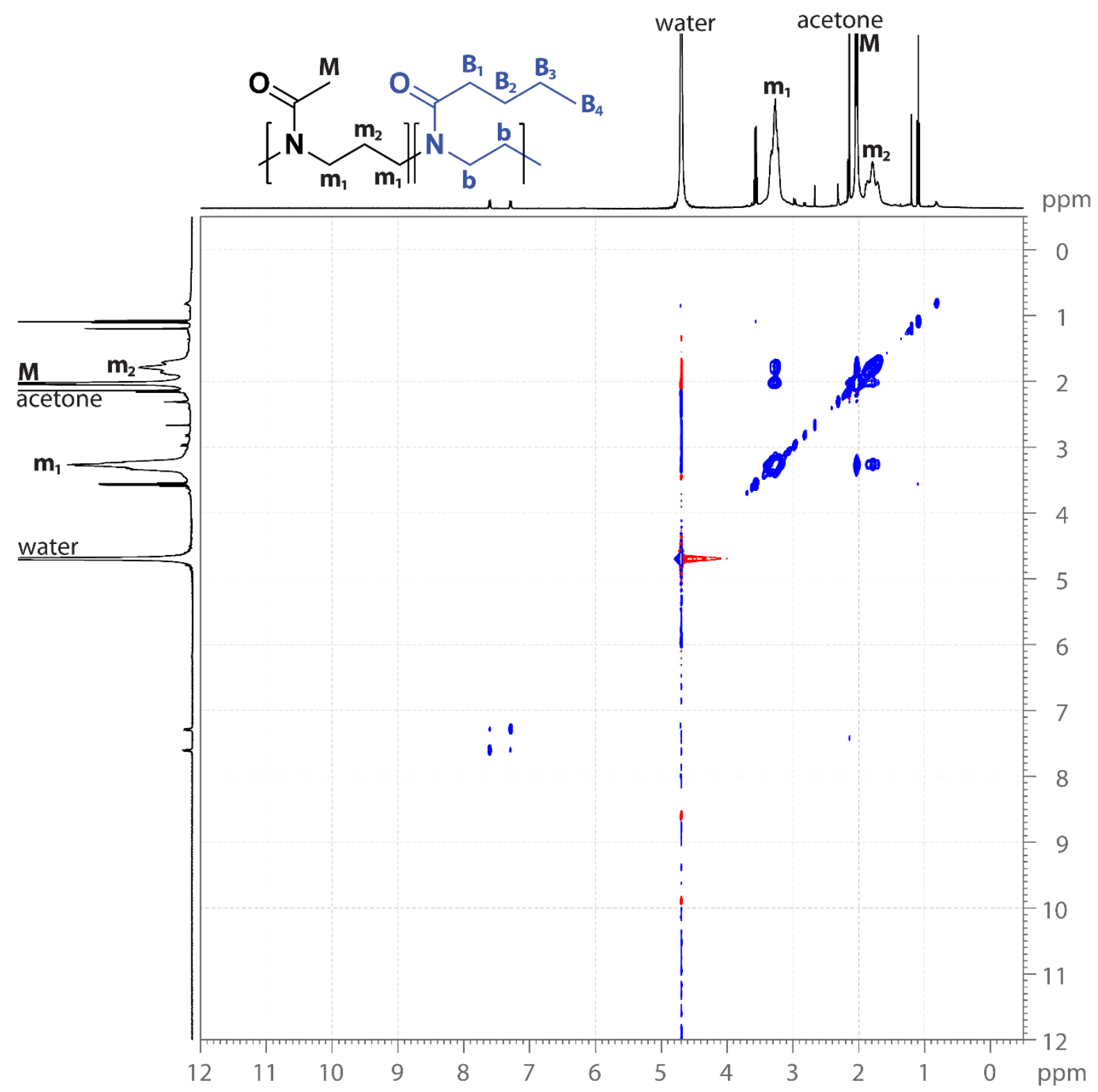

Figure S26. ${ }^{1} \mathrm{H}-{ }^{1} \mathrm{H}$ NOESY spectrum of $\mathrm{BB} 2$ in $\mathrm{D}_{2} \mathrm{O}$. ( $\mathrm{NS}=8$ scans, mixing time $300 \mathrm{~ms}, \mathrm{D}_{1}$ delay $2.00 \mathrm{~s}, \mathrm{TD}=2048$ by 256 ) 


\section{Detailed discussion of DLS results}

The monomer ratio of the copolymers has a significant influence on the self-assembly behavior, as expected. The copolymers with a monomer ratio of 1:2 (MeOzi:PrOx/BuOx), i.e. having the largest hydrophobic part, seem to be the most unstable leading to the formation of large aggregates and clusters (Samples BP1, BP1-L, GP1, GP1-L, BB1, BB1-L, GB1, Figures S15, S27, S18, S30, S21, S33, S24) or even a macroprecipitate at higher temperatures (GB1-L, Figure S36). The gradient copolymers (GP1, GP1-L, GB1, GB1-L, Figures S18, S30, S24, S36) show a stronger tendency to microprecipitate or even macroprecipitate at higher temperatures, most likely due to the presence of destabilizing hydrophobic units in the hydrophilic shell, which is not the case for the block copolymers.

The copolymers with a monomer ratio of 1:1 (MeOzi:PrOx/BuOx; samples BP2, BP2-L, GP2, GP2L, BB2, BB2-L, GB2, GB2-L, Figures S16, S28, S19, S31, S22, S34, S25, S37) form rather welldefined particle populations. The PrOx-containing block copolymers BP2, BP2-L, (Figures S16, S28) form smaller nanoparticles at higher temperatures while particle populations in BuOx-containing block copolymers BB2, BB2-L, (Figures S22, 1, S34) remain unchanged in the observed temperature range, whereby most of the polymer mass is present in the smaller nanoparticle population. The PrOxcontaining gradient copolymer GP2 (Figure S19) does not form significant populations of selfassembled particles and does not show significant change in particle populations across the studied temperature range. On the other hand, the same sample loaded with drug GP2-L, (Figures 1, S31) forms nanoparticle population which becomes significant in comparison to the present unimers at the topmost end of the used temperature range. The BuOx-containing gradient copolymers (GB2, GB2-L, Figures S25, 1, S37) form primarily smaller particles at lower temperatures and larger aggregates at higher temperatures. This difference in behavior could be ascribed to different hydrophobicity and $\mathrm{T}_{\mathrm{CPS}}$ of PPrOx and PBuOx homopolymers.

The copolymers with a monomer ratio of 2:1 (MeOzi:PrOx/BuOx), i.e. having the largest hydrophilic part, show overall a lower self-assembly tendency and are either mostly molecularly dissolved as unimers or undergo thermal changes at higher temperatures than the other copolymers. The PrOx-containing block copolymers BP3, BP3-L (Figures S17, S29) only form self-assembled particles well above physiological temperatures and the gradient copolymers GP3 and GP3-L (Figures S20, S32) remain almost exclusively in the unimer population across the studied temperature range with only slight observed changes of size distribution. Loading of the drug in these samples promotes formation of more compact nanoparticles, even though for the gradient copolymers the nanoparticles remain in the minority when compared to the unimers, even at higher temperatures.

The BuOx-containing block-copolymers BB3, BB3-L (Figures S23, S35) form populations of micelle-like particles in combination with larger aggregates. It is interesting to observe that these micelle-like particles become smaller at higher temperatures, this effect is more pronounced in the BB3L sample. The gradient copolymers exhibit a small thermal response above the physiological temperature. The sample GB3 (Figure S26) without drug preferentially remains as unimers, but in presence of drug the sample GB3-L (Figure S38) forms self-assembled nanoparticles that react to increasing temperature as described in the main article. 


\subsection{DLS size distribution figures}

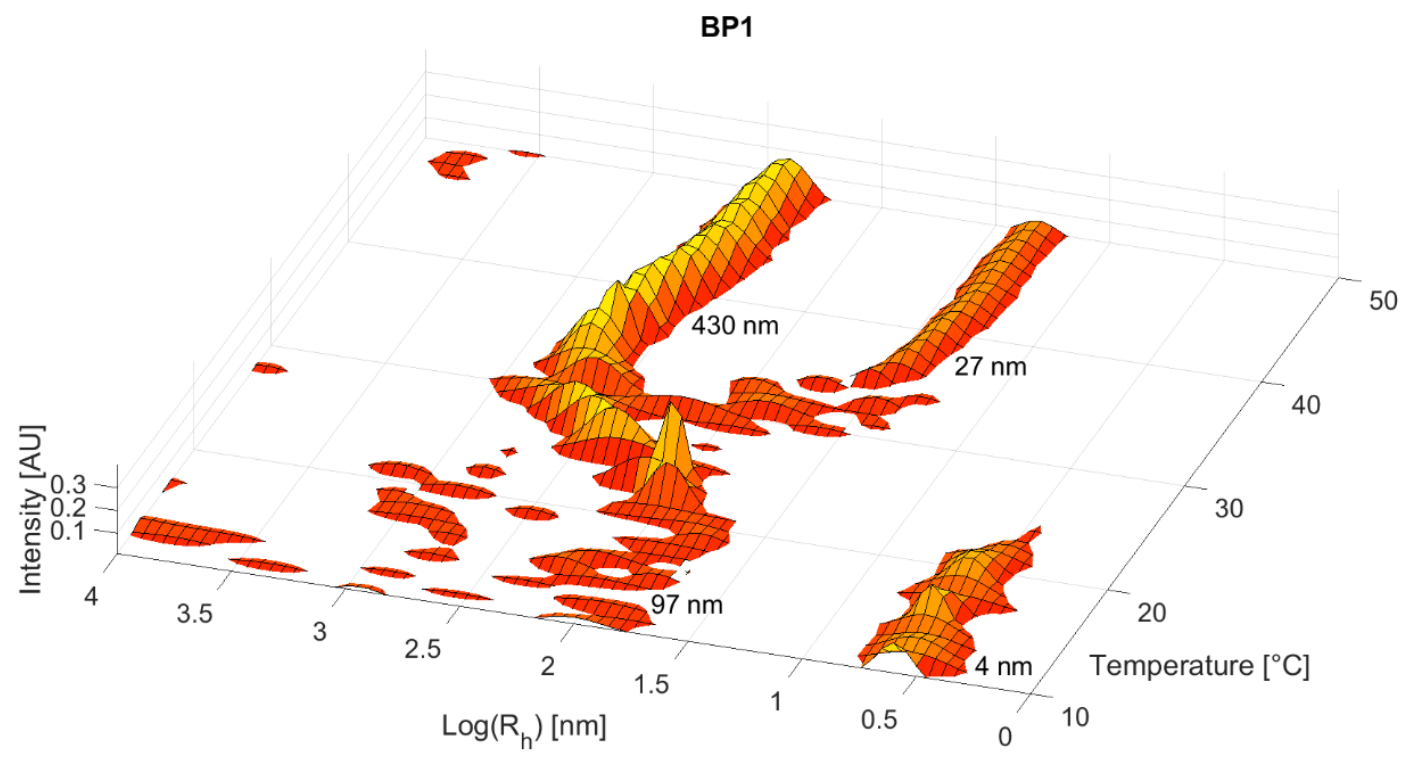

Figure S27. Size distributions of molecular assemblies of copolymer BP1 ( $0.1 \mathrm{wt}$. \% polymer solution in $140 \mathrm{mM}$ phosphate buffered saline, $\mathrm{pH}$ 7.4) as a function of temperature.

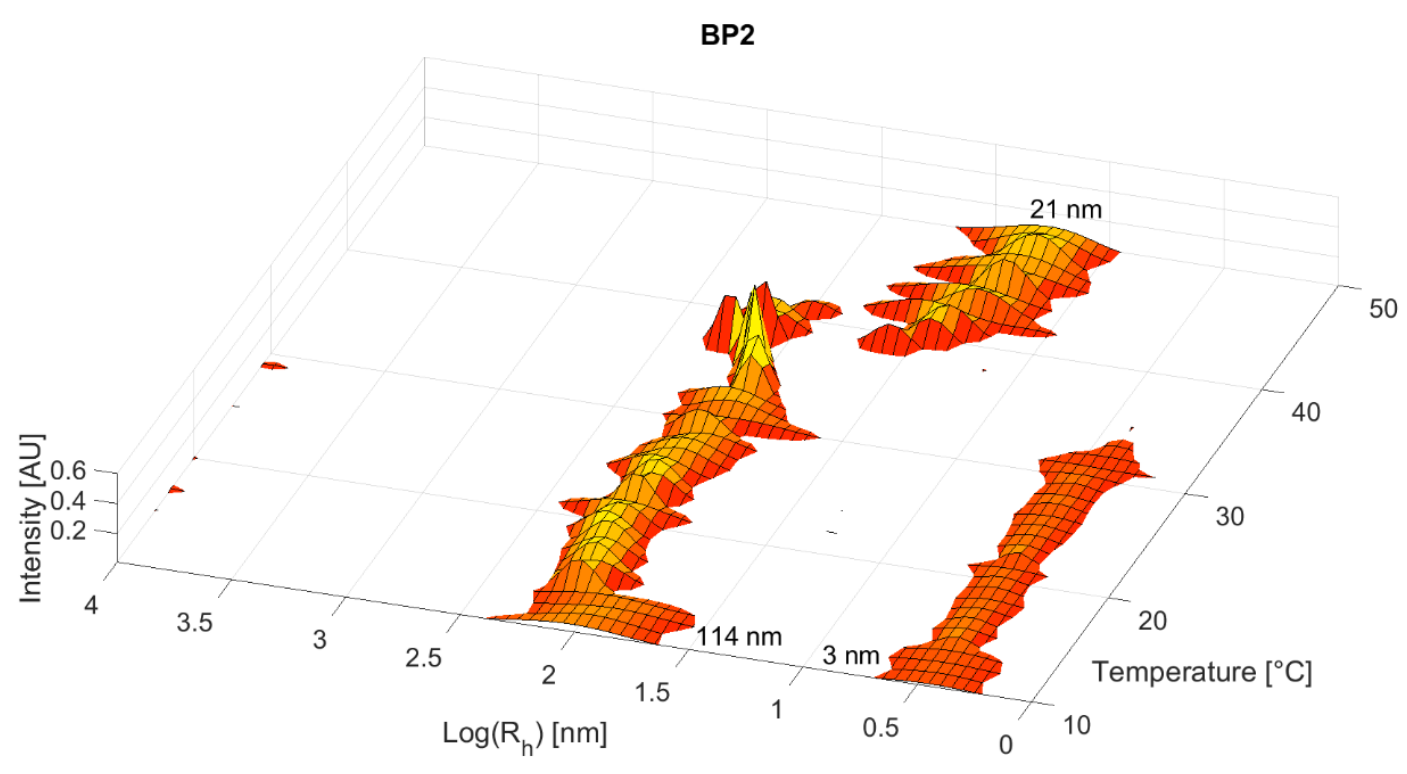

Figure S28. Size distributions of molecular assemblies of copolymer BP2 (0.1 wt. \% polymer solution in $140 \mathrm{mM}$ phosphate buffered saline, $\mathrm{pH}$ 7.4) as a function of temperature. 


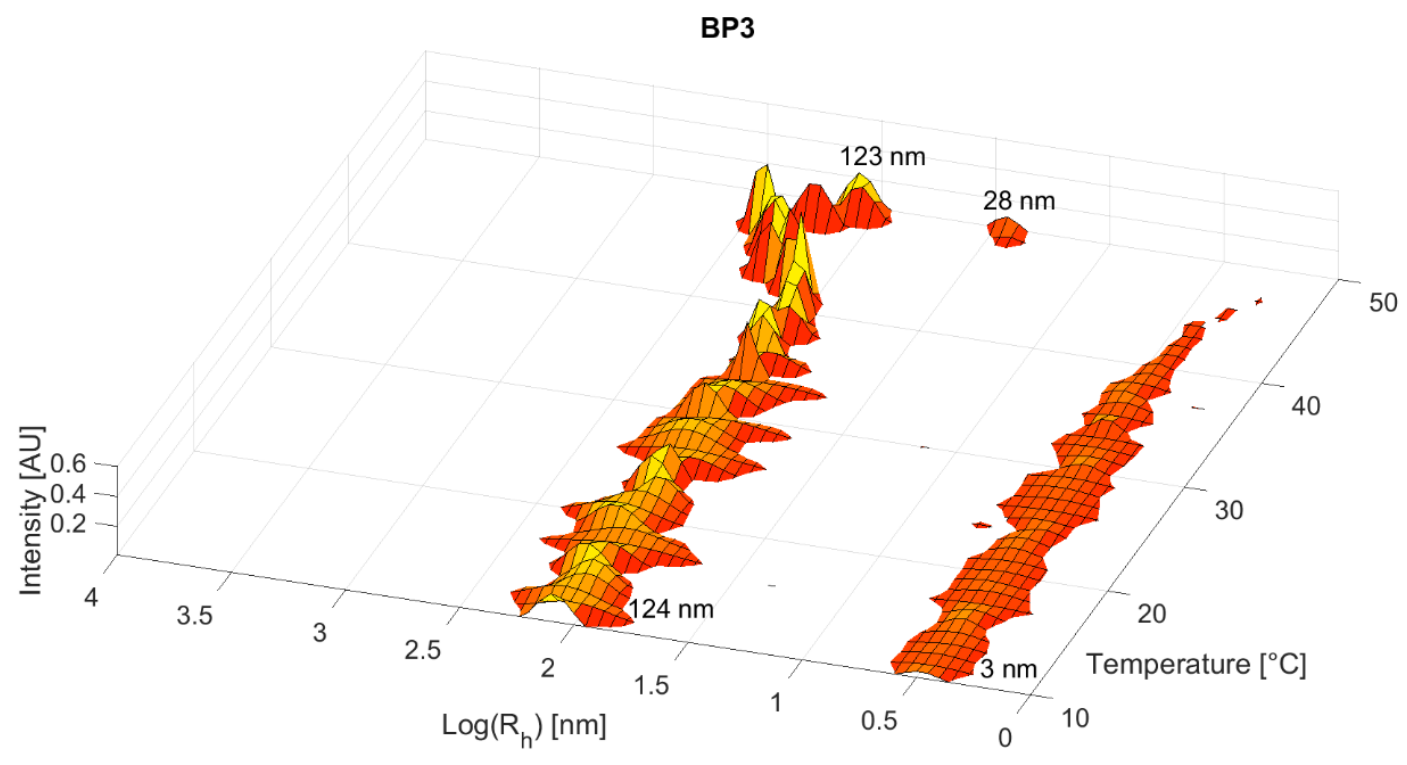

Figure S29. Size distributions of molecular assemblies of copolymer BP3 ( 0.1 wt. \% polymer solution in $140 \mathrm{mM}$ phosphate buffered saline, $\mathrm{pH}$ 7.4) as a function of temperature.

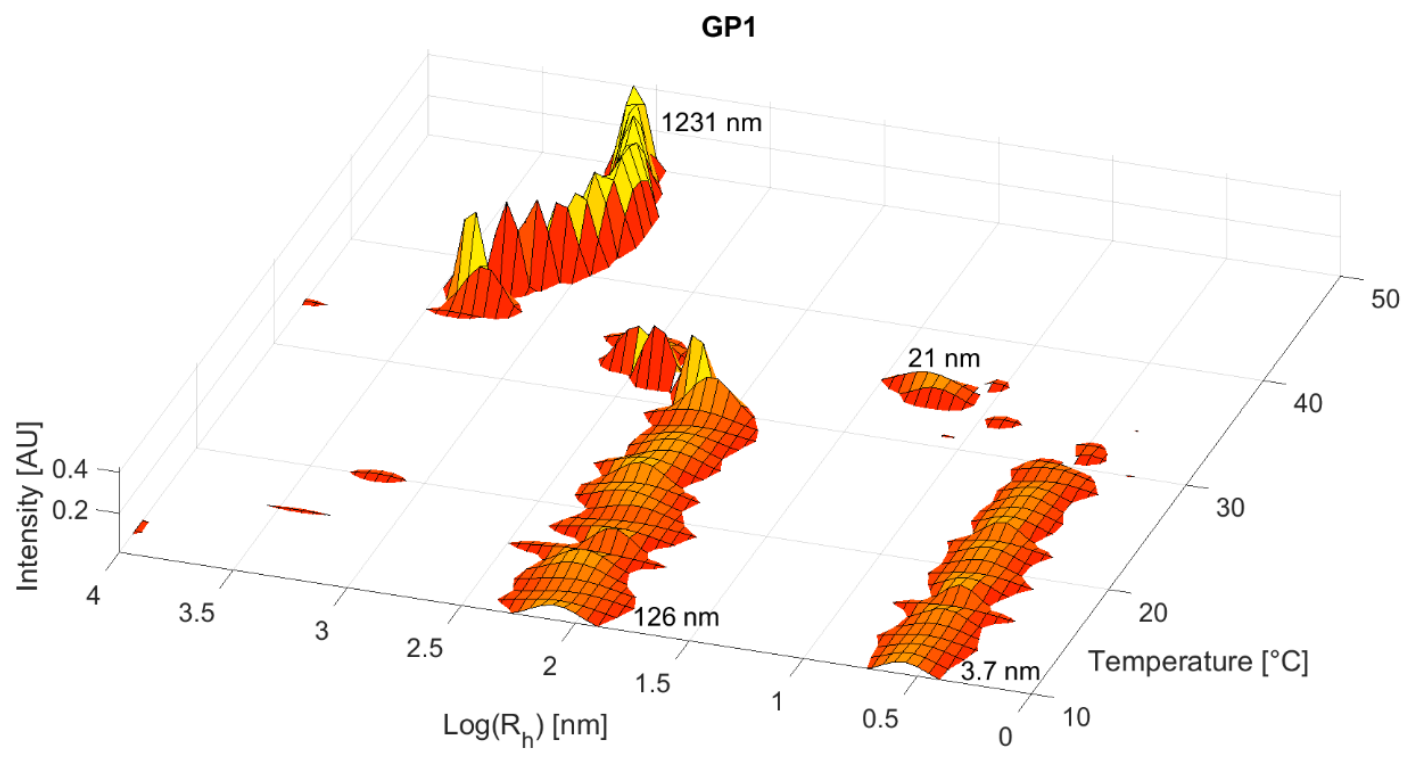

Figure S30. Size distributions of molecular assemblies of copolymer GP1 ( 0.1 wt. \% polymer solution in $140 \mathrm{mM}$ phosphate buffered saline, $\mathrm{pH}$ 7.4) as a function of temperature. 


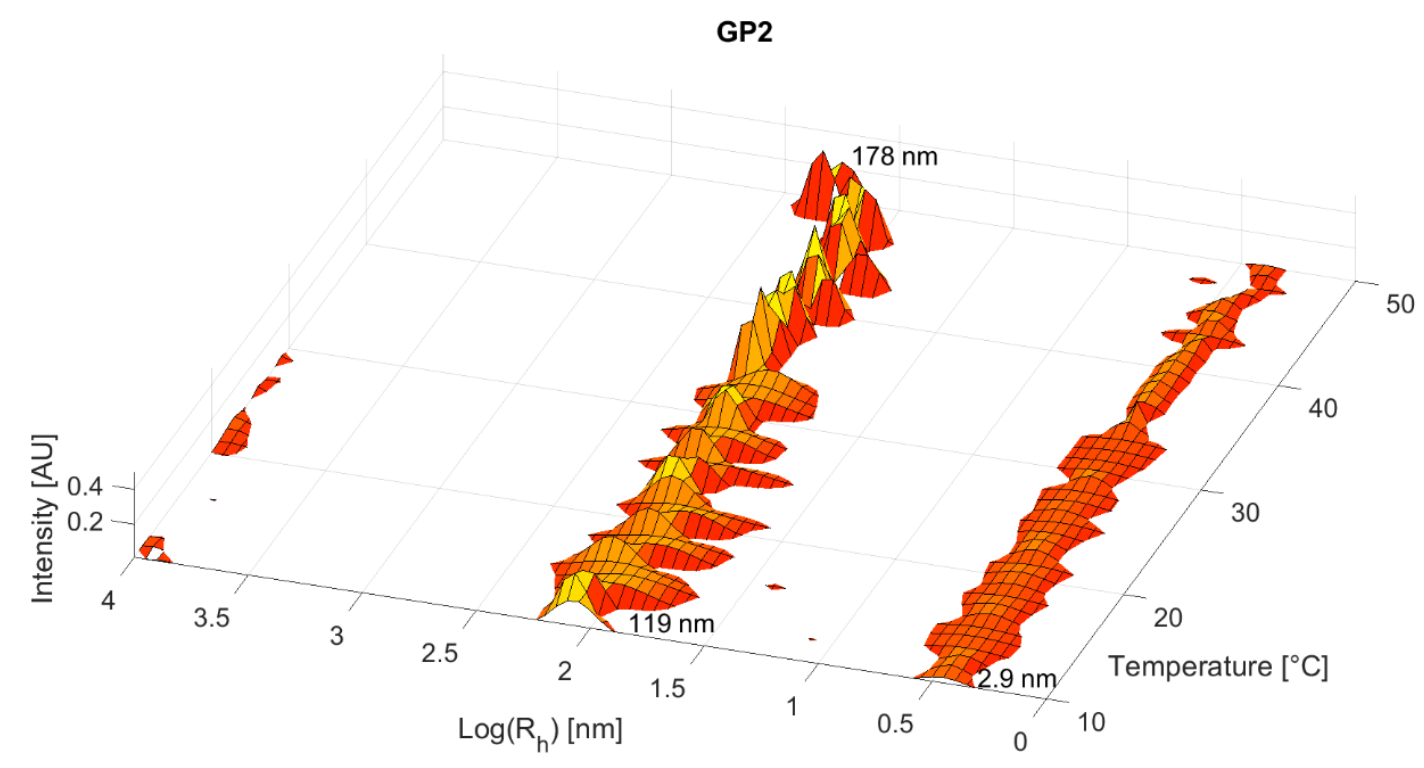

Figure S31. Size distributions of molecular assemblies of copolymer GP2 ( 0.1 wt. \% polymer solution in $140 \mathrm{mM}$ phosphate buffered saline, $\mathrm{pH}$ 7.4) as a function of temperature.

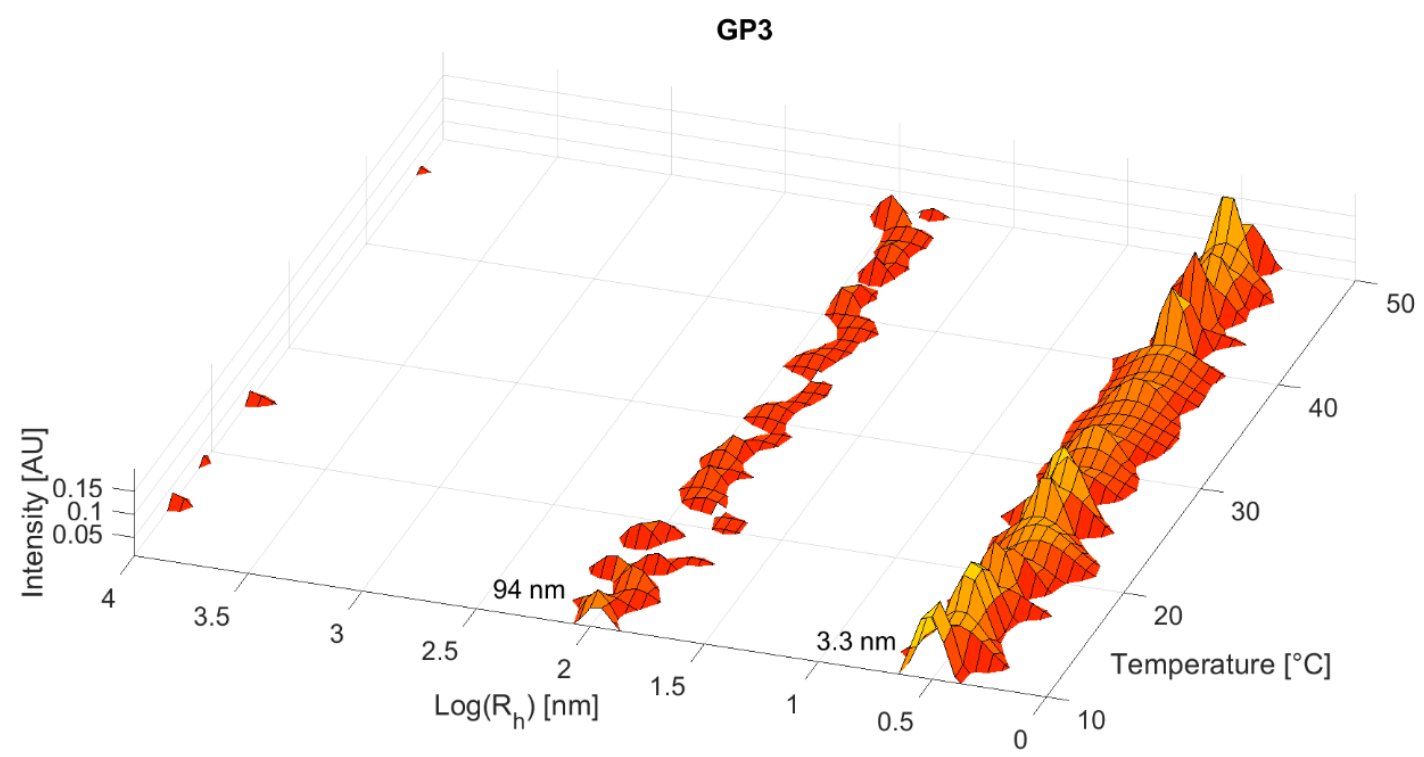

Figure S32. Size distributions of molecular assemblies of copolymer GP3 ( 0.1 wt. \% polymer solution in $140 \mathrm{mM}$ phosphate buffered saline, $\mathrm{pH}$ 7.4) as a function of temperature. 


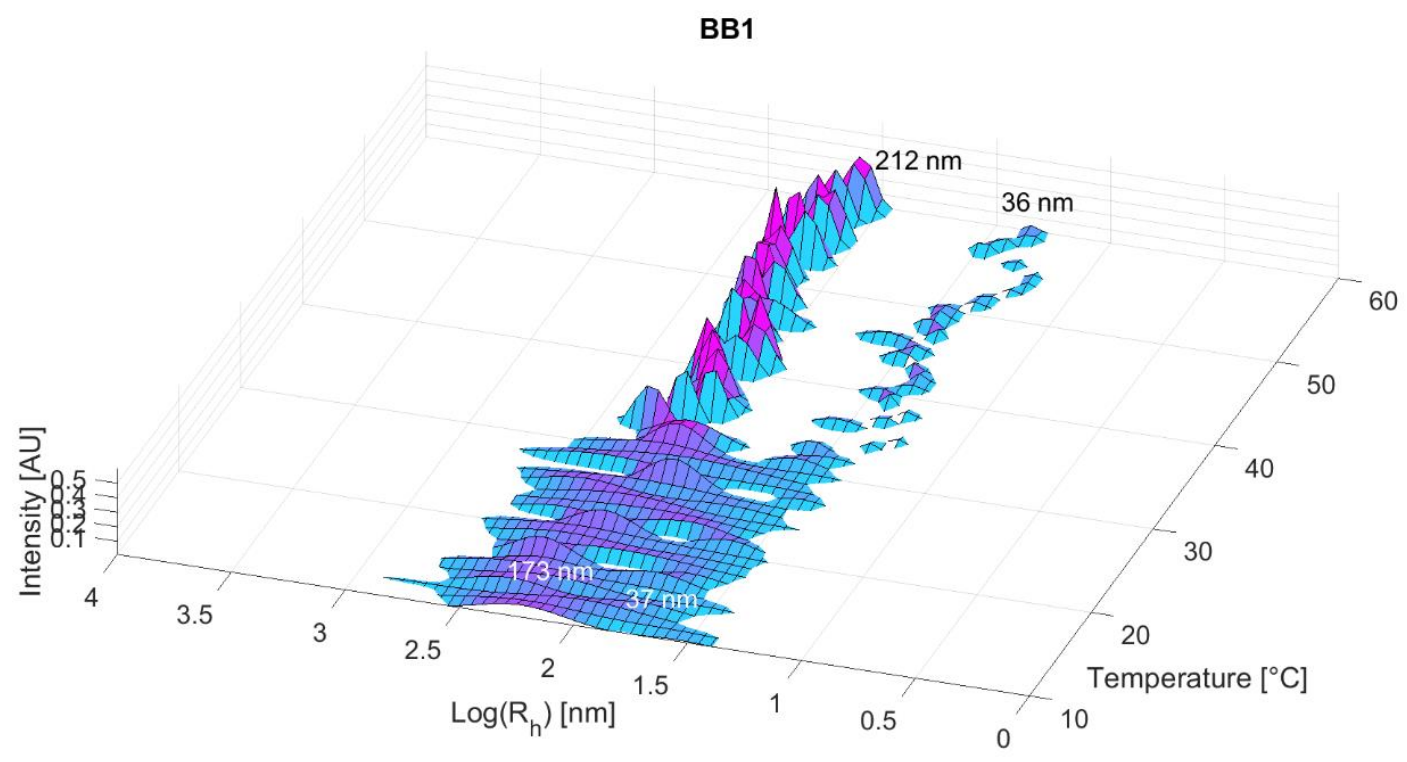

Figure S33. Size distributions of molecular assemblies of copolymer BB1 ( 0.1 wt. \% polymer solution in $140 \mathrm{mM}$ phosphate buffered saline, $\mathrm{pH}$ 7.4) as a function of temperature.

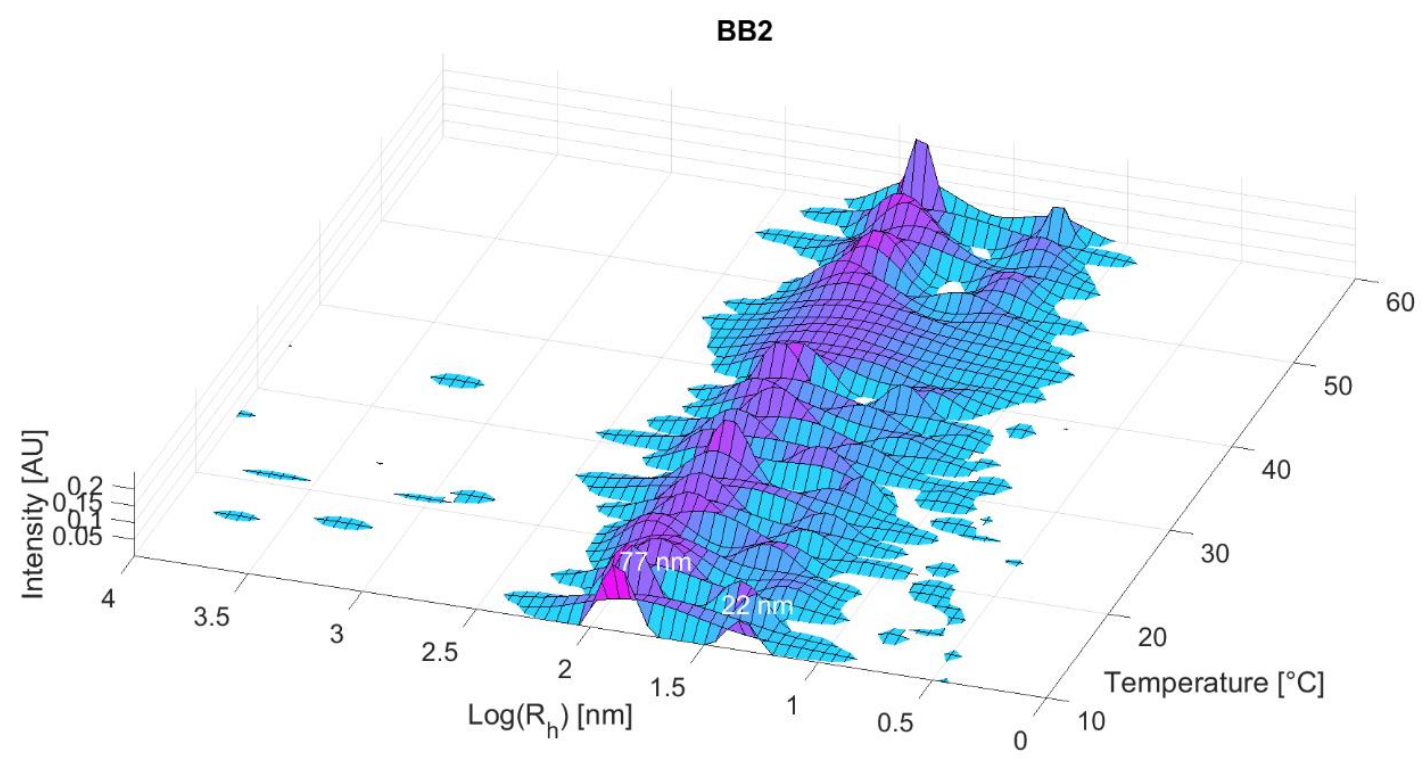

Figure S34. Size distributions of molecular assemblies of copolymer BB2 ( 0.1 wt. \% polymer solution in $140 \mathrm{mM}$ phosphate buffered saline, $\mathrm{pH}$ 7.4) as a function of temperature. 


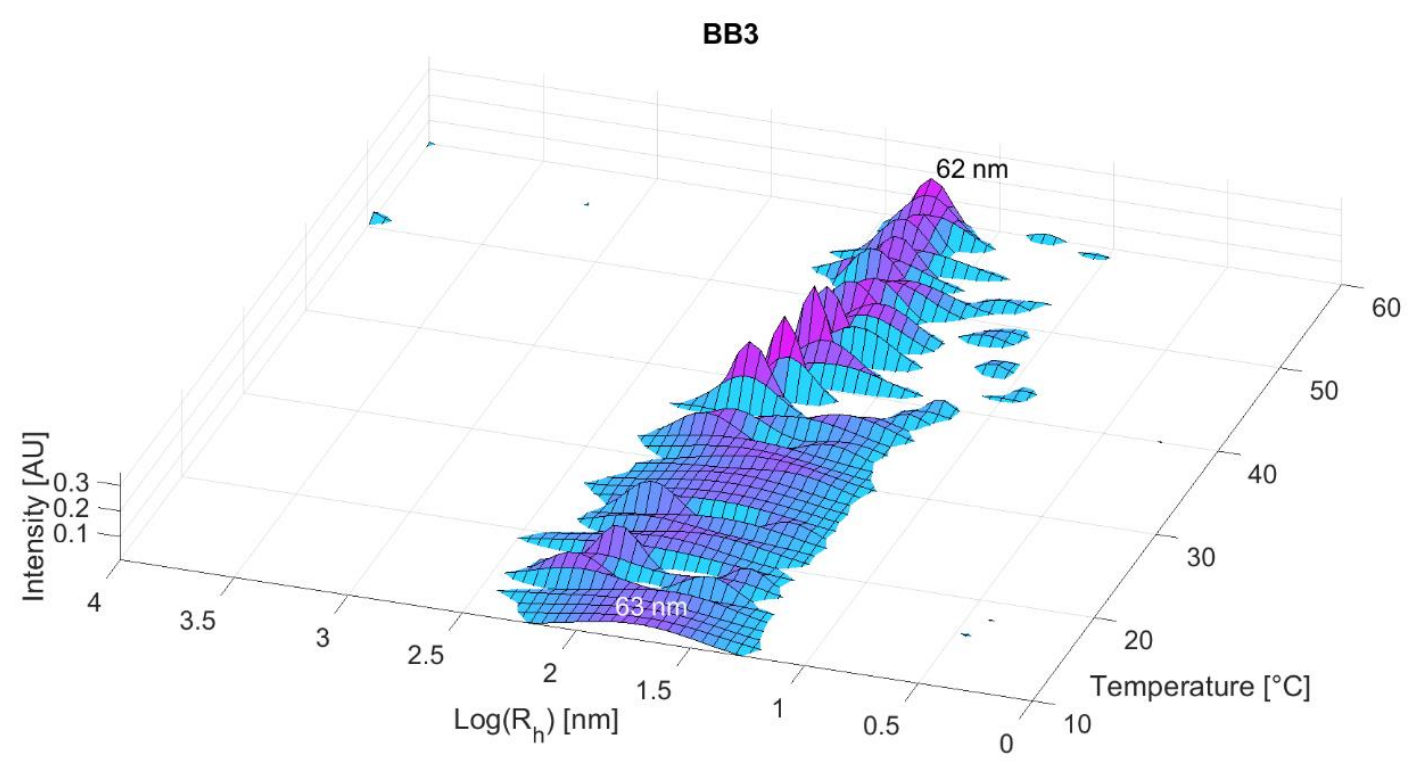

Figure S35. Size distributions of molecular assemblies of copolymer BB3 ( 0.1 wt. \% polymer solution in $140 \mathrm{mM}$ phosphate buffered saline, $\mathrm{pH}$ 7.4) as a function of temperature.

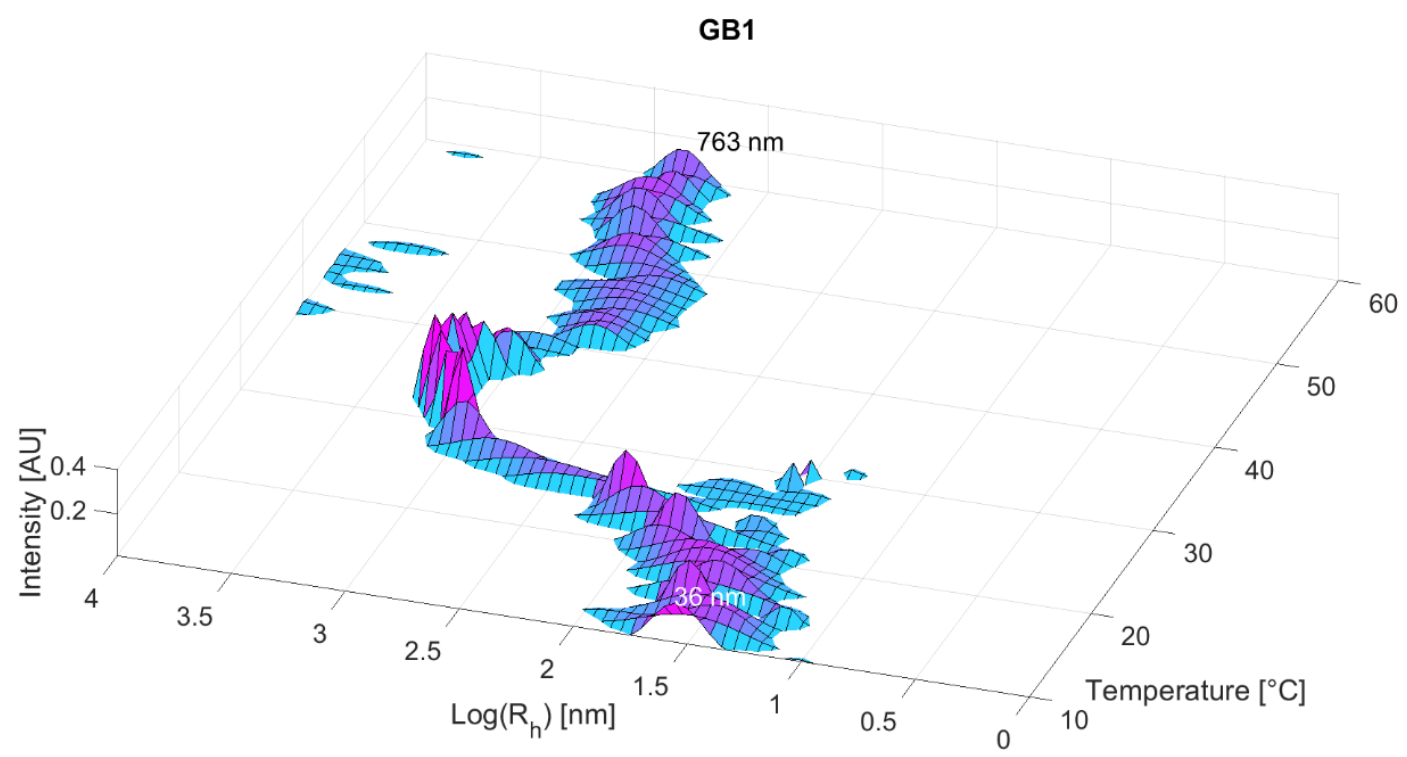

Figure S36. Size distributions of molecular assemblies of copolymer GB1 ( 0.1 wt. \% polymer solution in $140 \mathrm{mM}$ phosphate buffered saline, $\mathrm{pH}$ 7.4) as a function of temperature. 


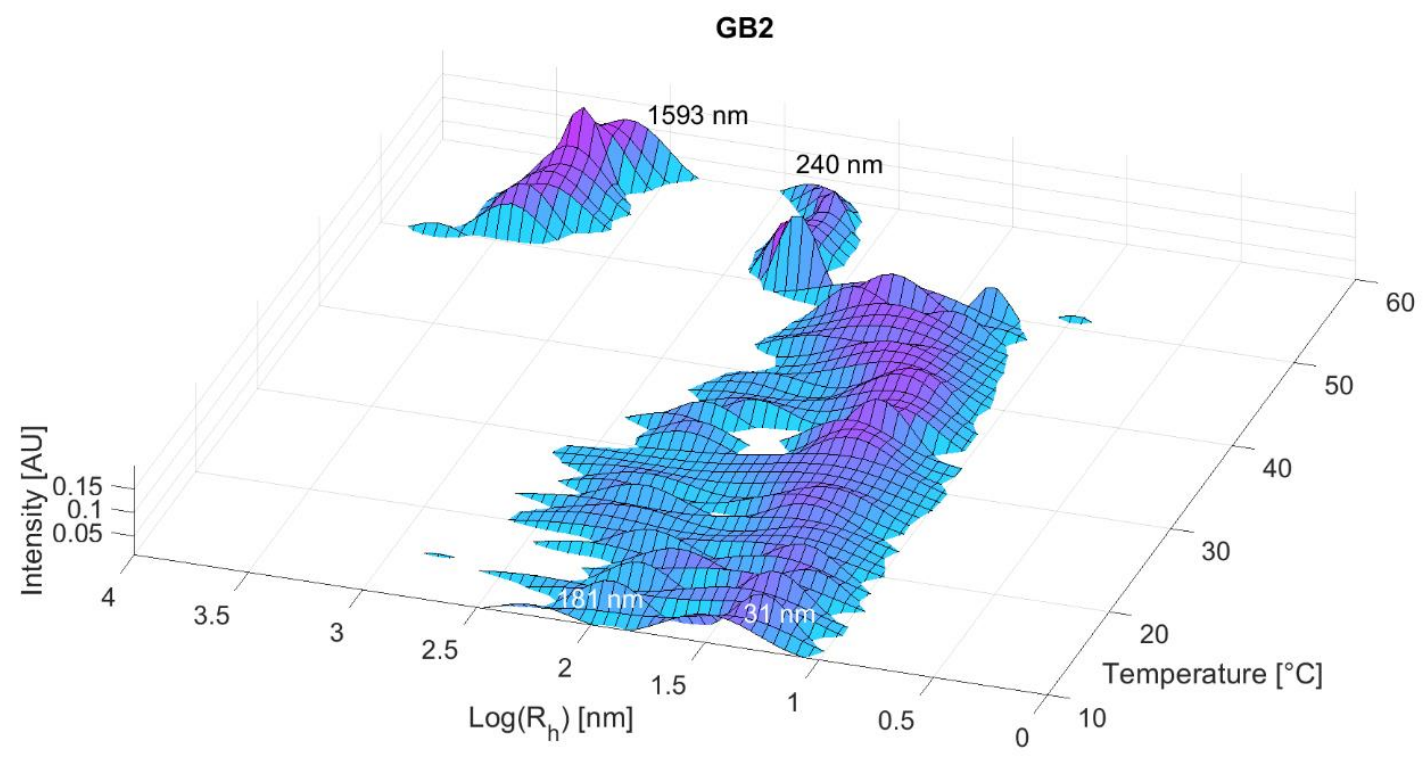

Figure S37. Size distributions of molecular assemblies of copolymer GB2 ( 0.1 wt. \% polymer solution in $140 \mathrm{mM}$ phosphate buffered saline, $\mathrm{pH}$ 7.4) as a function of temperature.

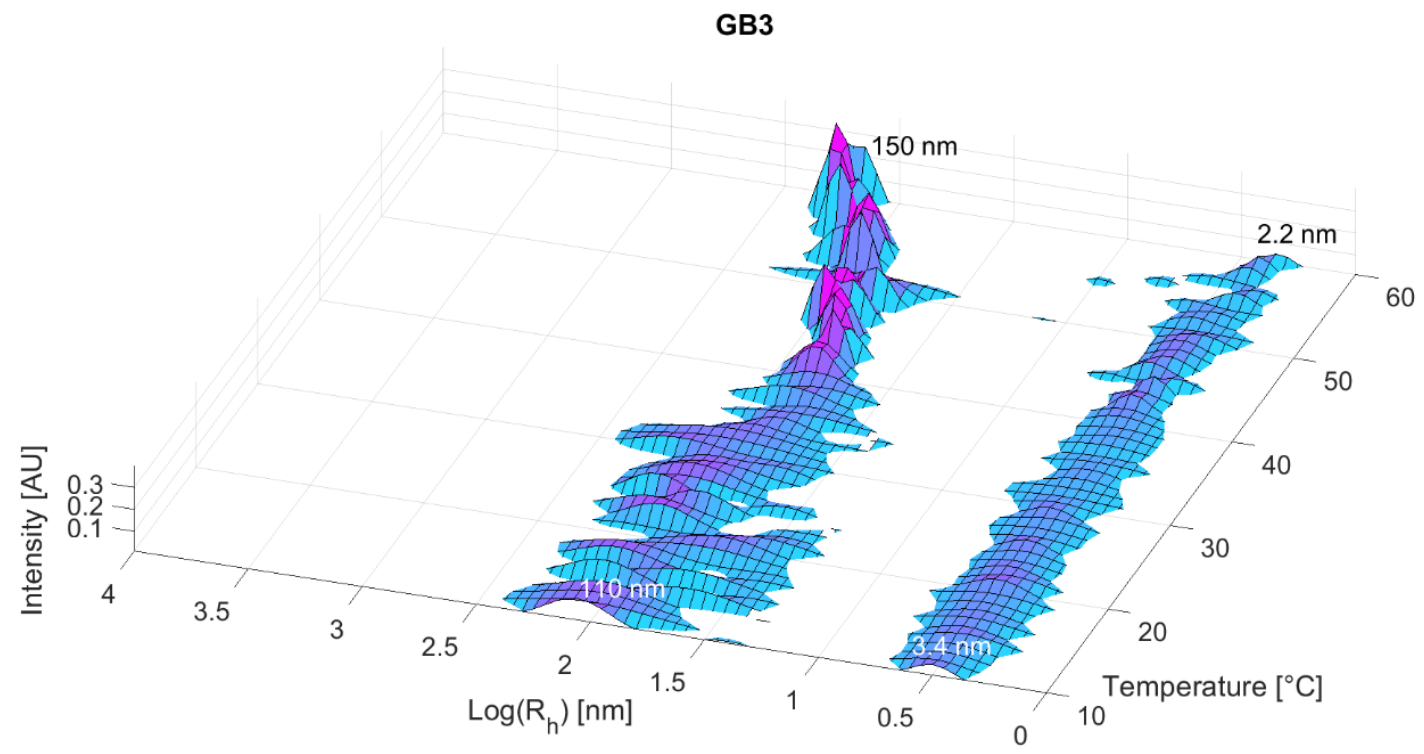

Figure S38. Size distributions of molecular assemblies of copolymer GB3 ( 0.1 wt. \% polymer solution in $140 \mathrm{mM}$ phosphate buffered saline, $\mathrm{pH} 7.4$ ) as a function of temperature. 


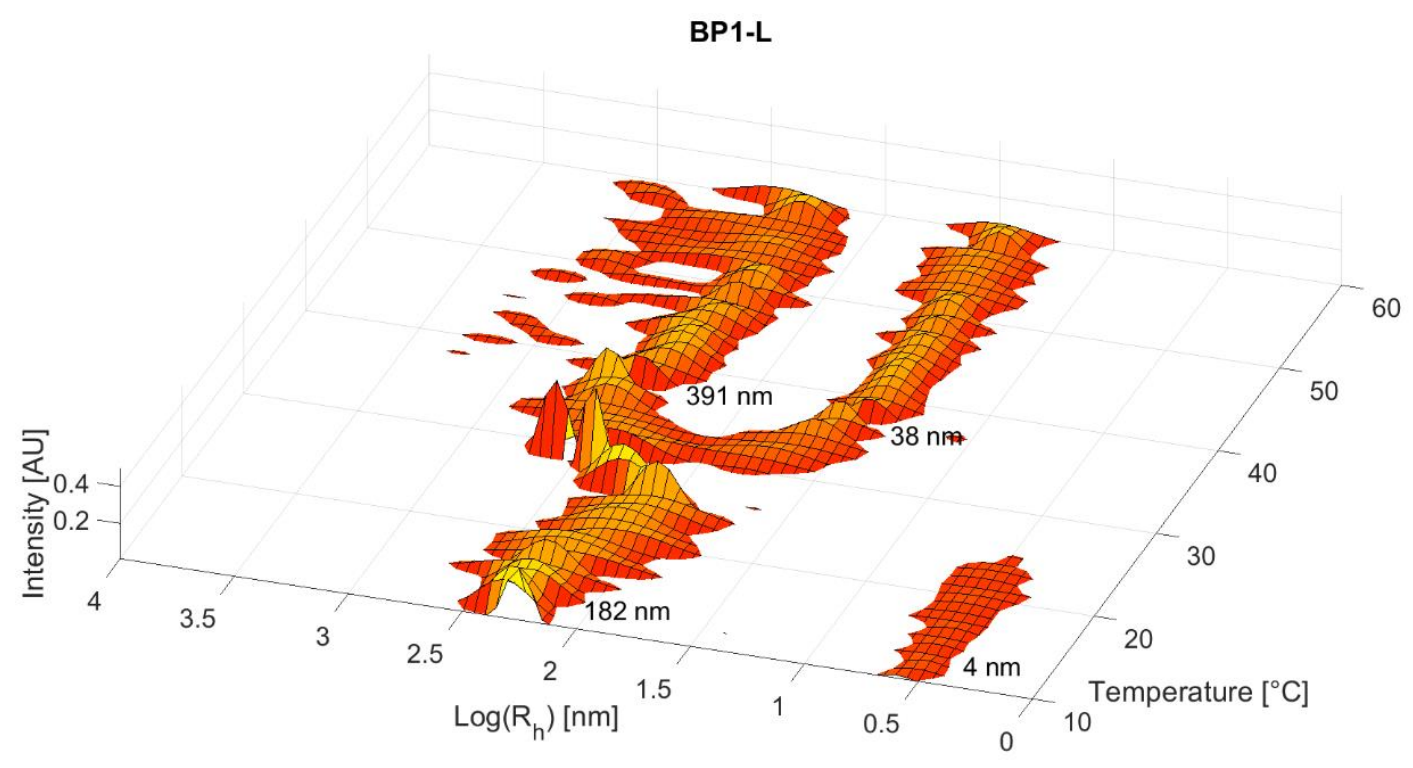

Figure S39. Size distributions of molecular assemblies of copolymer BP1-L ( 0.1 wt. \% polymer solution in $140 \mathrm{mM}$ phosphate buffered saline, $\mathrm{pH} 7.4$, loaded with $0.01 \mathrm{wt}$. \% of rifampicin) as a function of temperature.

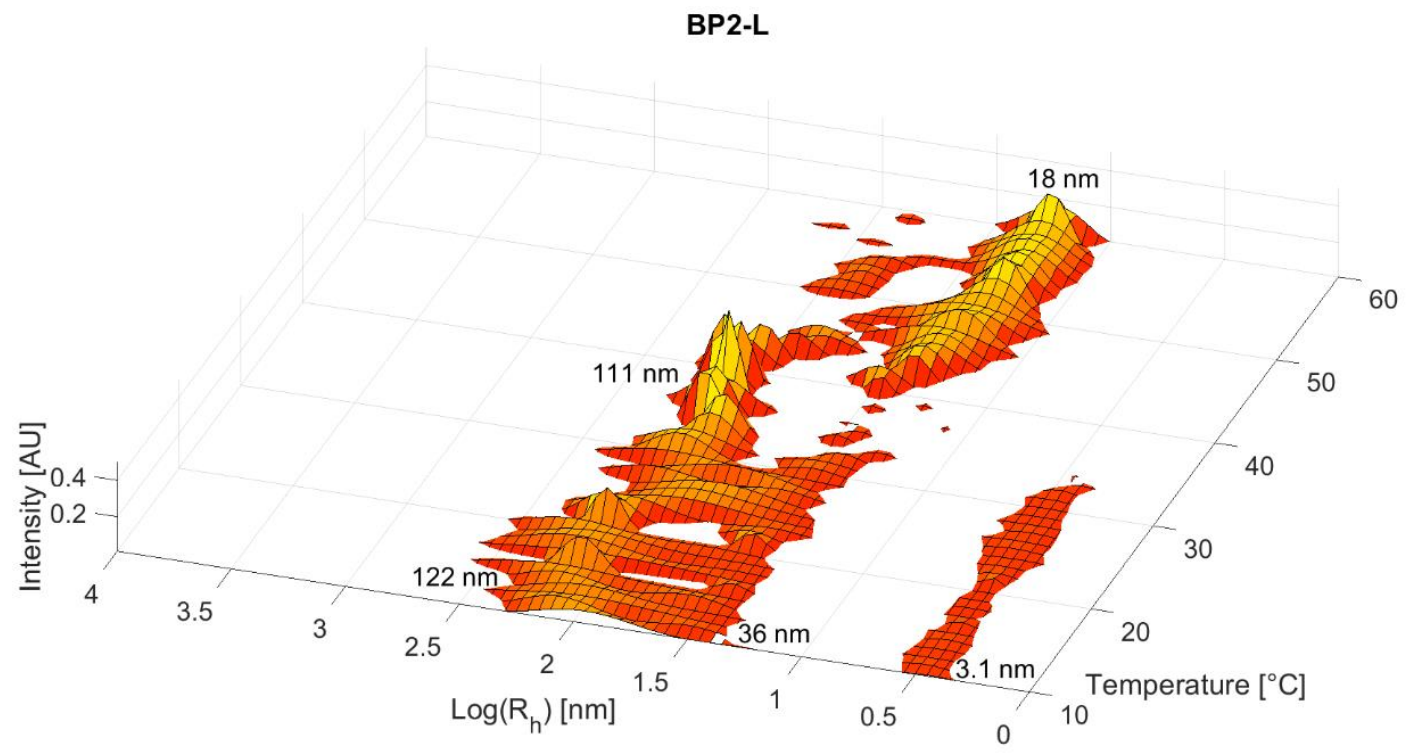

Figure S40. Size distributions of molecular assemblies of copolymer BP2-L ( 0.1 wt. \% polymer solution in $140 \mathrm{mM}$ phosphate buffered saline, $\mathrm{pH} 7.4$, loaded with $0.01 \mathrm{wt}$. \% of rifampicin) as a function of temperature. 


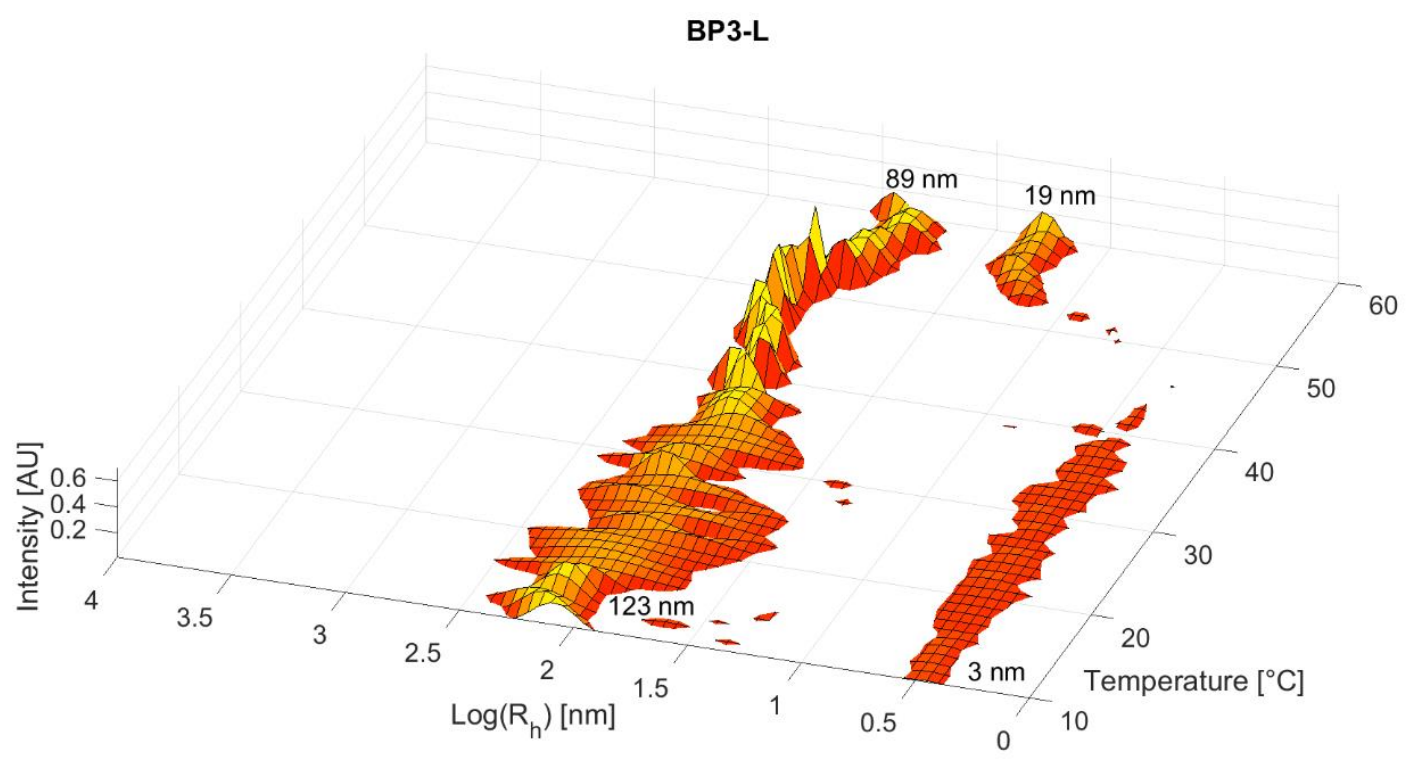

Figure S41. Size distributions of molecular assemblies of copolymer BP3-L ( 0.1 wt. \% polymer solution in $140 \mathrm{mM}$ phosphate buffered saline, $\mathrm{pH} 7.4$, loaded with $0.01 \mathrm{wt} . \%$ of rifampicin) as a function of temperature.

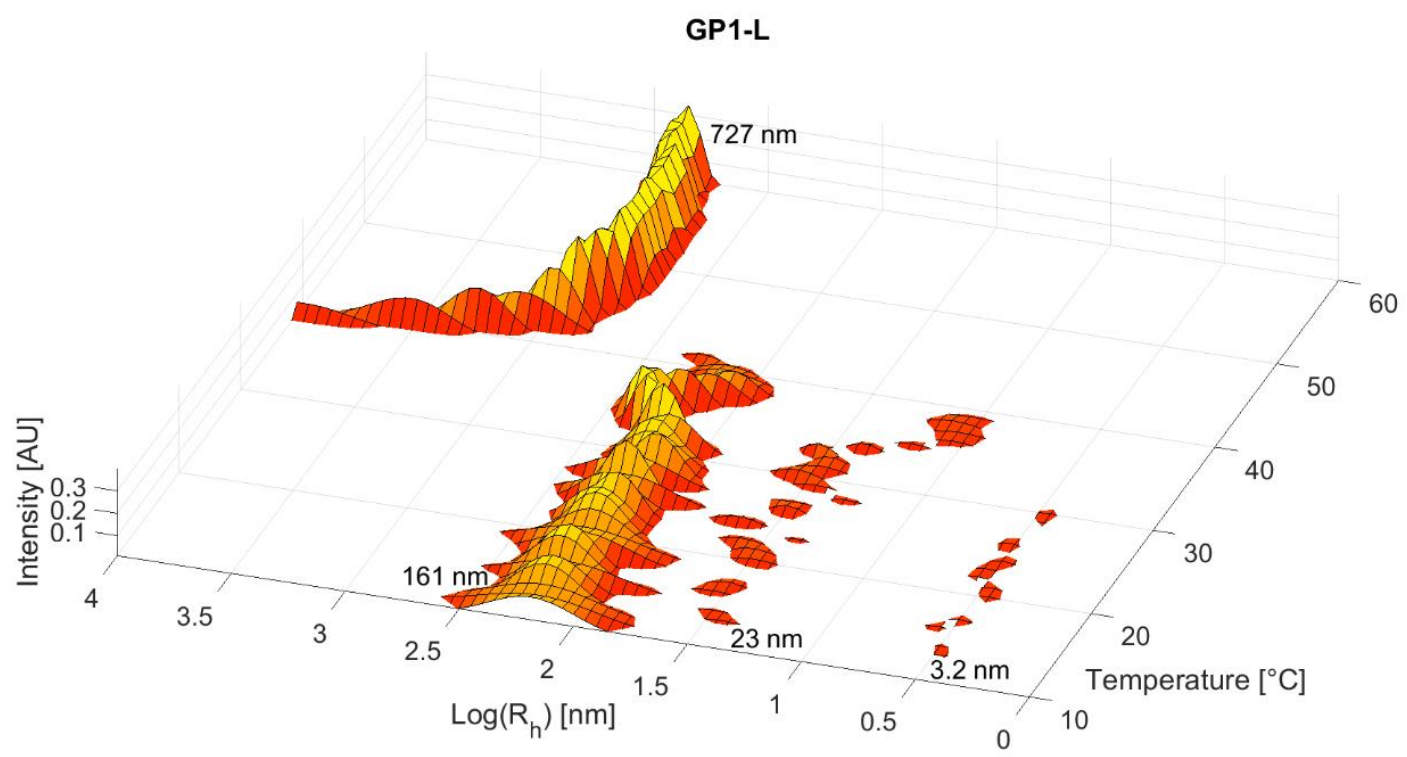

Figure S42. Size distributions of molecular assemblies of copolymer GP1-L ( $0.1 w t$. \% polymer solution in $140 \mathrm{mM}$ phosphate buffered saline, $\mathrm{pH} 7.4$, loaded with $0.01 \mathrm{wt}$. \% of rifampicin) as a function of temperature. 


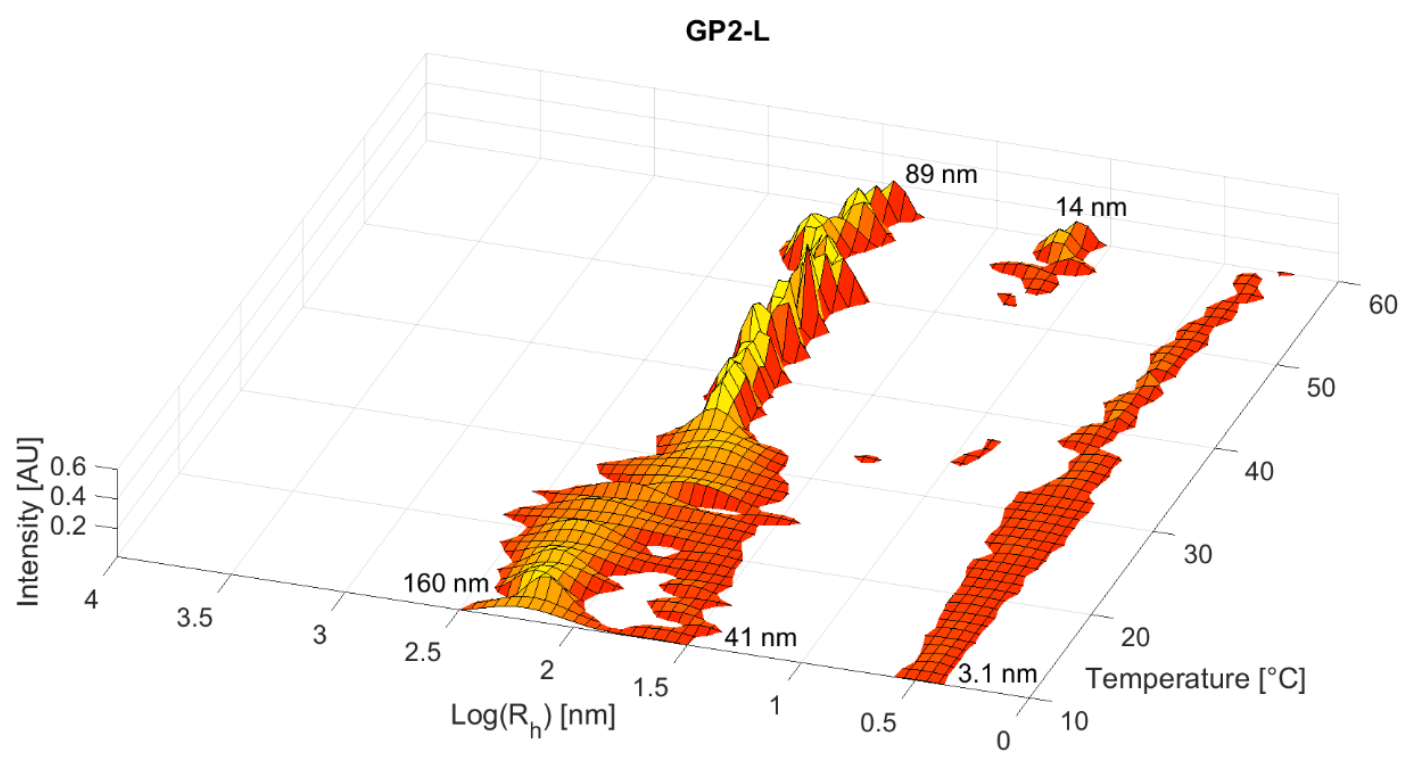

Figure S43. Size distributions of molecular assemblies of copolymer GP2-L ( 0.1 wt. \% polymer solution in $140 \mathrm{mM}$ phosphate buffered saline, $\mathrm{pH} 7.4$, loaded with $0.01 \mathrm{wt} . \%$ of rifampicin) as a function of temperature.

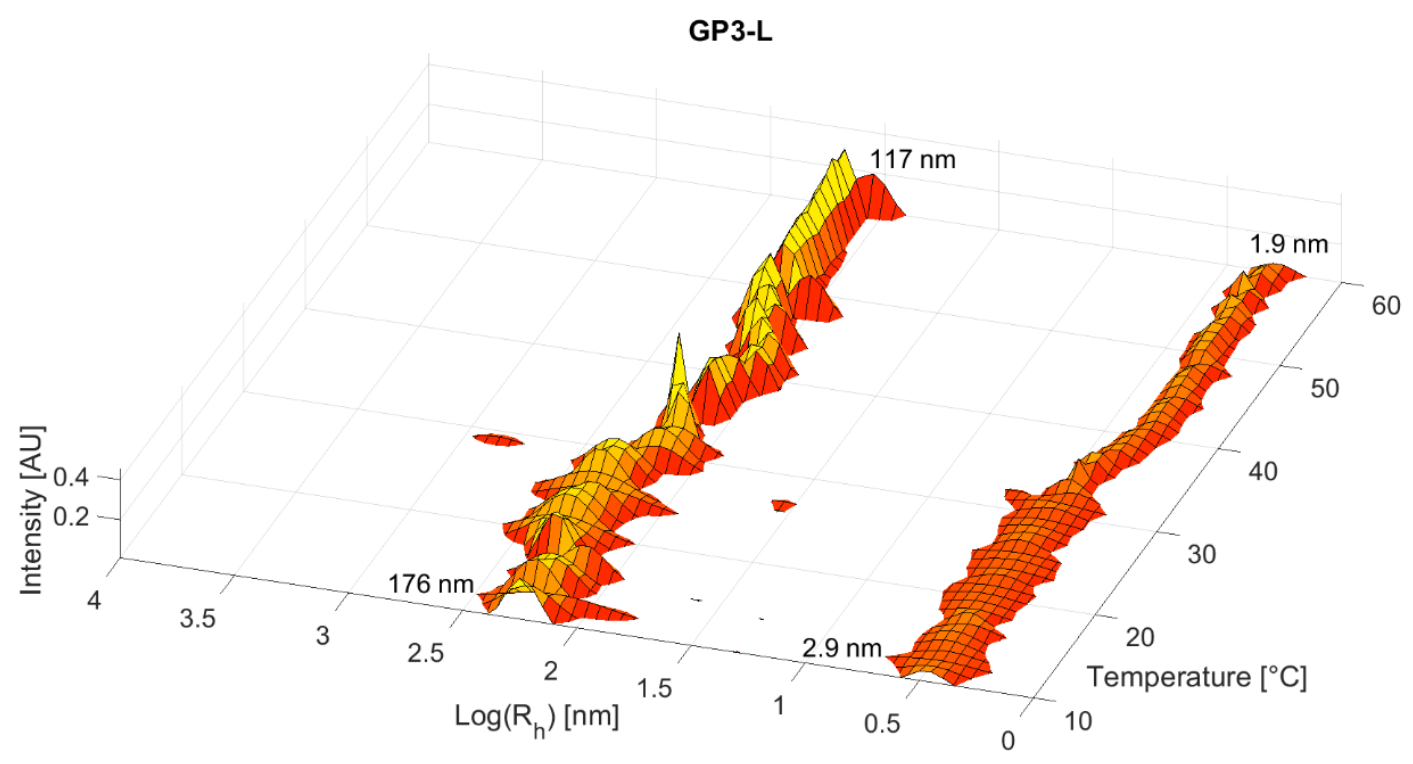

Figure S44. Size distributions of molecular assemblies of copolymer GP3-L ( $0.1 w t$. \% polymer solution in $140 \mathrm{mM}$ phosphate buffered saline, $\mathrm{pH} 7.4$, loaded with $0.01 \mathrm{wt}$. \% of rifampicin) as a function of temperature. 


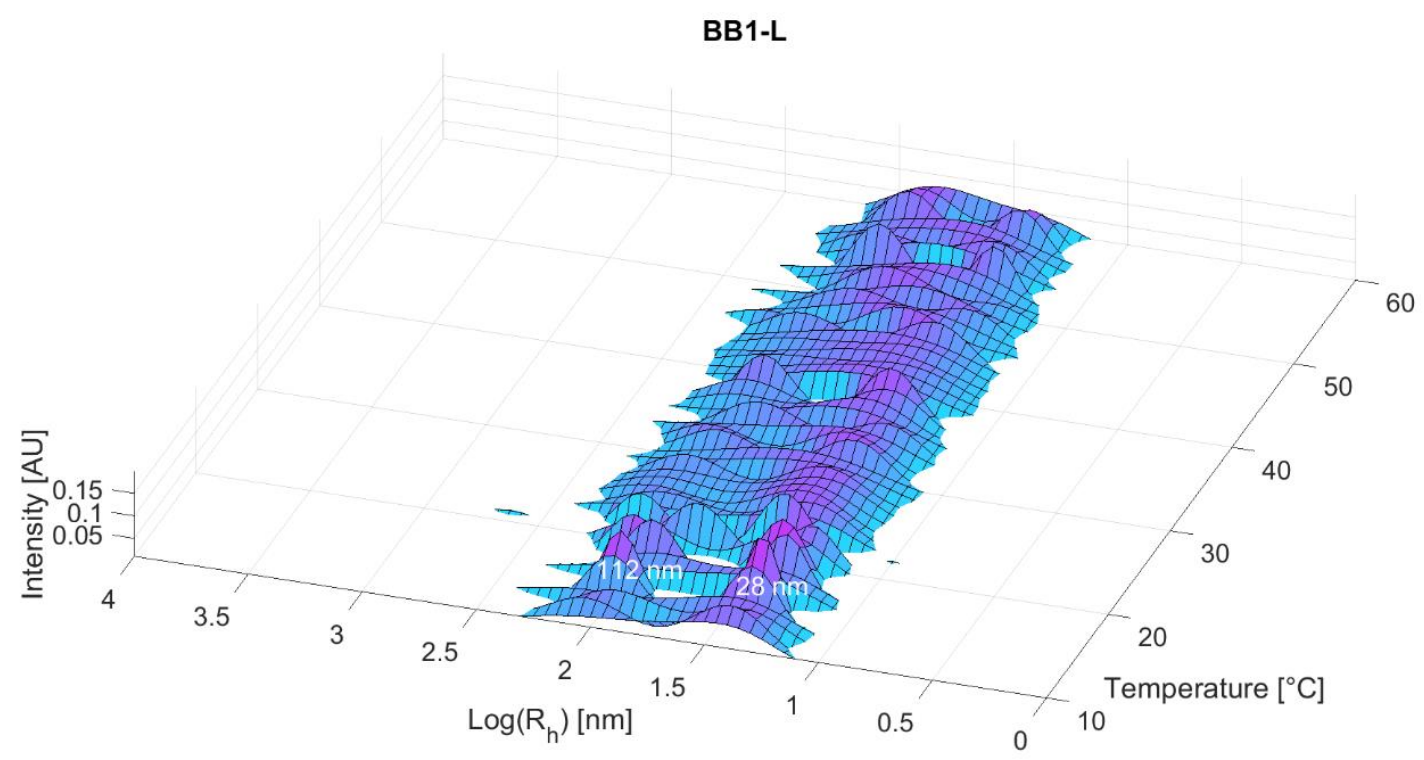

Figure S45. Size distributions of molecular assemblies of copolymer BB1-L ( $0.1 w t$. \% polymer solution in $140 \mathrm{mM}$ phosphate buffered saline, $\mathrm{pH} 7.4$, loaded with $0.01 \mathrm{wt} . \%$ of rifampicin) as a function of temperature.

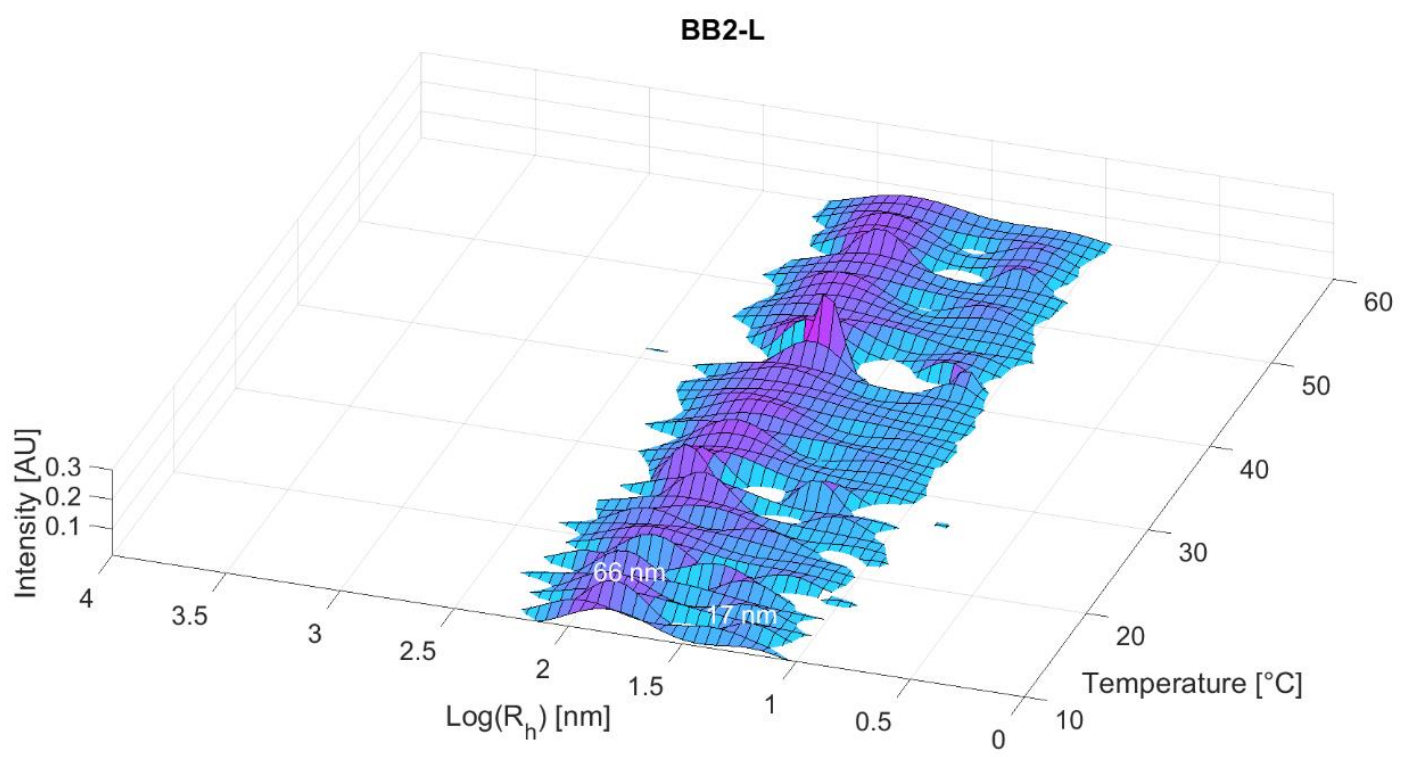

Figure S46. Size distributions of molecular assemblies of copolymer BB2-L ( 0.1 wt. \% polymer solution in $140 \mathrm{mM}$ phosphate buffered saline, $\mathrm{pH} 7.4$, loaded with $0.01 \mathrm{wt}$. \% of rifampicin) as a function of temperature. 


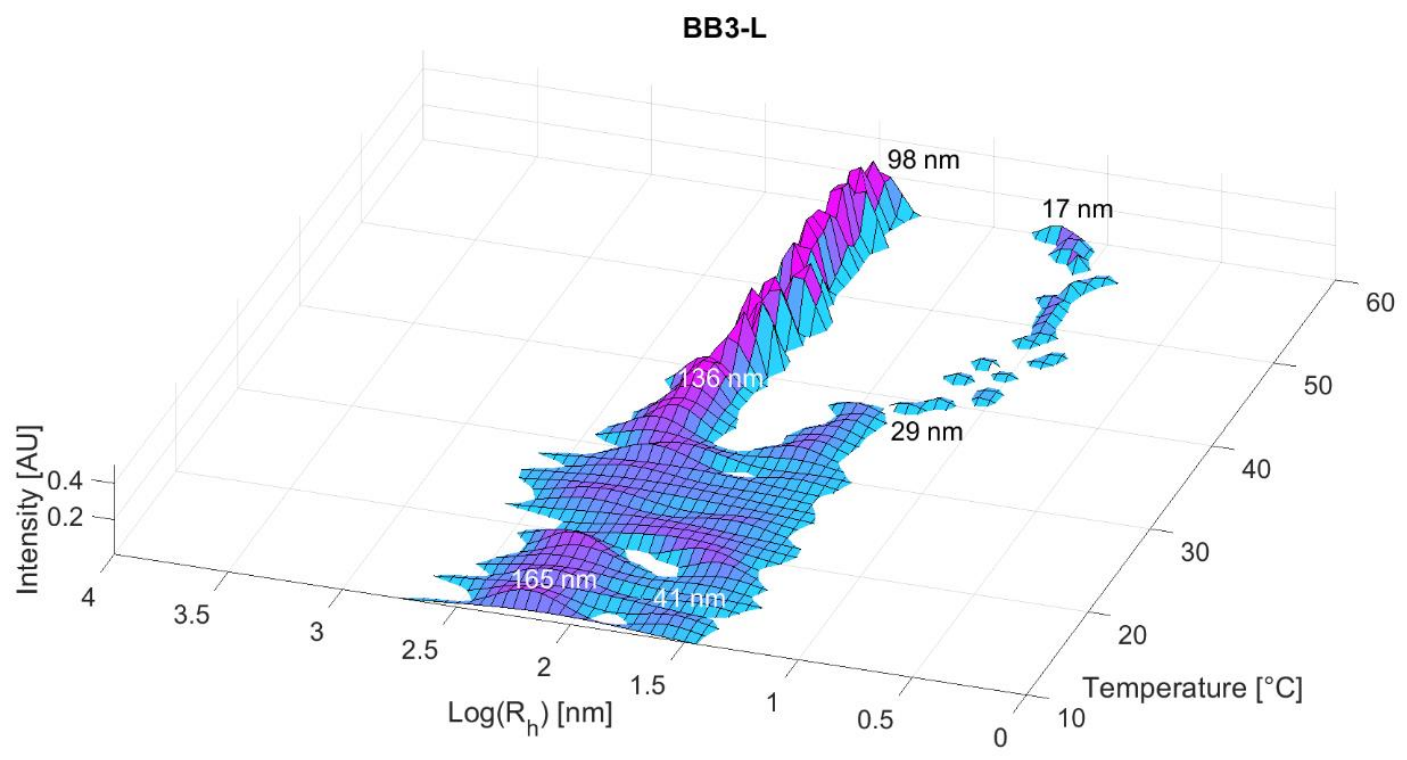

Figure S47. Size distributions of molecular assemblies of copolymer BB3-L ( $0.1 w t$. \% polymer

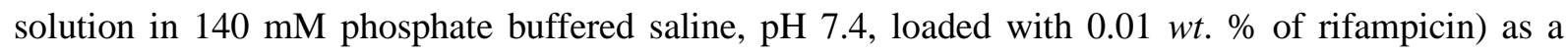
function of temperature.

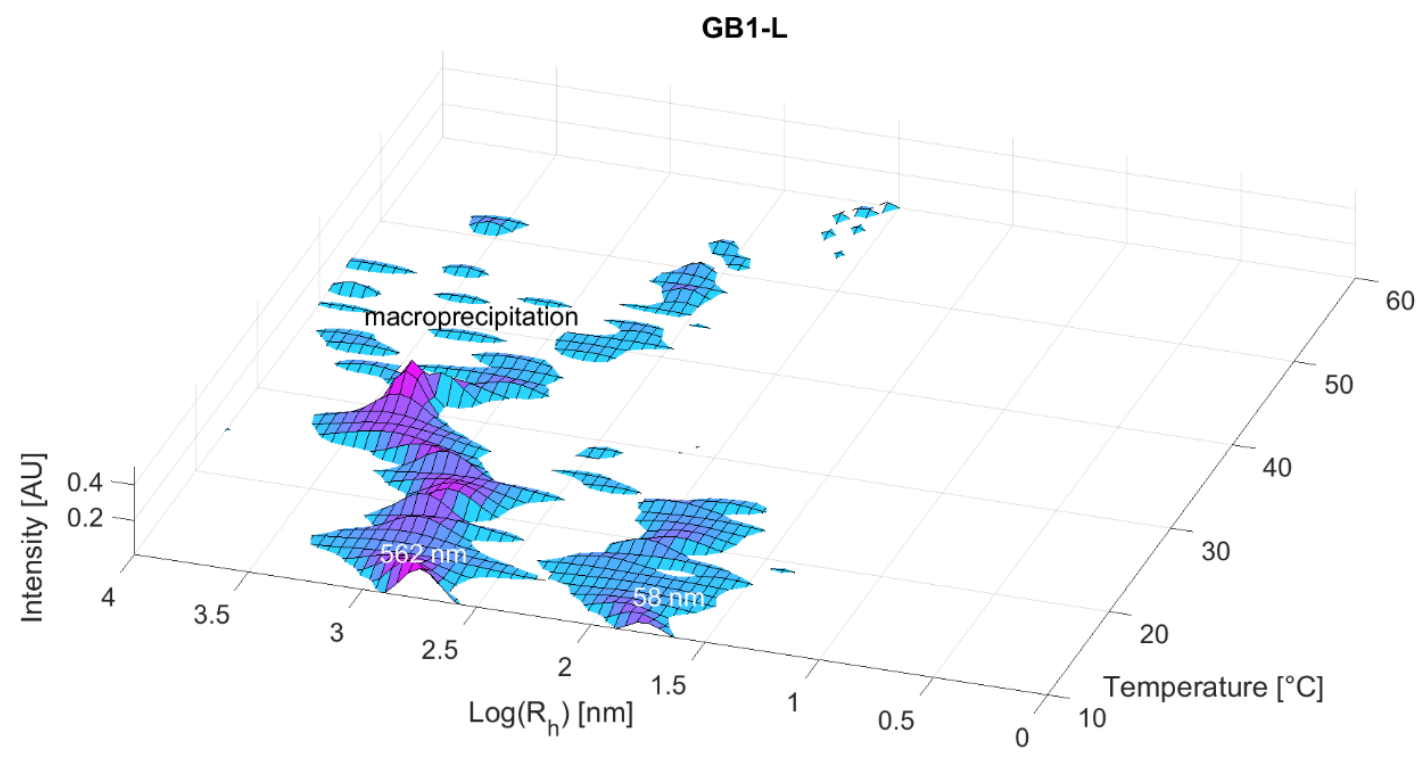

Figure S48. Size distributions of molecular assemblies of copolymer GB1-L ( 0.1 wt. \% polymer solution in $140 \mathrm{mM}$ phosphate buffered saline, $\mathrm{pH} 7.4$, loaded with $0.01 \mathrm{wt}$. \% of rifampicin) as a function of temperature. 


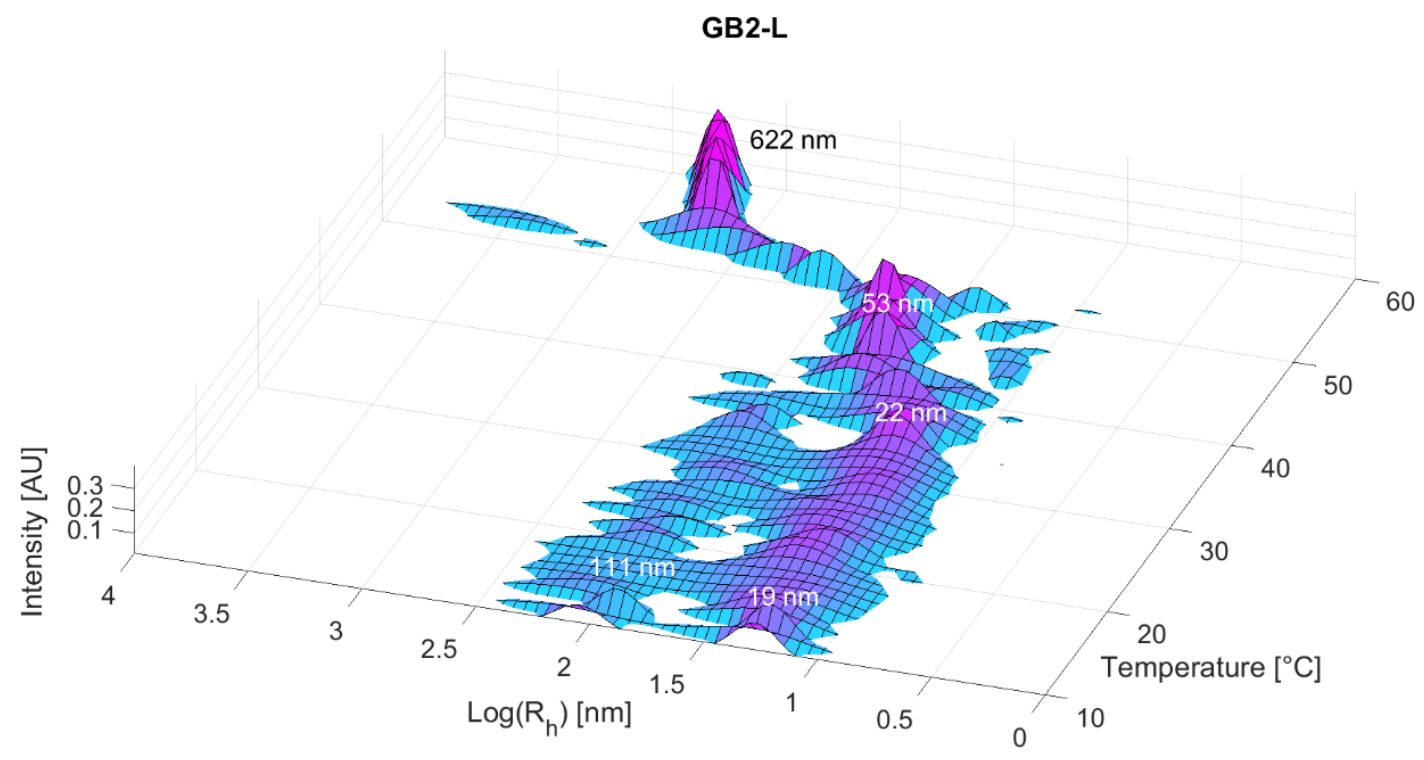

Figure S49. Size distributions of molecular assemblies of copolymer GB2-L ( $0.1 w t$. \% polymer

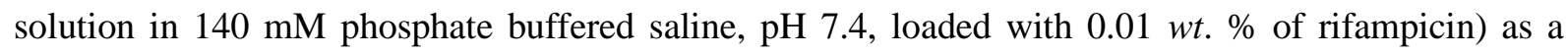
function of temperature.

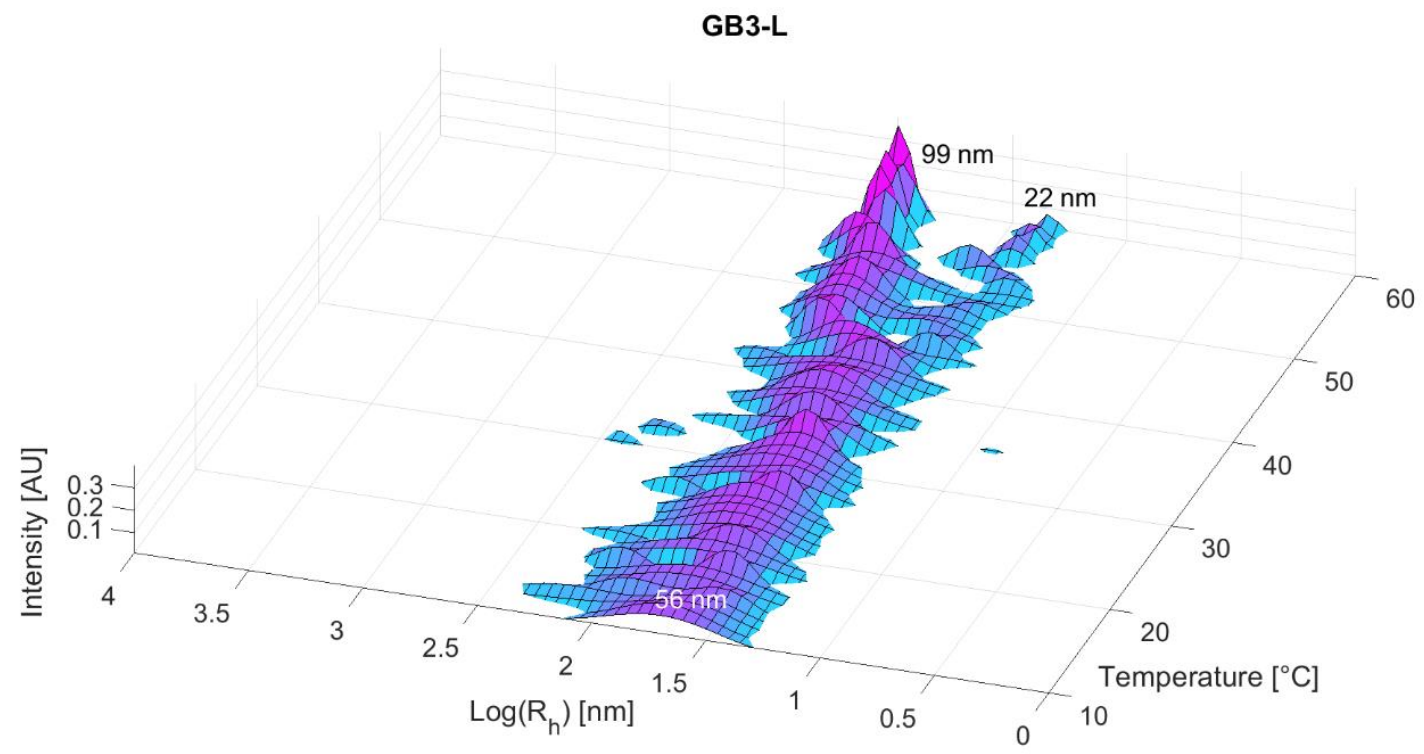

Figure S50. ze distributions of molecular assemblies of copolymer GB3-L $(0.1 \mathrm{wt}$. \% polymer solution in $140 \mathrm{mM}$ phosphate buffered saline, $\mathrm{pH} 7.4$, loaded with $0.01 \mathrm{wt}$. \% of rifampicin) as a function of temperature. 

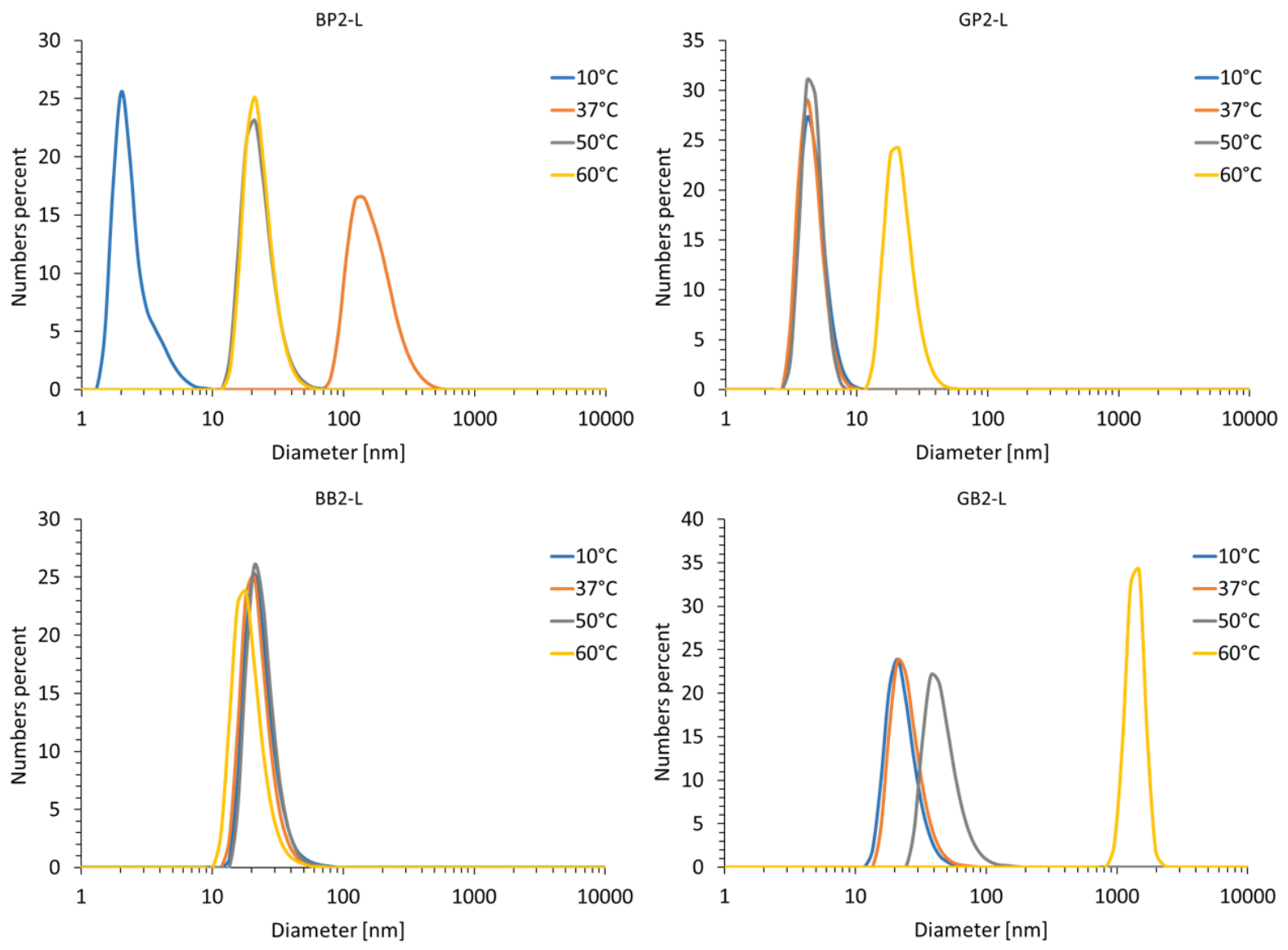

Figure S51. Number-weighted size distributions of molecular assemblies of copolymers BP2-L, GP2L, BB2-L, GB2-L (0.1 wt. \% polymer solution in $140 \mathrm{mM}$ PBS, pH 7.4, loaded with 0.01 wt. \% of rifampicin) at select temperatures. 


\section{Discussion of SANS results}

With the application of Porod's law to the obtained data, ${ }^{1,2}$ we were able to obtain the Flory exponents (v) of polymer chains in $\mathrm{D}_{2} \mathrm{O}$ for the PrOx samples. Even though the solvent affects the behavior of the polymer chains and their self-assembly, a comparison between the complete set of samples in the same solvent can be drawn. ${ }^{3}$

The obtained Flory exponents $(v)$ of the most hydrophobic copolymers (BP1, BP1-L, GP1, GP1-L) with a monomer ratio of 1:2 are close to $v=1 / 3$, which corresponds to tightly packed polymer chains in a bad solvent. The Flory exponent value grows with the increasing ratio of hydrophilic MeOzi in the copolymer chains. The most hydrophilic copolymers (BP3, BP3-L, GP3-L) with a monomer ratio of 2:1 revealed Flory exponents close to $v=3 / 5$, which corresponds to copolymer chains in a good solvent. Only the non-loaded GP3 had a low Flory exponent, which is in line with its thermal behavior (it does not form a significant particle population at $37^{\circ}$, see Figure S38). The Flory exponents obtained from the SANS measurements are depicted in Figure S52.
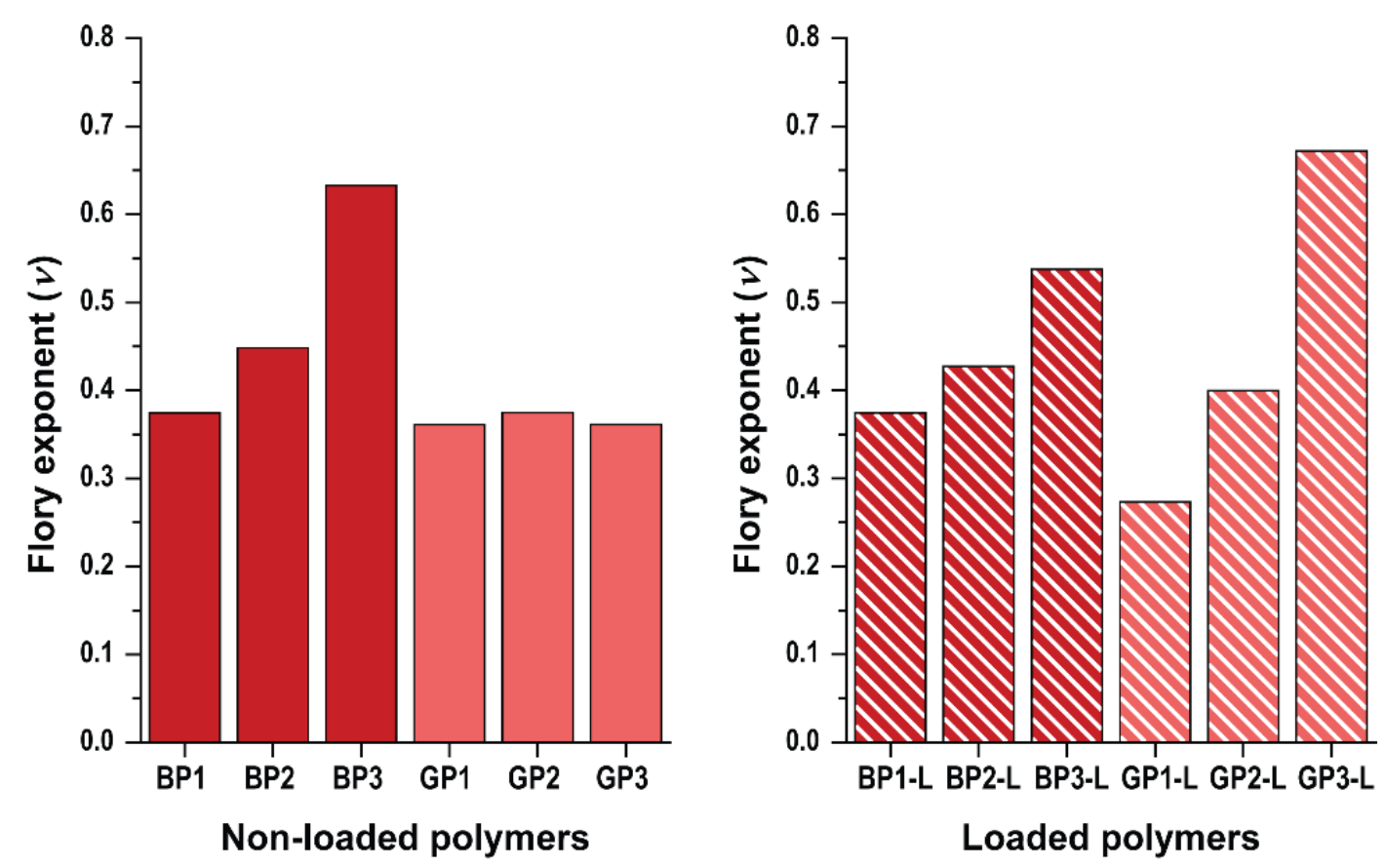

Figure S52. Comparison of Flory exponents obtained from SANS data for PrOx samples. 


\section{CAC and DL evaluation}
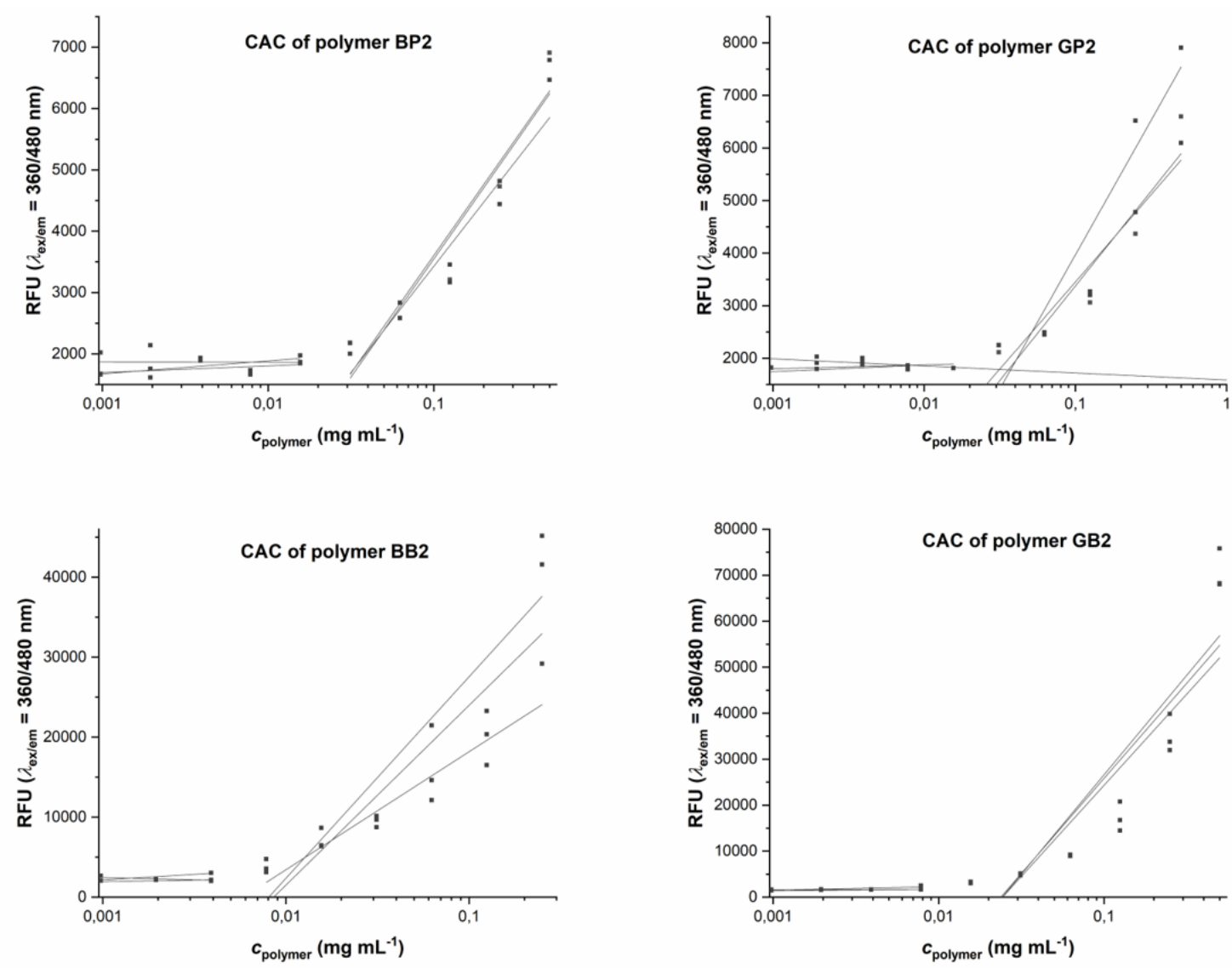

Figure S53. CAC determination for polymers GB2, GP2, BB2, BP2. Fluorescence spectra of 8anilinonaphthalene-1-sulfonic acid (ANS) solution $\left(0.01 \mathrm{mmol} \cdot \mathrm{L}^{-1}\right.$ in polymer solution) on a Synergy H1 Hybrid Reader instrument (Biotek, Winooski, USA) using black Nunc Cell Culture Microplates (Thermo Scientific Nunc, USA) at $37^{\circ} \mathrm{C}$ after $10 \mathrm{~min}$ of equilibration, using excitation/emission wavelengths of $360 / 480 \mathrm{~nm}$. 

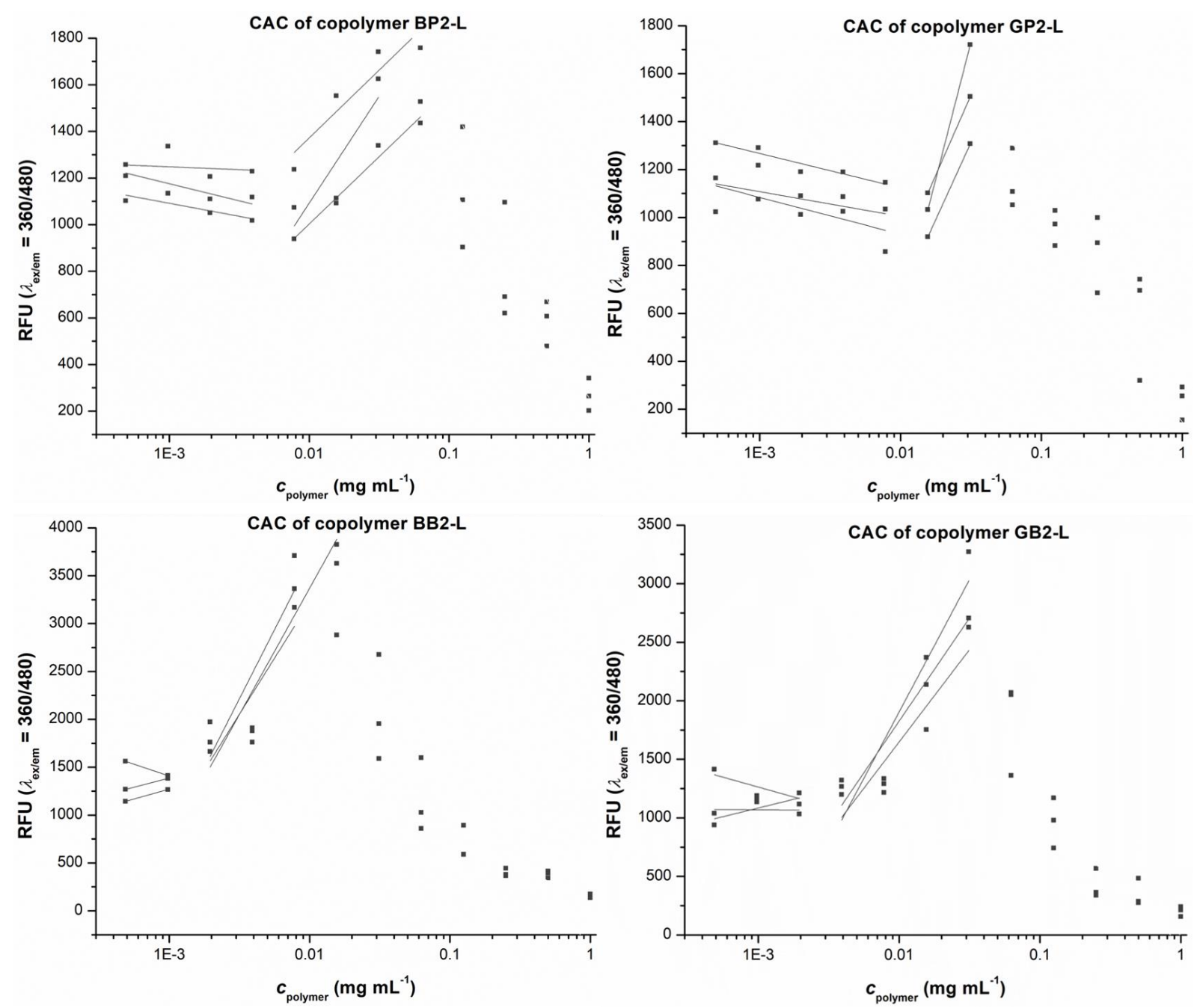

Figure S54. CAC determination for polymers GB2-L, GP2-L, BB2-L, BP2-L. Fluorescence spectra of 8 -anilinonaphthalene-1-sulfonic acid (ANS) solution $\left(0.01 \mathrm{mmol} \cdot \mathrm{L}^{-1}\right.$ in polymer solution) on a Synergy H1 Hybrid Reader instrument (Biotek, Winooski, USA) using black Nunc Cell Culture Microplates (Thermo Scientific Nunc, USA) at $37^{\circ} \mathrm{C}$ after $10 \mathrm{~min}$ of equilibration, using excitation/emission wavelengths of $360 / 480 \mathrm{~nm}$.

Table S3. Critical association concentrations (CACs) for each polymer, depicted as mean value \pm standard deviation from 5 independent experiments.

\begin{tabular}{ccccc}
\hline CAC $(\mathbf{m g} / \mathbf{L})$ & GP2 & BP2 & GB2 & BB2 \\
\hline non-loaded & $37.2 \pm 2.3$ & $36.7 \pm 2.7$ & $27.1 \pm 1.1$ & $10.2 \pm 0.7$ \\
loaded & $14.9 \pm 1.8$ & $7.8 \pm 1.9$ & $4.7 \pm 1.3$ & $1.7 \pm 0.2$ \\
\hline
\end{tabular}


Table S4. Evaluated data from drug loading experiments. The mass of the polymer was in all experiments $1 \mathrm{mg}$ per 1 milliliter of $140 \mathrm{mM}$ PBS buffer. The drug loading of polymers was measured for 6 varying amounts $(0.05$ to $0.6 \mathrm{mg}$ ) of drug added to the system (cumulative mass of the drug within both aqueous phase and polymer phase), $m_{\mathrm{drug}, \mathrm{I}}$. The $m_{\mathrm{drug}, \mathrm{II}}$ is the mass of the drug found in the ultrafiltered formulation determined by UV/VIS spectroscopy. The drug-loading factor $f_{\mathrm{DL}}$ and entrapment efficiency factor $f_{\mathrm{EE}}$ were calculated by equations (1) and (2) and the polymer-to-water distribution coefficient of RIF $(\log D)$ was calculated by equation (3).

\begin{tabular}{cccccc}
$\mathrm{m}_{\text {drug, I }}$ & $50 \mu \mathrm{g}$ & $100 \mu \mathrm{g}$ & $200 \mu \mathrm{g}$ & $400 \mu \mathrm{g}$ & $600 \mu \mathrm{g}$ \\
\hline & $\mathrm{m}_{\text {drug, II }}(\mu \mathrm{g})$ & $\mathrm{m}_{\text {drug, II }}(\mu \mathrm{g})$ & $\mathrm{m}_{\text {drug, II }}(\mu \mathrm{g})$ & $\mathrm{m}_{\text {drug, II }}(\mu \mathrm{g})$ & $\mathrm{m}_{\text {drug, II }}(\mu \mathrm{g})$ \\
$\mathrm{BB} 2$ & $44.3 \pm 0.6$ & $92.0 \pm 0.4$ & $183 \pm 2$ & $253 \pm 26$ & $208 \pm 15$ \\
$\mathrm{~GB} 2$ & $46 \pm 2$ & $94 \pm 1$ & $165 \pm 12$ & $149 \pm 35$ & $219 \pm 16$ \\
$\mathrm{BP} 2$ & $45.3 \pm 0.3$ & $86 \pm 8$ & $97 \pm 12$ & $214 \pm 29$ & $327 \pm 10$ \\
$\mathrm{GP} 2$ & $45 \pm 1$ & $88 \pm 4$ & $106 \pm 13$ & $204 \pm 20$ & $284 \pm 49$ \\
\hline & $\mathrm{f}_{\mathrm{DL}}(\%)$ & $\mathrm{f}_{\mathrm{DL}}(\%)$ & $\mathrm{f}_{\mathrm{DL}}(\%)$ & $\mathrm{f}_{\mathrm{DL}}(\%)$ & $\mathrm{f}_{\mathrm{DL}}(\%)$ \\
$\mathrm{BB} 2$ & $4.2 \pm 0.2$ & $8.42 \pm 0.03$ & $15.4 \pm 0.2$ & $20 \pm 2$ & $17 \pm 1$ \\
$\mathrm{~GB} 2$ & $4.41 \pm 0.05$ & $8.62 \pm 0.05$ & $14 \pm 1$ & $13 \pm 3$ & $18 \pm 1$ \\
$\mathrm{BP} 2$ & $4.33 \pm 0.02$ & $7.9 \pm 0.8$ & $9 \pm 1$ & $18 \pm 2$ & $24.7 \pm 0.8$ \\
$\mathrm{GP} 2$ & $4.3 \pm 0.1$ & $8.1 \pm 0.4$ & $10 \pm 1$ & $17 \pm 2$ & $22 \pm 4$ \\
\hline & $\mathrm{f}_{\mathrm{EE}}(\%)$ & $\mathrm{f}_{\mathrm{EE}}(\%)$ & $\mathrm{f}_{\mathrm{EE}}(\%)$ & $\mathrm{f}_{\mathrm{EE}}(\%)$ & $\mathrm{f}_{\mathrm{EE}}(\%)$ \\
$\mathrm{BB} 2$ & $89 \pm 3$ & $92.0 \pm 0.4$ & $91 \pm 1$ & $63 \pm 6$ & $35 \pm 3$ \\
$\mathrm{~GB} 2$ & $92 \pm 1$ & $94 \pm 1$ & $82 \pm 6$ & $37 \pm 9$ & $36 \pm 3$ \\
$\mathrm{BP} 2$ & $90.6 \pm 0.5$ & $86 \pm 8$ & $48 \pm 6$ & $54 \pm 8$ & $55 \pm 2$ \\
$\mathrm{GP} 2$ & $91 \pm 2$ & $88 \pm 4$ & $53 \pm 6$ & $51 \pm 5$ & $47 \pm 8$ \\
\hline & $\log \mathrm{D}$ & $\log \mathrm{D}$ & $\log \mathrm{D}$ & $\log \mathrm{D}$ & $\log \mathrm{D}$ \\
$\mathrm{BB} 2$ & $2.11 \pm 0.05$ & $1.94 \pm 0.02$ & $1.97 \pm 0.06$ & $2.8 \pm 0.1$ & $3.28 \pm 0.05$ \\
$\mathrm{~GB} 2$ & $1.9 \pm 0.3$ & $1.8 \pm 0.08$ & $2.3 \pm 0.2$ & $3.2 \pm 0.2$ & $3.24 \pm 0.05$ \\
$\mathrm{BP} 2$ & $2.02 \pm 0.03$ & $2.1 \pm 0.3$ & $3.0 \pm 0.1$ & $2.9 \pm 0.1$ & $2.92 \pm 0.03$ \\
$\mathrm{GP} 2$ & $2.0 \pm 0.1$ & $2.1 \pm 0.2$ & $2.9 \pm 0.1$ & $2.98 \pm 0.09$ & $3.0 \pm 0.1$
\end{tabular}




\section{Cellular assays}
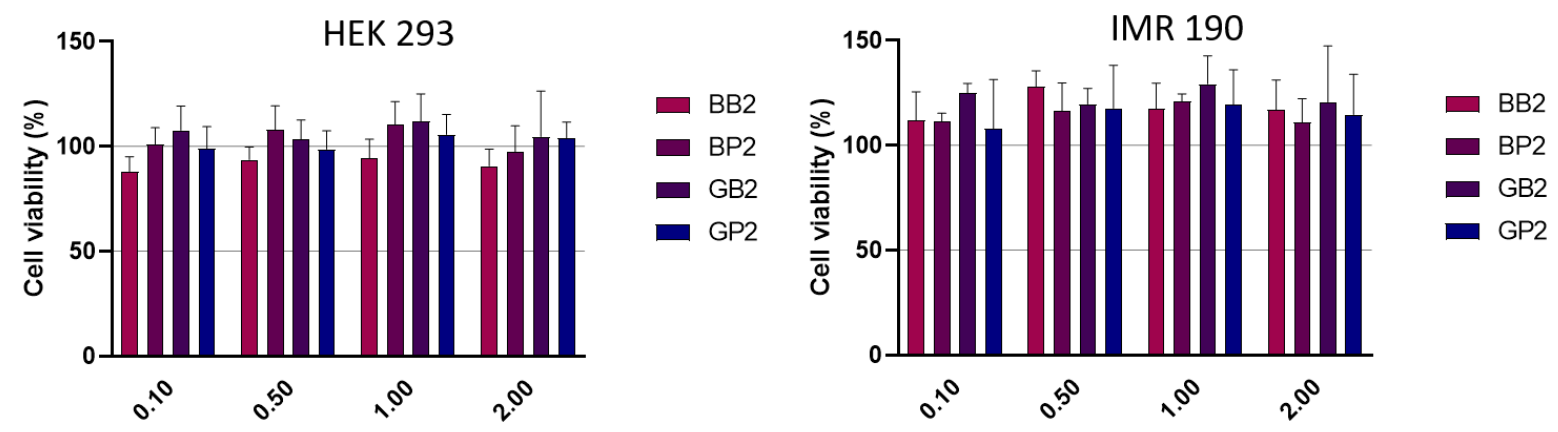

Concentration $\mathrm{mg} / \mathrm{ml}$

Concentration $\mathrm{mg} / \mathrm{ml}$

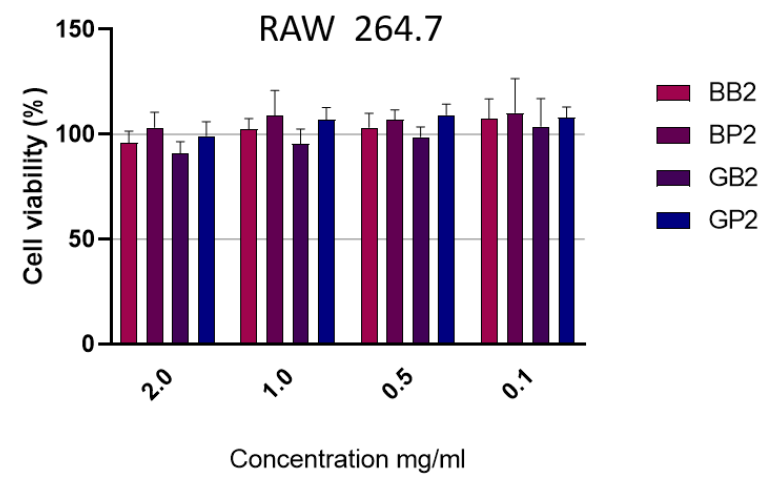

Figure S55. Viability of HEK 293, IMR 190 and RAW 264.7 cell line with an increasing polymer concentration (0.1 to $2.00 \mathrm{mg} \mathrm{mL}^{-1}$ ) of polymer GB2, GP2, BB2 and BP2. 


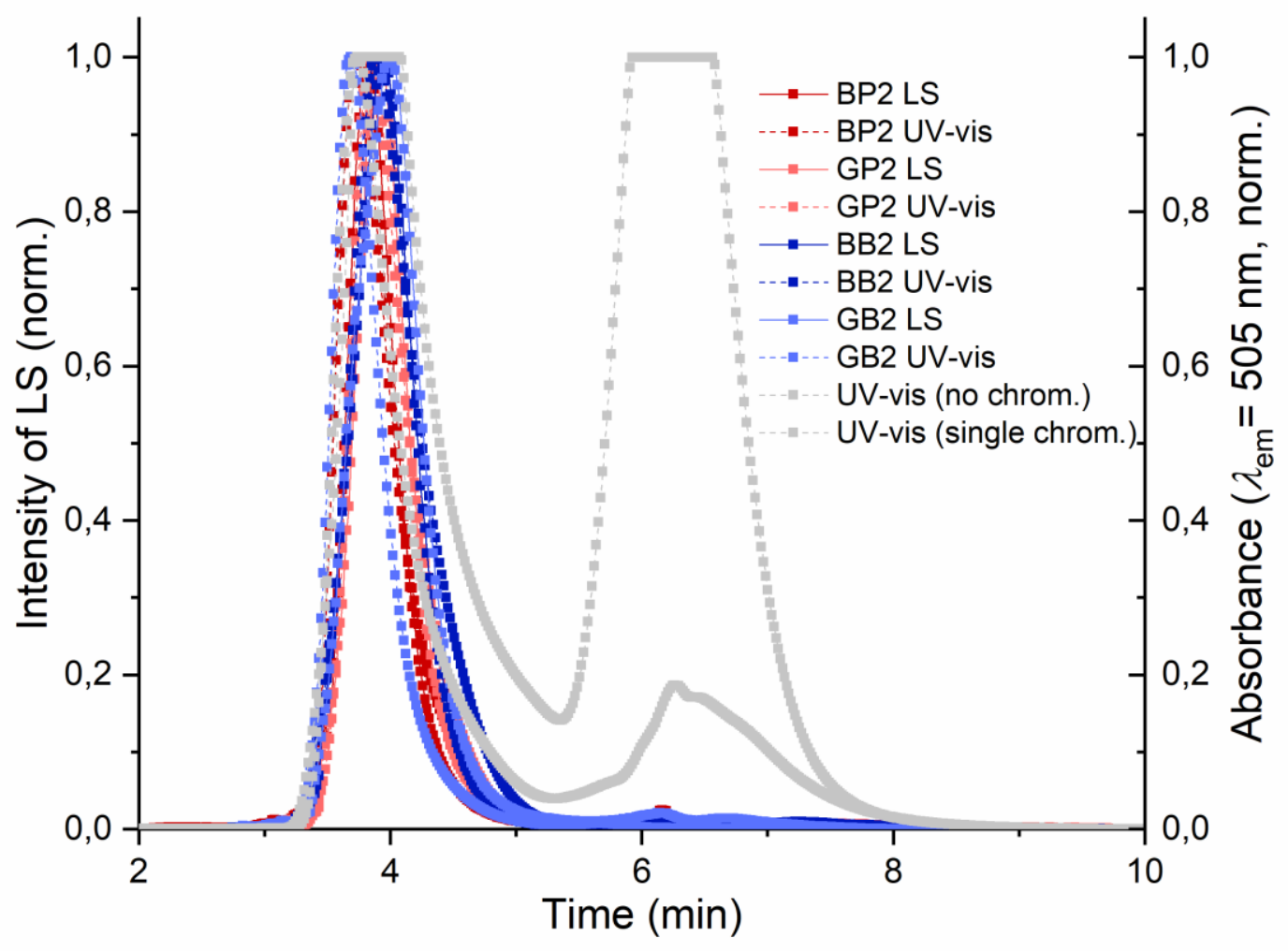

Figure S56. Size exclusion chromatography (SEC) traces for labeled polymers BP2, GP2, BB2, GB2 using HPLC Ultimate 3000 system (Dionex, USA) equipped with a SEC column (TSKgel SuperAW3000 $150 \times 6 \mathrm{~mm}, 4 \mu \mathrm{m})$. SEC traces correspond to the absorbance measured with UV-vis detector $\left(\lambda_{e m}=505 \mathrm{~nm}\right)$ and light scattering intensity measured with multi-angle light scattering (MALS) DAWN EOS (Wyatt Technology Co., USA) detector. All four polymers were purified by two sequential gel chromatographies. Grey traces correspond to the polymer GB2 before a gel chromatography purification and after a single gel chromatography, showing the peak of free Dy505 (retention time $6.1 \mathrm{~min})$. 

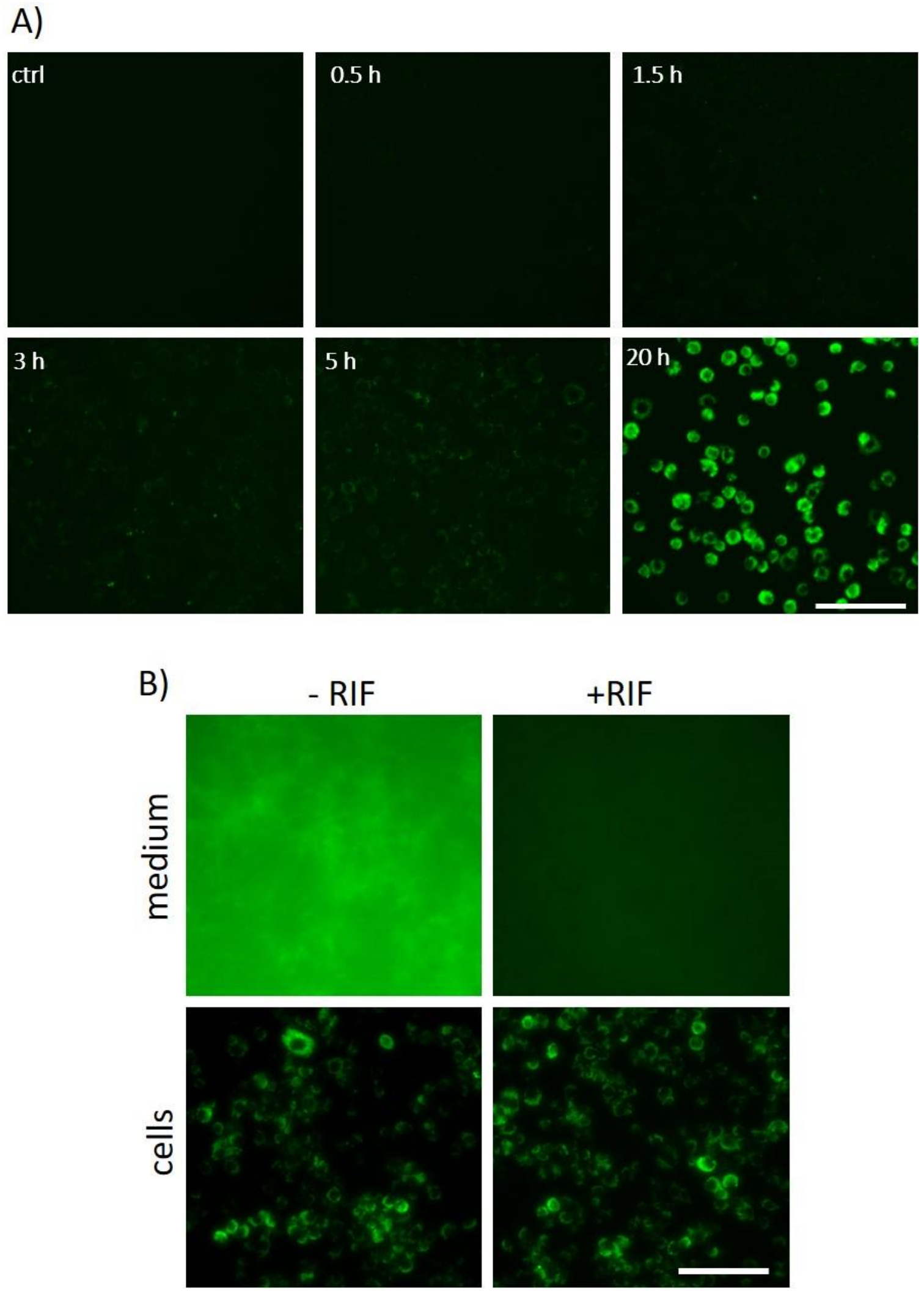

Figure S57. In vitro uptake of copolymer GB2 labeled with Dy505 by RAW 264.7 murine macrophage cells. A) A kinetic study of the GB2 polymer uptake. The polymer was layered onto the cells and at selected time points the polymer was washed away with fresh medium, and the cells were visualized by confocal microscopy. B) GB2 polymer labeled with Dy505 with or without encapsulated rifampicin 
(RIF) was added to cells. After $20 \mathrm{~h}$, the polymer was visualized in the cell media and inside the cells. Scale bars $100 \mu \mathrm{m}$.

\section{Structure of RIF}

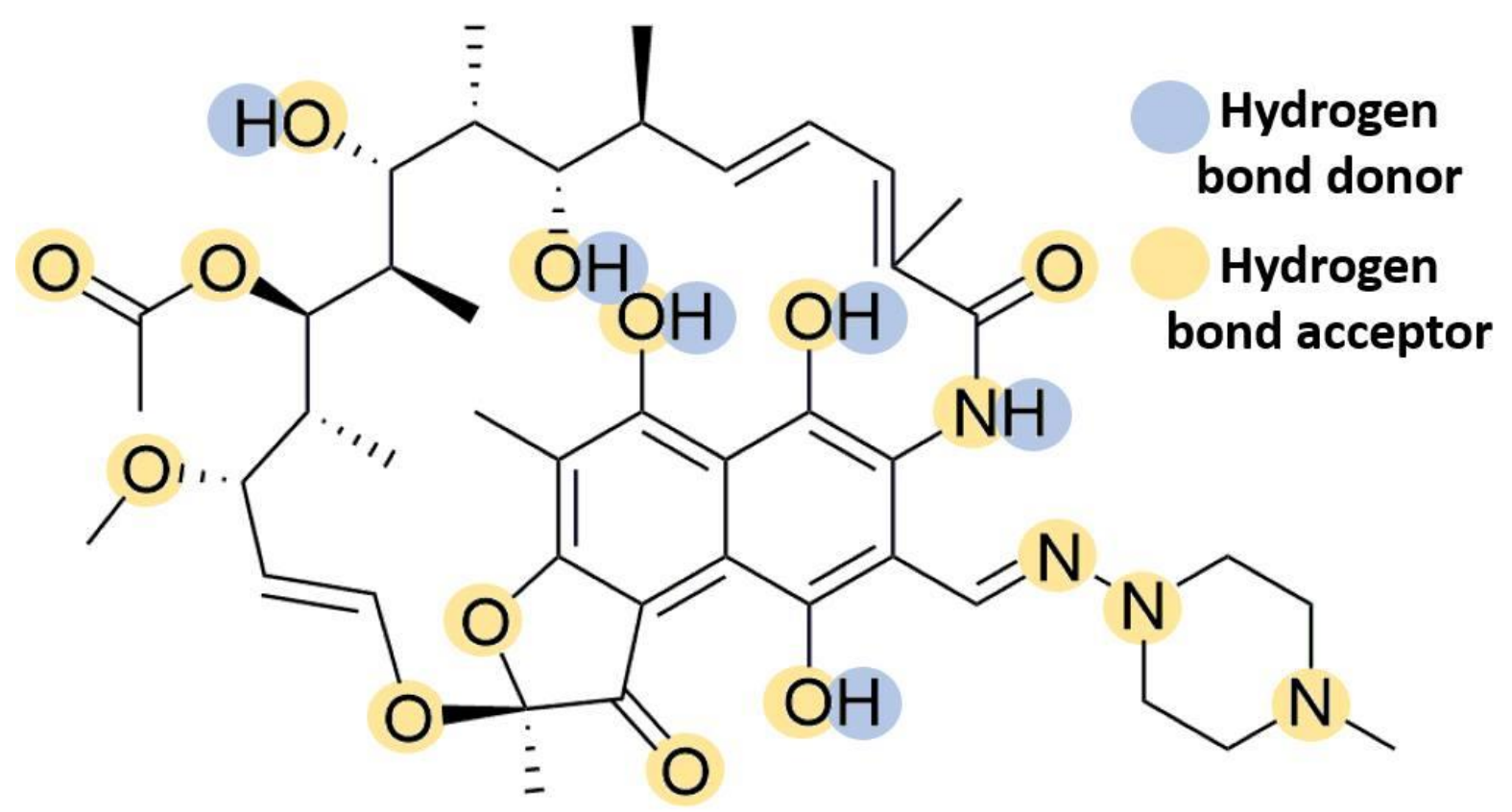

Figure S58. Structure of RIF in its neutral form with schematically marked possible hydrogen bonding sites. 


\section{References}

(1) Anitas, E. M. Small-Angle Scattering from Mass and Surface Fractals. In Complexity in Biological and Physical Systems - Bifurcations, Solitons and Fractals; 2018. https://doi.org/10.5772/intechopen.70870.

(2) Teixeira, J. Small-Angle Scattering by Fractal Systems. J. Appl. Crystallogr. 1988. https://doi.org/10.1107/S0021889888000263.

(3) Babuka, D.; Kolouchova, K.; Hruby, M.; Groborz, O.; Tosner, Z.; Zhigunov, A.; Stepanek, P. Investigation of the Internal Structure of Thermoresponsive Diblock Poly(2-Methyl-2Oxazoline)-b-Poly[N-(2,2-Difluoroethyl)Acrylamide] Copolymer Nanoparticles. Eur. Polym. J. 2019, 121, 109306. https://doi.org/https://doi.org/10.1016/j.eurpolymj.2019.109306. 